\title{
Social Mobility in Sweden Before the Welfare State*
}

\author{
Thor Berger $^{\dagger} \quad$ Per Engzell $^{\ddagger} \quad$ Björn Eriksson $^{\S} \quad$ Jakob Molinder $^{\llbracket}$ \\ October 1, 2021
}

\begin{abstract}
We use historical census data to show that Sweden exhibited high levels of intergenerational occupational mobility several decades before the rise of the welfare state. Mobility rates were higher than in other 19th- and 20th-century European countries, closer to those observed in the highly mobile 19th-century United States. We leverage mobility variation across Swedish municipalities to shed light on potential determinants: economic growth and migration are positively correlated with mobility, consistent with the patterns observed across countries.
\end{abstract}

Keywords: Intergenerational mobility; Sweden; Welfare state

JEL Codes: J62, J61, N33, N34

${ }^{*}$ We are grateful for comments and suggestions by Greg Clark, Neil Cummins, Robert Erikson, John Goldthorpe, Jan O. Jonsson, Chris Minns, Eric Schneider, Paul Sharp, Daniel Waldenström, and Zachary Ward, as well as seminar participants at the 45th Annual Meeting of the Social Science History Association in Chicago, the 2nd LSE Historical Economic Demography Workshop, Nuffield College, University of Oxford, the Swedish Institute for Social Research (SOFI), Stockholm University, Research Institute of Industrial Economics (IFN), Stockholm, the 2020 Historical Economics and Development Group (HEDG) Workshop, University of Southern Denmark, and the Center for Research in Economics and Statistics (CREST), Paris Graduate School of Economics, Statistics and Finance (ENSAE). Richard Breen and Jan O. Jonsson kindly shared the modern Swedish data used in this study. Berger acknowledges funding from Jan Wallanders and Tom Hedelius foundation. Engzell received funding from the Swedish Research Council for Health, Working Life, and Welfare (FORTE), grant no. 2016-07099, Nuffield College, and the Leverhulme Centre for Demographic Science, The Leverhulme Trust. Eriksson acknowledges support from Jan Wallanders and Tom Hedelius foundation and the research program "The Landskrona Population Study," funded by the Swedish Foundation for Humanities and Social Sciences (Riksbankens Jubileumsfond). Molinder acknowledges funding from Jan Wallanders and Tom Hedelius foundation and the Swedish Research Council. Any remaining errors are our own.

${ }^{\dagger}$ Research Institute of Industrial Economics (IFN), CEPR, and Department of Economic History \& Centre for Economic Demography, School of Economics and Management, Lund University.

${ }^{\ddagger}$ Leverhulme Centre for Demographic Science \& Nuffield College, University of Oxford, and Swedish Institute for Social Research, Stockholm University.

$\S$ Department of Economic History \& Centre for Economic Demography, School of Economics and Management, Lund University.

IDepartment of Economic History, Uppsala University, and Department of Economic History, School of Economics and Management, Lund University. 
A widely held belief among 19th-century observers was that the United States had exceptionally high rates of intergenerational mobility compared to European societies (Tocqueville, 1835; Marx, 1852). Indeed, Long \& Ferrie (2013a) show that the United States exhibited higher mobility than Britain through the early 20th century, which was recently extended by Pérez (2019) to argue that the Old and New World was characterized by distinctly different mobility regimes. ${ }^{1}$

Today, the highest rates of intergenerational mobility are observed in Scandinavian countries such as Sweden (Breen \& Jonsson, 2005; Björklund \& Jäntti, 2009; Blanden, 2013). Sweden's high mobility is often attributed to a compressed income distribution and redistributive welfarestate policies (Erikson \& Goldthorpe, 1992; Corak, 2013). However, a century ago Sweden exhibited higher levels of income inequality than the United States and had similarly low levels of redistribution as other European countries (Lindert, 2004; Roine \& Waldenström, 2008; Piketty, 2014). Was Sweden also unexceptional in terms of intergenerational mobility?

In this paper, we provide the first representative estimates of intergenerational occupational mobility in Sweden prior to the rise of the welfare state. We make use of full-count census data to link a representative sample of 240,000 sons born in the late-19th century to their fathers. To facilitate comparison, we pair our linked Swedish data with similarly constructed historical datasets for Argentina, Britain, Norway, and the United States (Long \& Ferrie, 2013a; Pérez, 2019; Modalsli, 2017). ${ }^{2}$ Combining these historical samples with survey data from the late-20th century further allows us to compare historical and modern mobility patterns. ${ }^{3}$

As in prior historical work, we focus on the intergenerational transmission of occupations, the only outcome consistently available in historical datasets. ${ }^{4}$ In the analysis, we examine two dimensions of occupational mobility. First, absolute mobility corresponds to the share of sons who transition into a different occupational group than that of their fathers. Second, we use the approach developed by Altham \& Ferrie (2007) to examine relative mobility, capturing how the chance of entering a particular occupation differs for sons born to fathers from different groups. Absolute and relative mobility thus capture distinct dimensions of mobility. For example, in a society where only the sons of one social group are upwardly mobile, relative mobility will remain low because

\footnotetext{
${ }^{1}$ Moreover, the United States also exhibited more mobility in the 19th century than it does today (Long \& Ferrie, 2007, 2013a; Feigenbaum, 2018; Song et al., 2019). However, Ward (2020a) provides an alternative account arguing that the long-run trend is one toward increased intergenerational mobility after adjusting for racial composition and measurement error.

${ }^{2}$ For brevity, we refer to these country groups respectively as the Americas or the New World (Argentina and the United States), and Europe or the Old World (Britain, Norway, and Sweden) throughout the paper.

${ }^{3}$ Our modern mobility estimates are based on data drawn from the Swedish Study of Living Conditions (ULF) used by Breen \& Jonsson (2020), the 1972 Oxford Mobility Study and 1973 Occupational Changes in a Generation Study used by Long \& Ferrie (2013a), and the linked set of Norwegian censuses used by Modalsli (2017).

${ }^{4}$ In line with most existent work on historical mobility we focus on fathers and sons due to the challenges involved in tracing daughters due to surname change upon marriage. Olivetti \& Paserman (2015) develop a creative solution to this problem by leveraging the socioeconomic content of first names which is unfortunately only feasible with cardinal measures of economic status such as income.
} 
although there are opportunities for upward mobility, those opportunities are not equally shared.

Our central finding is that present-day Sweden's high levels of intergenerational mobility predate the rise of the welfare state by several decades. To establish this result, we first compare historical levels of mobility in Sweden to those observed for its American and European counterparts. More than half of all Swedish sons born in the late-19th century transitioned into a different occupational group than their fathers, a higher level of absolute mobility than observed in both Europe and the United States. Sweden also exhibited high levels of relative mobility with a pattern of mobility closer to that observed in the American "land of opportunity" than to its European neighbors. We then go on to analyze how the relative mobility levels observed in Sweden prior to World War I compare to those in Europe and the United States during the post-World War II era. We find higher levels of relative mobility in Sweden historically than among cohorts born in mid20th century in Britain, Norway, and the US that grew up under the modern welfare state. Most strikingly, we document that Sweden exhibited more relative mobility in the early-20th century than it does today.

The finding of historically high levels of Swedish mobility survives extensive robustness testing. First, we find a similar mobility gradient when using a broader set of linked historical samples, varying the algorithm used to link individuals across censuses, or re-weighting our estimates to account for potential selection into the linked sample. Second, the results are robust to using alternative occupational classifications, adjusting for missing occupations, or decomposing mobility patterns to rule out that a particular occupational group is driving the estimates. Although the depletion of farming is an important driver of historical mobility, even when excluding farmers the Swedish mobility pattern is closest to that found in the US. Third, we link individuals in our data to emigrant registers to show that attrition due to trans-Atlantic migration does not appreciably affect our results. Together, these additional estimates suggest that the high levels of Swedish mobility we find are not an artefact of either the data or the way we measure occupational mobility. ${ }^{5}$

Why did Sweden display such high rates of occupational mobility historically? While much contemporary work has emphasized the role of welfare-state institutions (Corak, 2013), we study a period in which such policies were largely absent (Lindert, 2004). Moreover, the fact that we observe sharp mobility differences between countries such as Sweden and Norway, which share a similar cultural and institutional setting, suggests that other factors are more important to account for the variation in mobility. ${ }^{6}$ We therefore turn to examining four broad economic explanations-

\footnotetext{
${ }^{5}$ To further show that the results are not driven by the choice of specific mobility metrics, we additionally introduce a broader class of measures that address potential problems stemming from sampling variability and differences in marginal distributions across countries.

${ }^{6}$ In particular, Sweden and Norway were ruled by the same monarch until the dissolution of the union of the United Kingdoms of Sweden and Norway in 1905 and shared a similar ethnic, cultural, and institutional makeup that allows us to plausibly rule out such factors.
} 
growth and industrialization, fertility, human capital, and migration - that have been emphasized in the mobility literature. When evaluated against the historical record, two of these seem particularly plausible: economic change and geographic dynamism.

A long-standing hypothesis holds that intergenerational mobility may increase during times of rapid economic change (Lipset \& Bendix, 1959; Nybom \& Stuhler, 2014). Notably, while Sweden did not stand out in terms of equality or redistribution prior to World War I, it was one of the fastest growing economies in Western Europe. Across countries, there is a clear gradient between mobility and economic growth where the most rapidly growing economies-Argentina, Sweden, and the United States-are more mobile than the relatively more stagnant European countries. A closely related explanation is migration. All industrializing countries saw vast spatial disparities in economic development. By investing in migration, individuals were thus able to reap the benefits of significant locational arbitrage. Indeed, our analysis suggest that Sweden exhibited high rates of internal migration also in a comparative perspective. These cross-country patterns are suggestive, but not sufficient to allow us to discriminate between explanations.

We therefore leverage the significant variation in mobility within Sweden to shed further light on these explanations. First, we characterize the variation in absolute and relative mobility across 282 municipalities. Mobility differences within Sweden span those observed between the least mobile (Norway) and most mobile (Argentina) economies in our sample, much like mobility varies locally in countries with less extensive social welfare institutions today (Chetty et al., 2014; Güell et al., 2018; Alesina et al., 2019; Berger \& Engzell, 2019; Asher et al., 2020). Next, we examine the local correlates of these regional mobility differences. Consistent with the cross-country patterns, we find that municipalities that underwent more rapid growth and industrialization also tend to have higher levels of absolute mobility, though not necessarily relative mobility. Instead, the most robust correlate of local differences in both absolute and relative mobility is internal migration.

Migrants primarily invested in "moves to opportunity" by migrating to areas that exhibited higher levels of growth, industrialization, and occupational mobility. To identify whether migrants also enjoyed higher occupational mobility, we use individual-level variation in migration and mobility outcomes within families, as common in the historical literature (Abramitzky et al., 2012; Ward, 2020b). We show that migrant brothers were significantly more likely to transition out of their father's occupation compared to their brothers that stayed behind. In particular, this increase in mobility is evident among sons to farmers and unskilled workers that left more stagnant rural places for the city. While we cannot fully rule out that (non-)migrant brothers differed in nonobservable ways, these results are suggestive of a causal link between migration and occupational mobility. More broadly, these results are consistent with a large literature suggesting that migration induced by spatial disparities in economic development is a central lever to open up avenues for occupational mobility (Long, 2005; Long \& Ferrie, 2013a; Young, 2013; Tan, 2020; Ward, 2020b; 
Connor \& Storper, 2020; Abramitzky et al., 2021).

By providing a representative estimate of occupational mobility in Sweden around 1900, we extend backwards the large literature on intergenerational mobility in the post-World War II period (Björklund \& Jäntti, 2000; Breen \& Jonsson, 2007, 2020; Jonsson \& Mills, 1993). The few studies that have examined occupational mobility in pre-industrial Sweden have relied on samples from a single city or rural area (Maas \& Van Leeuwen, 2002; Dribe et al., 2015; Lindahl et al., 2015), which is unlikely to be representative of national mobility rates. ${ }^{7}$ Clark (2015) studies the relative representation of rare surnames within occupations and concludes that the rate of mobility in Sweden is far lower than estimates based on microdata suggest, and largely stable over time. Surname-based estimates of mobility, however, place a heavy weight on group-level (e.g., ethnic) differences and extremes of the distribution that make them less comparable to conventional measures of intergenerational mobility using individual-level data (Chetty et al., 2014; Solon, 2018; Torche \& Corvalan, 2018). More broadly, the results in this paper challenge longstanding beliefs about a fundamental mobility divide between the Old and the New World (Long \& Ferrie, 2007, 2013a; Pérez, 2019). Our results suggest that historical mobility differences between the Old and the New World were smaller than previously thought, and have a simple economic explanation.

\section{Measuring Occupational Mobility}

Historical research on intergenerational mobility has inferred social standing from occupational titles, and our work is no exception (Long \& Ferrie, 2013a; Modalsli, 2017; Pérez, 2019). Occupations are an important social indicator as the main source of income, a marker of identity, and the way people spend much of their waking time. They capture a range of factors not limited to pay but also including fixed capital, working conditions, earnings stability, autonomy, job security, and social prestige. Unlike unidimensional indicators such as income or wealth, there is no unambiguous ranking of occupational positions. ${ }^{8}$ Thus, the data have to be analyzed using methods appropriate for nominal categories.

Comparing intergenerational occupational mobility between two countries involves a comparison of two-dimensional $r \times s$ mobility tables where rows $(r)$ denote fathers' occupations and columns $(s)$ denote occupations of sons. A simple metric of absolute mobility in this table is the fraction of sons that enter into a different occupational group than their father, which simply corresponds to the share of sons that end up in cells that lie off the main diagonal. ${ }^{9}$ This fraction

\footnotetext{
${ }^{7}$ Moreover, none of these studies compare the Swedish case with the level of mobility in other countries that were industrializing at the time.

${ }^{8}$ For example, Appendix Figure D.1 shows that there is important overlap in the income distributions of the four occupational groups on which we base our analysis.

${ }^{9}$ Sometimes described as "total" or "structural" mobility.
} 
depends mechanically on structural change: if certain sectors such as farming shrink over time, sons are forced out of those sectors and into other occupations. Therefore, we also present adjusted rates of absolute mobility where transitions have been scaled to ensure identical marginal distributions across tables (Deming \& Stephan, 1940). Specifically, we impose the marginal distribution of Sweden, which lets us answer the question: what would absolute mobility have looked like in other countries, had they undergone the same structural transformation at the time?

Absolute mobility captures the historical experience of individuals. It is therefore what would have been noticeable by contemporary observers and influenced debate at the time. ${ }^{10}$ Yet, one shortcoming of absolute mobility metrics is that they do not distinguish between (a) mobility that occurs mechanically due to shifts in the marginal distribution of occupations between generations, and (b) mobility that might have occurred even if the margins had stayed identical (Long \& Ferrie, 2013a; Pérez, 2019). The latter type of mobility—-known as relative mobility-is believed to better capture the underlying structure of opportunities, or the "openness" of a society (Erikson \& Goldthorpe, 1992). Any society can show high mobility in times of rapid structural transformation, but only one that offers its members relatively equal chances will achieve high mobility absent such transformation. A common way to assess relative mobility is to use odds ratios, which reflect the relative chances of reaching a given occupational standing for sons from different origins. The odds-ratio comparison can be expressed:

$$
\theta_{i j, i^{\prime} j^{\prime}}=\frac{p_{i j} / p_{i^{\prime} j}}{p_{i j^{\prime}} / p_{i^{\prime} j^{\prime}}}=\frac{p_{i j} p_{i^{\prime} j^{\prime}}}{p_{i j^{\prime}} p_{i^{\prime} j}},
$$

contrasting, for example, the odds $p$ for a white-collar father's son $j$ of entering a white-collar job $i$ as opposed to a job as a manual laborer $i^{\prime}$, relative to the corresponding odds for a son of a manual worker $j^{\prime}$. However, in an $r \times s$ table there are $[r(r-1) / 2][s(s-1) / 2]$ unique odds ratios, which results in a large number of coefficients instead of a single summary measure of mobility. ${ }^{11}$

As a solution, Altham (1970) proposed a method to summarize all the odds ratios in a crosstable, subsequently named the "Altham statistic", which has become standard in this literature (Long \& Ferrie, 2013a). Since it is based on odds ratios, this statistic is invariant to differences in marginal

\footnotetext{
${ }^{10}$ For example, Tocqueville (1835) noted that "Among aristocratic peoples, families remain for centuries in the same condition and often in the same place... Among democratic peoples, new families continually spring from nowhere while others disappear to nowhere". This statement is one about absolute mobility.

${ }^{11}$ In sociology, the common approach has been to impose more structure on the table by fitting what has become known as "log-multiplicative" models (Erikson \& Goldthorpe, 1992; Xie, 1992). This approach consists in imposing a more or less parsimonious pattern of movements across the cells that provide an acceptable fit for all tables that are to be compared. The parameters of such a model are constrained to be equal across all tables, up to a constant that is allowed to vary across tables ("layers") and which captures the relative degree of mobility. Such an approach may be problematic when comparing historical cases, however, as the pattern and not just the strength of mobility can be expected to differ. The Altham statistic, described below, has the distinct advantage that it is agnostic with regards to the structure of mobility and thereby more flexible than these alternative approaches.
} 
distributions across tables. Hence, it allows us to compare relative mobility in two or more tables without adjusting the table's margins. If we let $\mathbf{P}$ and $\mathbf{Q}$ denote the $r \times s$ mobility table for two countries, the Altham $d(\mathbf{P}, \mathbf{Q})$ statistic is calculated as:

$$
d(\mathbf{P}, \mathbf{Q})=\sqrt{\sum_{i=1}^{r} \sum_{j=1}^{s} \sum_{i^{\prime}=1}^{r} \sum_{j^{\prime}=1}^{s}\left[\log \left(\frac{p_{i j} p_{i^{\prime} j^{\prime}}}{p_{i j^{\prime}} p_{i^{\prime} j}}\right)-\log \left(\frac{q_{i j} q_{i^{\prime} j^{\prime}}}{q_{i j^{\prime}} q_{i^{\prime} j}}\right)\right]^{2}}
$$

which summarizes the square root of all squared log odds-ratio comparisons in each table. The resulting measure ranges between 0 and infinity, where 0 denotes that each odds ratio is identical across the two tables. In other words, a larger $d(\mathbf{P}, \mathbf{Q})$ statistic corresponds to a greater distance between the row-column associations in tables $\mathbf{P}$ and $\mathbf{Q}$ and consequently a greater difference in mobility. To test whether such a difference is statistically significant, we can establish whether the gap between $\mathbf{P}$ and $\mathbf{Q}$ is non-zero using a likelihood-ratio $\chi^{2}$ statistic with $(r-1)(s-1)$ degrees of freedom (Altham \& Ferrie, 2007). However, even in the case of a significant difference between the row-column associations in the two tables, the $d(\mathbf{P}, \mathbf{Q})$ statistic is in itself not informative about which matrix displays more mobility.

To assess which table entails more mobility, we also compare how much each of them deviates from the case of full mobility (i.e., where the occupational attainment of sons is completely independent of their fathers). That is, we compare occupational transitions to a benchmark table with no row-column association I, a matrix where all the row and column probabilities are equal to their margins and hence all odds-ratio comparisons amount to 1 . Since each log-odds ratio in the matrix of independence $\mathbf{I}$ is unity, its logarithm will amount to 0 and the Altham $d(\mathbf{P}, \mathbf{I})$ statistic in this case simplifies to:

$$
d(\mathbf{P}, \mathbf{I})=\sqrt{\sum_{i=1}^{r} \sum_{j=1}^{s} \sum_{i^{\prime}=1}^{r} \sum_{j^{\prime}=1}^{s}\left[\log \left(\frac{p_{i j} p_{i^{\prime} j^{\prime}}}{p_{i j^{\prime}} p_{i^{\prime} j}}\right)\right]^{2}}
$$

where the statistic again takes on values between 0 and infinity. A larger distance between table $\mathbf{P}$ (or Q) and I here represents a greater divergence from the case of full mobility. Hence, the larger the Altham $d(\mathbf{P}, \mathbf{I})$ is, the lower the level of relative mobility.

Establishing whether two countries differ in terms of occupational mobility then involves two steps: to (1) estimate the distance between the mobility matrix in each country relative to the case of full mobility (i.e., $d(\mathbf{P}, \mathbf{I})$ and $d(\mathbf{Q}, \mathbf{I})$ respectively); and (2) establish whether the matrices are different from one another by estimating the $d(\mathbf{P}, \mathbf{Q})$ statistic. A useful property of the Altham statistic is that, since it is simply an aggregate of the underlying odds ratios, it can be decomposed into its constituent odds-ratio comparisons. This makes it possible to attribute total immobility to the contribution from each cell, row, or column of the table - a feature we make use of below. 
At the same time, the Altham statistic has the drawback that it assigns equal weight to all cells in the table and hence to each odds-ratio contrast. This may end up assigning disproportionate weight to cells that are very sparsely populated, which gives rise to two potential problems. First, sparse cells entail a larger sampling error and one may end up mistaking sampling variability for substantive variation. We address this issue by employing a Bayesian shrinkage estimator (Zhou, 2015). Second, even abstracting from sampling error one may want to assign lesser substantive importance to groups that make up a small part of the population. ${ }^{12}$ An ad hoc solution is to reestimate associations excluding certain cells (e.g., farmers) from the table (Long \& Ferrie, 2013a). A more principled approach is to weight each pairwise comparison $p_{i j} p_{i^{\prime} j^{\prime}} / p_{i j^{\prime}} p_{i^{\prime} j}$ directly by the marginal proportion of each row and column (Bouchet-Valat, 2019). We implement both solutions as robustness checks below.

\section{Data}

Our main source of data is the full-count 1880 and 1910 Swedish censuses, distributed through IPUMS International (Swedish National Archives, 2014, 2016; IPUMS, 2019). Each census contains detailed individual- and household-level demographic and occupational information, coded into consistent international standards, for the universe of Swedish residents.

Census enumeration in Sweden differed from British, Norwegian, and US censuses in that it was not based on self-reports to census takers walking door to door. Instead, the demographic information comes from parish records that were kept on a running basis by the church, which created extracts for inclusion in each decennial census. ${ }^{13}$ Consequently, the Swedish data possess some unique strengths relative to that of other countries. In particular, birthplace is recorded at the parish level, a much finer geographic unit than, for example, US states (there were approximately 2,500 parishes in Sweden in 1880). In addition, since individual information in the censuses was sourced from continuous parish registers, birth years do not suffer from recall error. ${ }^{14}$ We next describe how these advantages let us achieve high linkage rates without sacrificing match quality when tracing individuals between censuses.

\footnotetext{
${ }^{12}$ This was a point of contention surrounding the findings of Long \& Ferrie (2013a) where farmers account for a decreasing proportion of the population but their contribution to estimated persistence remains constant (Xie \& Killewald, 2013).

${ }^{13}$ In Stockholm, a system of civil registrars was established in 1878 on the same principles, to relieve the church which was struggling to keep pace with the growth of the city at this time.

${ }^{14}$ This is evident from the lack of heaping of reported ages, something which is otherwise common in historical data (see Appendix Figure D.2 for the distribution of ages in Swedish, Norwegian, UK and US censuses). Whipple's index, a common measure of the extent of age heaping in populations, is 100.2 for the Swedish 1910 census, implying a complete lack of age heaping. Whipple's index for the Norwegian 1900 census, UK 1881 census and US 1880 census are $105.5,114.8$ and 144.5 respectively.
} 


\subsection{Record Linkage}

Our aim is to create a representative sample of fathers and sons observed in both 1880 and 1910. As with historical census data for other countries, the main challenge is to trace individuals over time in the absence of unique individual identifiers. To link adult sons to their childhood households we therefore rely on time-invariant attributes and probabilistic matching methods (Abramitzky et al., 2019). We provide a summary of our linking approach here, and lay out a more detailed description of the procedure in Appendix A.

To link individuals between the two censuses we proceed as follows. We first designate index variables which have to match exactly for two records to be considered potential matches: sex, birth year and parish of birth. For candidates that constitute a match on these criteria, we compare the similarity of first and last names using the Jaro-Winkler algorithm (Winkler, 1990) which assigns a score between 0 (no similarity) and 1 (identical) by comparing characters and transpositions in text strings. ${ }^{15}$ We consider individuals linked if there is a unique match within the same sex $\times$ birth year $\times$ place of birth cell that satisfies a Jaro-Winkler threshold of at least 0.85 for both the first and the last name. In Appendix A we show that this threshold value is an optimum that maximizes both the number of realized links and the share of those links that are confirmed true by matching middle initials in our sample.

We focus on cohorts born 1864-1880, who were 16 years old or less in 1880 and thus in their 30s or 40s in 1910. In total we observe 849,996 boys belonging to these cohorts in the 1880 census. Thirty years later, following attrition due to out-migration and mortality, 543,155 of these men were enumerated in the 1910 census. ${ }^{16}$ In total our method succeeds in linking 310,183 men between the two censuses, which corresponds to $36.5 \%$ of the relevant cohorts enumerated in 1880 and $57.1 \%$ in 1910 . These linkage rates are significantly higher than typically achieved when linking historical censuses. For other linked samples the retrospective rates (comparable to our rate of $57.1 \%$ ) range from $20.3 \%$ and $21.9 \%$ for Britain and the US (Long \& Ferrie, 2013a) to $37.0 \%$ for Norway (Modalsli, 2017). We discuss below why this is unlikely to bias our comparisons, and also implement alternative linking algorithms that mimic the links in other countries.

\subsubsection{Assessing the Linked Sample}

An important question is how well the resulting linked sample represents the underlying population, since differential matching rates based on demographic or economic characteristics could introduce bias in the subsequent analysis.

\footnotetext{
${ }^{15}$ To allow for transcription errors or minor spelling differences, we standardize names by removing nobility prefixes, patronymic suffixes and all non-alphabetic characters.

${ }^{16}$ We discuss the role of emigration further below, where we also present results where we link sons in the 1880 census to emigrant records to directly account for attrition from the sample.
} 
We first address this question by comparing the distribution of fathers' and sons' characteristics for linked individuals compared to the relevant population in the 1880 and 1910 censuses. Appendix Table E.1, columns 1 and 2 show that fathers' and sons' ages are very similar on average, though linked sons are somewhat less likely to have grown up in urban households, or households where the head has migrated from his parish of birth. ${ }^{17}$ However, there are virtually no differences in terms of father's occupational class: the difference between linked and non-linked sons is less than one percentage point for all four occupational groups (column 3). The linked sample thus closely resembles the occupational distribution in the underlying population.

We similarly find that fathers' occupational status is a poor predictor of successful matches in multivariate regressions where we regress an indicator of a match in the 1910 census on demographic, economic, and name characteristics recorded in the 1880 census. Appendix Table E.2, column 1 shows that sons with white-collar fathers are slightly more likely to be matched than, for example, sons to unskilled fathers. However, this may be driven by the fact that naming patterns differ across social groups (Olivetti \& Paserman, 2015). In particular, white-collar sons may be easier to link if they have longer and/or less common names. The higher match probability for sons to white-collar fathers indeed becomes attenuated when controlling for name length and name commonness in column 3. ${ }^{18}$ Moreover, the overall explanatory power of fathers' occupational status and the included covariates is limited. ${ }^{19}$

Taken together, the fact that occupational distributions are nearly identical among our linked sample and the underlying population suggests that any bias is likely to be small. However, to assess whether potential selection into the linked sample affects our mobility estimates, we also present estimates where we weight each father-son pair by the inverse probability that a son is linked based on the demographic, economic, and name characteristics analyzed in this section.

\subsection{Classifying Occupations}

Occupational titles in the Swedish censuses are coded according to the Historical International Standard of Classification of Occupations (HISCO), where titles are allocated to five-digit codes indicating one of 1,600 possible occupational unit groups (Van Leeuwen et al., 2002). ${ }^{20}$ This allows

\footnotetext{
${ }^{17}$ In columns 4 and 5 we find a similar pattern when we compare place of residence and migrant status among linked and non-linked sons as adults in the 1910 census.

${ }^{18}$ Having a white-collar father is associated with a $4.5 \%$ increase in the probability of being matched when controlling only for father's occupational group and age, which drops to $2.3 \%$ once we control for name characteristics.

${ }^{19} \mathrm{McFadden}$ 's $R^{2}$ is below $1 \%$ in the model with father's occupational group as the only explanatory variable, which only increases to $2.4 \%$ in the model including name characteristics and county of birth fixed effects.

${ }^{20}$ Examples of five-digit codes include 87310 "Sheet metal worker," 37020 "Mail sorting clerk," or 02220 "Railway construction engineer". To aggregate occupations into broader occupational skill or status groups, we use the HISCO codes together with a status variable that encodes information contained in the original occupational strings which does not always appear in the occupational code itself: details on ownership, stages in an artisan's career, and whether
} 
us to aggregate occupations recorded in the census to the HISCLASS scheme, a harmonized categorization created for the purpose of comparison across countries and time periods (Van Leeuwen \& Maas, 2011). Following Long \& Ferrie (2013a), we aggregate the 12 HISCLASS groups into four broad groups more suitable for the analysis of occupational mobility: "White collar," "Farmers," "Skilled/semi-skilled," and "Unskilled" (see Appendix Table E.3). Given the difficulty in unambigously ranking the four groups, we base our comparisons on methods treating these groups as nominal rather than ordinal. In supplementary analyses, we also show additional results introducing further distinctions within the most and least skilled groups.

\subsection{Additional Father-Son Datasets}

We complement our linked sample of Swedish fathers and sons with similar linked samples for several additional countries. In particular, we draw on data from Pérez (2019) for Argentina (1869-1896), Britain (1851-1881), Norway (1865-1900), and the United States (1850-1880). ${ }^{21}$

The latter three datasets are all based on individual-level census data available from IPUMS International (IPUMS, 2019). In all these samples, sons are linked across the two points in time using algorithmic matching based on information on reported names, place of birth, and year of birth. The sample restrictions are also similar as in our Swedish data: all samples are limited to father-son pairs in which (1) the son co-resided with his father at the time of the initial census; (2) the son was 16 years old or younger when observed with their father in the initial census year; and (3) where the father and the son were between the ages 30 and 60 when their occupations were recorded.

To measure mobility in the post-World War II period, we mainly rely on retrospective survey data where respondents were asked to report the occupation that their father held when they grew up. In particular, we use the 1976-1990 rounds of the Swedish Study of Living Conditions (ULF), carried out annually by Statistics Sweden (Vogel et al., 1988), and restrict the sample to native-born sons aged 30-60 at the time they were surveyed. ${ }^{22}$ We use estimates for British sons born between 1935 and 1941 surveyed in the 1972 Oxford Mobility Study and US sons born between 1934 an 1940 in the 1973 Occupational Changes in a Generation Study, both reported by Long \& Ferrie (2013a). Finally, the mobility table for post-World War II Norway comes from the 1910-1960 linked father-son sample analyzed by Modalsli (2017). ${ }^{23}$

someone is a principal or subordinate.

${ }^{21}$ The estimates are based on the following number of observations: US (1850-1880), 180,000 father-son pairs; Argentina (1869-1896), 12,000 father-son pairs; Britain (1851-1881), 2,500 father-son pairs; Norway (1865-1900), 18,000 father-son pairs.

${ }^{22}$ These data were made available to us by Jan O. Jonsson (Breen \& Jonsson, 2020). The underlying mobility matrix is presented in Appendix Table E.5 and the class scheme used for conversion in Appendix Table E.3.

${ }^{23}$ Although the Norwegian data point is earlier than those of other countries, Modalsli (2017) shows that mobility 


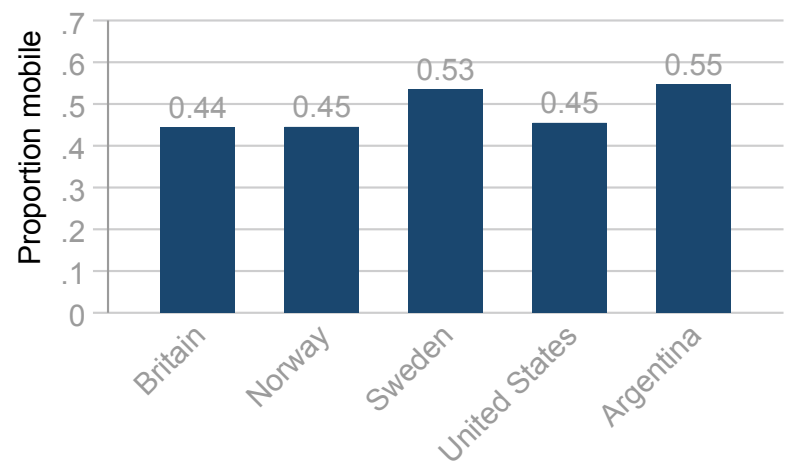

(A) Absolute mobility

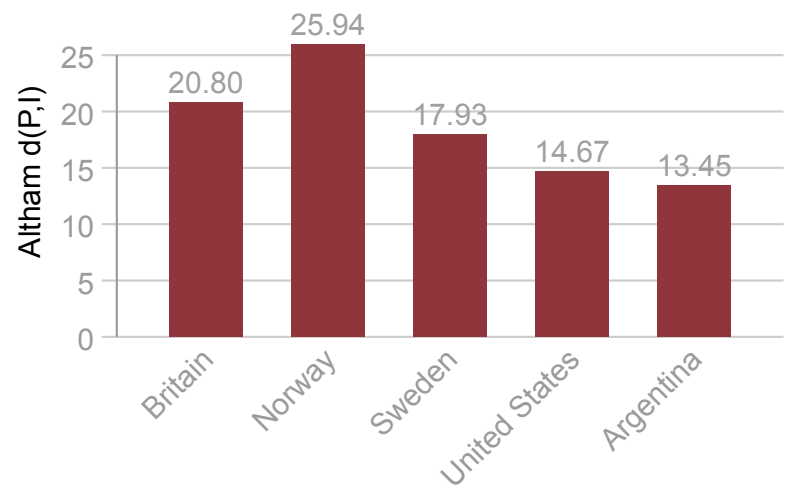

(C) Relative (IM)MOBiLity

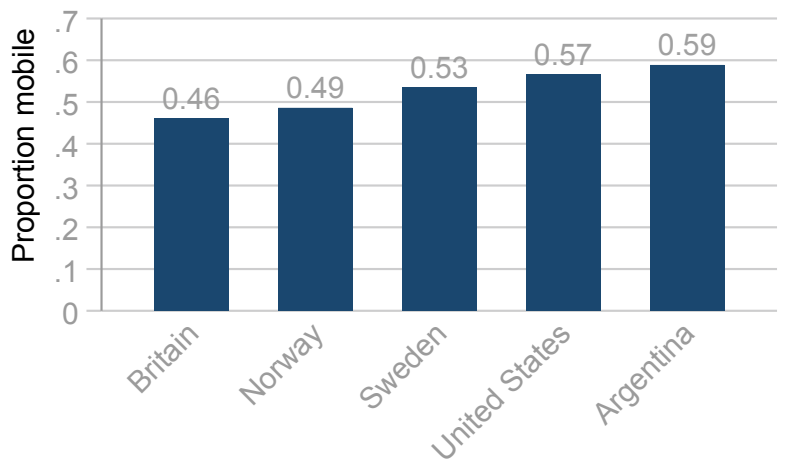

(B) Absolute mobility (SWeden's margins)

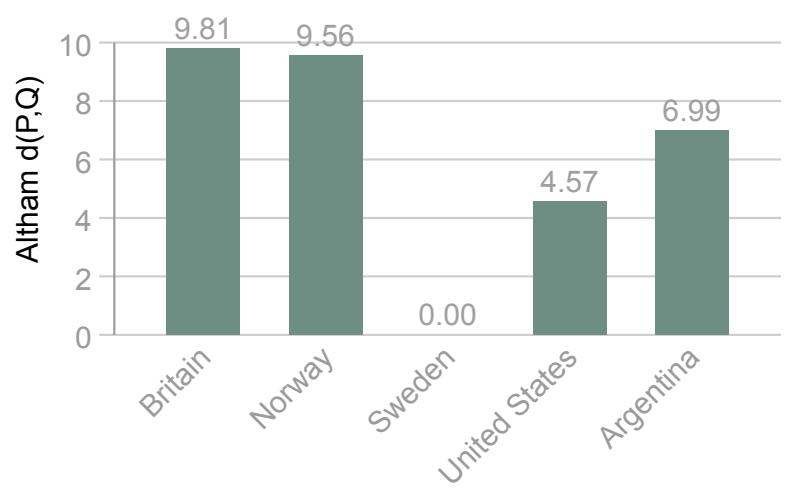

(D) Relative Mobility (VS SWEDEN)

Figure 1: Mobility in the Old AND New World: SWEDEN In INTERnATIONAL PERSPeCtive

Notes: Panel A displays estimates of absolute mobility, or the share of sons that are observed in a different occupational group than their father. Panel B reports similar measures of absolute mobility adjusted to the occupational distribution in Sweden. Panel $\mathbf{C}$ displays Altham $d(\mathbf{P}, \mathbf{I})$ statistics that capture the distance from the case of full mobility where a larger statistic corresponds to less mobility. Panel D reports Altham $d(\mathbf{P}, \mathbf{Q})$ statistics that measure the distance between each country's mobility table and the Swedish mobility table. See section 2 for information about data sources.

\section{How Mobile was Sweden Before the Welfare State?}

\subsection{Main Results}

\subsubsection{Historical Differences in Mobility}

We first examine historical differences in absolute mobility across countries. Figure 1A displays absolute mobility rates, the share of sons that are observed in a different occupational group than their father, for Sweden and the four other countries in our sample. Swedish sons born in the lateremained at a comparable level throughout the 20th century. 
Son's occupation

\begin{tabular}{lccccc}
\hline & \multicolumn{3}{c}{ White-collar } & Farmer & Skilled/semi-skilled \\
Father's occupation & $\%$ & $\%$ & $\%$ & $\%$ & $\%$ \\
\hline White-collar & 57 & 9 & 21 & 13 & 100 \\
Farmer & 9 & 47 & 22 & 21 & 100 \\
Skilled/semi-skilled & 16 & 10 & 53 & 21 & 100 \\
Unskilled & 10 & 14 & 39 & 38 & 100 \\
Total & 14 & 29 & 32 & 25 & 100 \\
\hline $\mathrm{N}$ & 34,792 & 69,209 & 77,099 & 59,841 & 240,941 \\
\hline
\end{tabular}

TABLE 1: OCCUPATIONAL TRANSITIONS FOR FATHERS AND SONS, 1880-1910

Notes: This table displays occupational transitions for sons relative to their fathers. Each row corresponds to the occupational group of fathers observed in the 1880 census. Each column corresponds to the occupation of sons observed in the 1910 census.

19th century experienced significant absolute mobility: 53\% worked in a different occupational group in the early 20th century compared to their father. Thus, absolute mobility in Sweden was close to levels observed in Argentina and considerably higher than in Britain, Norway, as well as the United States, where less than half of sons transitioned into a different occupational group than their father. All these differences are significant at the 1\% level, as shown in Appendix Table E.6.

Table 1 presents the full transition matrix for fathers' and sons' occupations, to shed more light on the underlying patterns of mobility. ${ }^{24}$ Intergenerational persistence was strongest among sons to white-collar and skilled/semi-skilled fathers where more than half of all sons ended up in the same occupational group as adults. Among sons to farmers, only 9\% transitioned into white-collar jobs, while almost half ended up in skilled or unskilled jobs. By contrast, $62 \%$ of sons born to unskilled fathers are observed in a different occupational group, most commonly transitioning into skilled or semi-skilled occupations.

Absolute mobility results from two different processes: (a) changes in occupational composition across generations, and (b) the relative ease with which social boundaries can be crossed. When a society undergoes rapid structural transformation, many sons will be "forced" into new occupations due to the unavailability of employment in their father's industry. Figure 1B illustrates this, where each mobility table has been constrained to Sweden's marginal distribution (Deming \& Stephan, 1940; Altham \& Ferrie, 2007). This figure demonstrates that Sweden's high absolute mobility is partly attributable to its rapidly shifting industrial landscape compared to other countries at the time. We therefore focus mainly on relative mobility, which adjusts for marginal distributions.

Relative mobility is captured by the Altham statistic, which aggregates all possible odds-ratio

\footnotetext{
${ }^{24}$ Appendix Table E.4 reports the frequencies of occupational transitions in each cell of the transition matrix.
} 
comparisons between origins and destinations in the mobility table. Unlike absolute mobility, it is independent of marginal distributions and reflects the relative ease with which sons can enter a different occupational group from their father, compared with incumbents of that group (or sons from any other group). Figure 1C displays Altham $d(\mathbf{P}, \mathbf{I})$ statistics for Sweden and the other American and European countries in our sample. The Altham $d(\mathbf{P}, \mathbf{I})$ statistic represents the deviation of each country's mobility table from the case of perfect independence between sons' and fathers' occupation. Hence, for our relative mobility metric, higher values indicate lower mobility. As evident from Figure 1C, Sweden's mobility matrix is closer to independence than those of both Britain and Norway, but slightly further away than the countries in the Americas. The cross-country pattern is similar to what we found in the comparison of absolute mobility using adjusted margins in Figure 1B. According to the $\chi^{2}$ statistic, the deviation from the case of full mobility is significant at the $1 \%$ level for all countries in our sample. However, while the Altham $d(\mathbf{P}, \mathbf{I})$ statistics presented in Figure 1C allow us to compare differences in the distance to the case of full mobility, it does not tell us whether country-level mobility patterns differ in a direct comparison.

To determine whether mobility differs significantly between Sweden and the other countries, we estimate the Altham $d(\mathbf{P}, \mathbf{Q})$ statistic aggregating the differences in row-column associations between the Swedish mobility table $(\mathbf{P})$ and that of each comparison country $(\mathbf{Q})$. These estimates are presented in Figure 1D. All estimated differences are statistically significant at the $1 \%$ level, which shows that Swedish mobility diverged from that in all other countries in the comparison. Combined with the estimates of mobility relative to independence (Figure 1C) this provides evidence that Sweden was more mobile than the other European countries, and only slightly less mobile than the Americas. Since the Altham $d(\mathbf{P}, \mathbf{Q})$ statistic is a distance measure, it also informs us about how (dis)similar mobility patterns are. Notably, the distance between Sweden compared to the Americas is smaller than to the two European countries. Specifically, the distance between Sweden and Britain (9.81) or Norway (9.56) is more than twice as large as the distance between Sweden and the United States (4.57). Thus, the pattern of mobility in Sweden lies closer to the New than the Old World. Indeed, the distance between the Swedish and US mobility pattern is virtually identical to the difference between Argentina and the United States. ${ }^{25}$ In other words, differences in the mobility patterns within the New World (i.e., US vs. Argentina) are equally small as the difference between individual countries in the Old and the New World (i.e., US vs. Sweden).

\subsubsection{Mobility Before and After the Welfare State}

Our primary interest is to establish levels of occupational mobility in Sweden relative to that observed in other countries prior to World War I. Yet, another informative comparison is with mobility

\footnotetext{
${ }^{25}$ As reported above, the distance metric $d$ (Sweden, United States) is 4.41 , while the analogous metric $d($ Argentina, United States) is 4.23; both differences are statistically significant at the $1 \%$ level.
} 
rates observed in the post-World War II era. Here we compare our historical estimates of Swedish mobility to mobility rates in Britain, Norway, Sweden, and the United States among cohorts that came of age during the rise of welfare states in the latter half of the 20th century. We focus on analyzing differences in relative mobility, since comparisons of absolute mobility among cohorts born a century apart are likely to be significantly shaped by differences in occupational distributions across countries and time. ${ }^{26}$

Figure 2 reports the estimated Altham $d(\mathbf{P}, \mathbf{I})$ statistics for Sweden and the other three countries for which we have both historical linked census data and modern retrospective survey or census data available. ${ }^{27}$ Comparing estimated levels of relative mobility shows that, with the exception of the 19th-century United States, historical Sweden exhibited a smaller departure from the case of full mobility than any of the other samples. In each sample, the $\chi^{2}$ statistic indicates that we can reject (at the 1\% level) the null hypothesis that row-column associations in the mobility table is the same as would have been observed in the case of full mobility. To directly examine the extent to which Sweden's historical mobility pattern departs from that of other countries, we present additional estimates of Altham $d(\mathbf{P}, \mathbf{Q})$ statistics in Appendix Figure D.3. Interestingly, the Altham $d(\mathbf{P}, \mathbf{Q})$ statistics show that Sweden's pattern of mobility lies much closer to that observed in the 19th-century United States than to any other country or period. At the same time, Sweden's historical mobility pattern deviates significantly from that observed in the late-20th century samples; based on the $\chi^{2}$ statistics, we can reject at the $1 \%$ level that mobility patterns in historical Sweden are identical to that in any of the other samples. Taken together with the estimated Altham $d(\mathbf{P}, \mathbf{I})$ statistics, these estimates show that Sweden at the turn of the 20th century displayed significantly higher rates of relative mobility than Britain, Norway, and the United States did in the post-World War II era.

How did Sweden's historical levels of occupational mobility compare to that observed among cohorts who grew up during the rise of the welfare state? Figure 2 demonstrates that the level of relative mobility that we observe among Swedish cohorts born in the late-19th century is higher than among those growing up in the post-World War II era. The estimated Altham $d(\mathbf{P}, \mathbf{I})$ statistic for our historical and post-World War II cohorts are 17.93 and 20.43 respectively, which reflects a slight decline in mobility. Based on the Altham $d(\mathbf{P}, \mathbf{Q})$ statistic we can reject at the $1 \%$ level that mobility patterns are identical in both periods. Thus, Sweden's high levels of intergenerational

\footnotetext{
${ }^{26}$ We present estimates of absolute mobility in Appendix Figure D.3 showing that Sweden historically also displayed high levels of absolute mobility compared to countries in the post-World War II era.

${ }^{27}$ The census and survey data are subject to distinct sources of bias, but as these are both downward in magnitude, they are likely to counterbalance each other. Error in the probabilistic matching may introduce attenuation bias in the census data that is absent in survey data. Conversely, retrospective survey data contain recall errors which, if random, will lead to attenuation bias that is absent in the census data. Bielby et al. (1977) evaluate misreporting of occupations in the 1973 Occupational Changes in a Generation data and find that errors are strictly random. Research also shows that for the analysis of occupational transition matrices, the resulting bias is small (Breen \& Jonsson, 1997).
} 


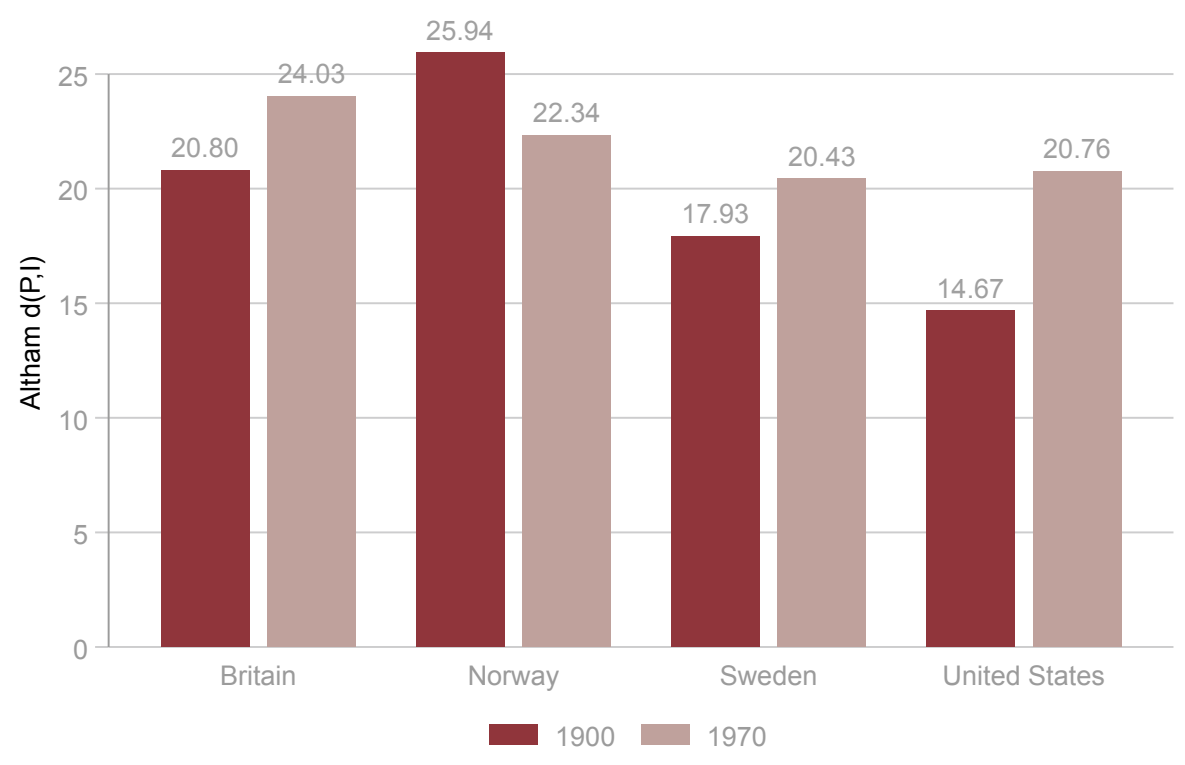

FIGURE 2:

RELATIVE (IM)MOBILITY IN HISTORICAL AND MODERN SAMPLES

Notes: This figure displays Altham $d(\mathbf{P}, \mathbf{I})$ statistics that capture the distance from the case of full mobility. Note that a larger statistic corresponds to less mobility. See section 2.3 for information about the historical and modern data sources.

occupational mobility are evident several decades before the emergence of the welfare state.

\subsection{Additional Estimates and Robustness}

In this section, we begin by demonstrating the importance of farming in understanding crossnational differences in mobility. We also provide a disaggregation of the relative contribution of all occupational groups, and show how estimates differ when the relative sizes of groups are taken into account. Thereafter we assess the robustness of our findings along several dimensions. In particular, missing occupational information (in large part driven by emigration) or life-cycle differences in occupational attainment may bias mobility estimates. Moreover, selection into our linked sample, differences in linking algorithms, or the choice of specific census years may affect international mobility comparisons. Below, we provide evidence that high levels of historical Swedish mobility remain evident when addressing all of these points.

The Role of Farmers A key concern in historical mobility research is that the differential depletion of the farming class may explain a substantial part of cross-country differences and long-run 
trends in mobility (Long \& Ferrie, 2013b; Xie \& Killewald, 2013; Song et al., 2019). ${ }^{28}$ While no meaningful estimate of 19th-century mobility can exclude farmers, it is important to establish whether mobility differences are driven solely by this group. To investigate this issue, we estimate Altham $d(\mathbf{P}, \mathbf{I})$ and $d(\mathbf{P}, \mathbf{Q})$ statistics excluding all farmer cells from the underlying mobility table in Appendix Figure D.4. This reduces the mobility differences between countries and puts Sweden and Britain at a comparable level, but otherwise keeps the ranking of countries intact. Interestingly, Figure D.4B reveals that the pattern of mobility in Sweden remains closest to that found in the US, even with farmers excluded.

Contribution of Individual Origins/Destinations A useful property of the Altham statistic is that it can be broken down into contributions per cell. Doing so tells us which combinations of fathers' and sons' occupational group are most overrepresented relative to independence. We present disaggregations of $d(\mathbf{P}, \mathbf{I})$ by row and column in Appendix Figure D.5, using the method described by Bouchet-Valat (2019). The row-wise decomposition shows us which groups of fathers' occupations contribute the most to the deviation from independence, while the column-wise decomposition shows us which groups of sons' occupations do so. Because dependencies are strongest in the main diagonal of the mobility table, reflecting sons who stay immobile, the results look similar regardless of whether we disaggregate by father's or son's occupation. The lion's share of persistence in Sweden is accounted for by the white-collar and farming sector, whereas the boundary between skilled and unskilled labor is more permeable. This pattern is replicated in the United States and Argentina, which helps explain the similarities between Sweden and the New World. By contrast, the skilled/unskilled distinction matters more in Britain. In Norway, entry into the white-collar elite is extremely restricted and this accounts for a large part of the difference between Norway and Sweden.

Alternative Estimators of Relative Mobility So far, our analyses of relative mobility have assigned equal weight to each occupational group in the calculation of Altham statistics. This may be undesirable for at least two reasons. First, cells with few father-son pairs have a larger sampling error, which leads to a risk of mistaking sampling variability for substantive variation. In Appendix Figure B.1, we use a Bayesian shrinkage estimator to deal with small cell sizes (Zhou,

\footnotetext{
${ }^{28}$ Indeed, a relative ease of transitioning into farming is emphasized by both Long \& Ferrie (2013a) and Pérez (2019) as an avenue for occupational mobility in both Argentina and the United States due to the existence of a vast internal frontier. Here Sweden resembles the New World in some respects: as new farms were established due to the clearing of large swaths of land in northern Sweden, the rural proletariat could advance into the farmer group by securing their own piece of land (Myrdal \& Morell, 2011; Bäcklund, 1988). However, high rates of mobility in the Americas extended beyond frontier areas and remained elevated several decades after the "closure" of the frontier (Long \& Ferrie, 2013a). Similarly, areas in Sweden that saw extensive land clearing in the North exhibit relatively lower rates of mobility (see Figure 4A below).
} 
2015). Second, it might be desirable to assign lesser importance to groups that make up a small part of the population. ${ }^{29}$ In Appendix Figure B.1, we also present Altham statistics where each pairwise comparison $p_{i j} p_{i^{\prime} j^{\prime}} / p_{i j^{\prime}} p_{i^{\prime} j}$ is weighted by the marginal proportions of the corresponding rows and columns. We describe these measures in more detail in Appendix Section B, where we also present results imposing these adjustments jointly. Across all specifications, our results remain qualitatively similar and Sweden's relatively high historical mobility is maintained. ${ }^{30}$

More Detailed Occupational Classifications Could the high rate of mobility in Sweden be an artefact of a relatively coarse categorization of occupations that fails to distinguish immobility at the extremes of the distribution? In Appendix Figure D.6 we introduce two alternative, more finegrained occupational codings following Long \& Ferrie (2013a) and Pérez (2019). We first split the "white collar" category into a higher group, comprising managers and higher professionals (HISCLASS groups 1-3), and a lower, composed of lower professionals and clerical and sales personnel (HISCLASS groups 4-5). Using this categorization leads to a higher Altham statistic for all countries, but less so in Britain than elsewhere. Nevertheless, the relative ranking of countries is preserved. Next, we split the low-skilled group into farm (HISCLASS groups $10 \& 12$ ) and non-farm workers (HISCLASS groups 9 \& 11). The latter recoding reverses the ranking between Sweden and the United States, such that the only country more mobile than Sweden is Argentina.

Life-cycle Bias One challenge in measuring mobility between generations is that occupational attainment differs over the life cycle. Ideally, we want to measure the attainment of fathers and sons when they have reached occupational "maturity", which motivates the age restrictions of the sample to fathers (aged 30-60) and sons (30-46) in our main analysis. As a more flexible way to examine how life-cycle bias may affect our estimates, we re-estimate the Altham $d(\mathbf{P}, \mathbf{I})$ statistic for each cohort of sons born between 1850 and 1880 in Appendix Figure D.7A. Mobility stabilizes among sons born in the late 1850 s and remains stable throughout the window used in our baseline sample (i.e., sons aged 16 or below in 1880). We perform a similar robustness exercise restricting the sample by fathers' age, showing that Altham $d(\mathbf{P}, \mathbf{I})$ statistics stabilize in the age range used in our baseline sample (i.e., fathers aged 30-60) in Appendix Figure D.7B. Together, these estimates demonstrate that life-cycle bias is not a major concern for the cohorts that we study.

\footnotetext{
${ }^{29}$ If farmers, for example, account for a small share of the population their contribution to estimated persistence should not remain constant (Xie \& Killewald, 2013).

${ }^{30} \mathrm{~A}$ related issue is that the Altham statistic lacks an upper bound, which makes it hard to interpret in substantive terms. Bouchet-Valat (2019) introduces a transformation of the Altham-statistic that is bounded in the range $[0,1]$, similar to a correlation. We describe this alternative mobility metric and report estimates in Appendix Section B.
} 
Selection into the Linked Sample Another concern is that the linked individuals in our Swedish sample differ from the underlying population, which could lead to biased estimates of mobility. Above, we showed that individuals with, for example, more unusual first names are slightly more likely to be successfully linked across censuses. To examine whether such selection affects our estimates, we re-estimate our baseline Altham $d(\mathbf{P}, \mathbf{I})$ statistic after reweighting the linked data. First, we estimate individual-level regressions of the probability of a successful link on observable childhood characteristics. ${ }^{31}$ Second, we use the inverse of the predicted probability of being included in the linked sample to reweight all father-son pairs in the original mobility table. The reweighted Altham $d(\mathbf{P}, \mathbf{I})$ statistic is 18.05 , which is very close to our baseline estimate of 17.93. Thus, our results are unlikely to be driven by selection into the linked sample based on observable childhood characteristics.

Alternative Linking Procedures A potential source of bias to mobility estimates are: (1) differences in the quality of the underlying data and (2) linking methodology. To ensure that this does not drive our results, we create supplementary samples using alternative linking methodologies.

A key difference between in particular the U.S. and Swedish censuses is the detail by which place of birth and accuracy by which birth years are recorded. Place of birth is recorded at the state level, while birth years are commonly misreported in the U.S. censuses. Thus, links may be less precise than for the Swedish censuses, where place of birth is recorded at the parish level and age heaping is non-existent (see Appendix Figure D.2).

To examine whether such underlying data differences could affect the estimated mobility levels in Sweden relative to the other countries in our sample, we create alternative links that mimic the level of detail available in other censuses. First, we replicate our linking approach identifying the place of birth of individuals based on 24 counties, rather than 2,500 parishes. Second, we allow up to a 5-year difference in birth years, rather than requiring an exact match. The Altham $d(\mathbf{P}, \mathbf{I})$ statistics for the sample created by matching on county of birth and allowing birth years to differ are 18.81 and 19.02 respectively.

In order to ensure that the specific linking algorithm is not the cause of mobility differences, we use the methods employed by Pérez (2019) and Abramitzky et al. (2019) to create alternative linked samples. Both methods are similar to our approach, but use slightly different cutoffs for the JW scores and allow for misreporting and age heaping by considering candidates within age bands (see Table E.7). ${ }^{32}$ The samples produced using the linking approach of Pérez (2019) and

\footnotetext{
${ }^{31}$ More specifically, we regress an indicator for being included in the matched sample on fixed effects for the childhood household's county of residence, the son's age and birthplace, as well as the father's birthplace and occupation.

${ }^{32}$ When implementing the alternative linking methods we use sex and birth parish as index variables. Pérez (2019) uses the JW scores and age differences (which may not exceed 5 year) to predict matching scores. We set the upper and lower thresholds for the matching scores to 0.7 (the absolute score which a match has to exceed) and 0.3 (the margin
} 
Abramitzky et al. (2019) results in Altham $d(\mathbf{P}, \mathbf{I})$ statistics of 18.81 and 18.38 respectively. ${ }^{33}$

These alternative estimates are close to our baseline Altham $d(\mathbf{P}, \mathbf{I})$ statistic of 17.93 and well within the variation displayed across the other four countries when considering alternative linked samples (see Appendix Figure D.8). Importantly, when considering alternative samples, the ranking of countries in terms of relative mobility is maintained. Consequently, differences in linking procedure and data quality is unlikely to account for our main findings.

Additional Linked Datasets Another concern is that mobility in Sweden and the other four countries in our sample is measured over different time intervals, due to the years when censuses were conducted in different countries. Here we show that the mobility gradient is similar when we expand our sample to include additional mobility estimates for the 19th and 20th century. Although these datasets are all generated in a broadly similar way, they differ in terms of census years, linking procedures, and sample restrictions, which allows us to examine whether such discrepancies are likely to affect our cross-country comparisons. In Appendix Figure D.8, we display our historical estimates for Sweden compared with a range of alternative estimates for Britain (Long \& Ferrie, 2013a), Norway (Modalsli, 2017), and the United States (Long \& Ferrie, 2013a; Feigenbaum, 2018; Ward, 2020a). Reassuringly, alternative estimates of mobility are similar to those used in our main analysis and the ranking of countries remains identical.

Missing Occupations A common problem in historical census data is missing occupational information. In our linked sample, about $5.5 \%$ of sons do not report an occupational title which can be assigned to one of the four occupational groups. If this group is less mobile, it may bias our estimates. To bound any potential upward bias in mobility due to missing occupations, we re-estimate the Altham $d(\mathbf{P}, \mathbf{I})$ statistic under the extreme assumption that all sons with missing occupational information are perfectly immobile (i.e., that they hold the same occupation as their father). The estimated $d(\mathbf{P}, \mathbf{I})$ statistic is 19.30, naturally somewhat larger than our baseline estimate of 17.93. However, even this lower level of relative mobility is higher than our estimates for Britain (20.80) and Norway (25.94). Consequently, even assuming that sons with missing occupational information are completely immobile in Sweden and that British and Norwegian census data do not suffer from the same problem, Sweden still appears more mobile. Thus, missing occupational information is unlikely to explain our main finding of high levels of mobility in Sweden.

by which a match has to exceed the second best match). In order for a match to be classified as true by Abramitzky et al. (2019) method, JW scores must exceed 0.9, age differences must not exceed 5 years and there must not be a competing match within a 2 year age band.

${ }^{33} \mathrm{We}$ also create a sample which only includes the links which all methods agree on by considering the intersection of samples created using Pérez (2019) and Abramitzky et al. (2019) and our preferred method. This sample of jointly made links have an Altham $d(\mathbf{P}, \mathbf{I})$ statistic of 18.81. The full transition matrices for these alternative samples are presented in Appendix Tables E.8, E.9, E.10, E.11 and E.12. 
Emigration About a quarter of the Swedish population emigrated to the United States prior to World War I. This could skew our remaining sample toward higher mobility, if emigration was driven by poor economic prospects in the circumstances that emigrants chose to leave (Abramitzky et al., 2012). Constructing a counterfactual mobility estimate absent emigration requires two inputs. First, we need to identify individuals in the 1880 census that emigrated before 1910 . To do this, we link the 1880 census to emigrant records available from church books and passenger lists. Second, we need to approximate emigrants' occupational attainment had they stayed in Sweden. We impute their occupations using information on the occupations that their non-emigrant brothers had attained in $1910 .{ }^{34}$ More details on the linkage and imputation procedure is provided in Appendix C. We estimate the counterfactual Swedish mobility rates by adding all identified emigrants based on their imputed occupations to our baseline mobility table, which results in marginally more mobility: the resulting Altham $d(\mathbf{P}, \mathbf{I})$ statistic is 17.6 as opposed to 17.9 in the baseline estimate.

\section{What Explains Historical Mobility Differences?}

Our results provide strong evidence that absolute and relative occupational mobility in Sweden prior to World War I was significantly higher than in other European countries and in some respects comparable to the highly mobile settler societies in the New World. The analysis above, however, sheds no light on potential explanations for the relatively high level of mobility in Sweden. In this section, we discuss four potential explanations for these observed cross-country mobility patterns that has been emphasized in the historical and modern mobility literature: (1) growth and industrialization; (2) migration; (3) human capital; and (4) fertility. While stylized country comparisons may be informative, we cannot conduct a formal statistical assessment since our sample is essentially limited to five observations. To examine these explanations in more detail, we therefore leverage spatial variation in mobility within Sweden. We document significant regional differences in mobility, which rival the mobility gap between the most and least mobile country in our sample. Using this variation, we examine whether the four explanations outlined above can account for mobility differences across Swedish municipalities.

\footnotetext{
${ }^{34}$ This procedure eliminates the influence of migrant self-selection that is constant across households where brothers grew up, for example, due to financial constraints or unobserved ability that is shared between brothers. It does not eliminate within-household selection. Within households, it is likely that emigrants were selected on traits that predisposed them toward higher mobility, which means that the actual counterfactual mobility rate may be even higher than we estimate.
} 


\subsection{Mobility Patterns Across Countries}

What underlying economic and social factors are consistent with Sweden's high levels of intergenerational mobility? Two interrelated factors with potential to account for Sweden's relatively high levels of mobility are economic development and migration. A longstanding hypothesis is that persistence may weaken during times of economic transformation, owing to swift changes in occupational structure and the relative returns to different types of endowments and human capital (Lipset \& Bendix, 1959; Nybom \& Stuhler, 2014). Indeed, Sweden was among the fastest growing European economies in the decades prior to World War I, outpacing both Britain and its Scandinavian neighbors, including Norway. Across the countries in our sample, there is a clear positive link between the rate of GDP per capita growth and mobility: the most rapidly growing countries in our sample-Argentina, Sweden, and the United States - also had the highest rates of absolute and relative mobility (see Figure 3). ${ }^{35}$ Thus, differences in the rate of economic development closely align with observed differences in mobility.

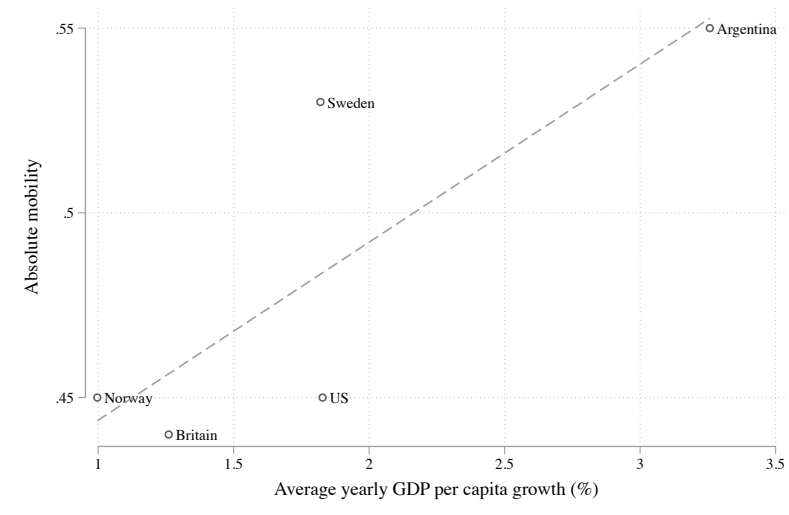

(A) Absolute mobility: Cross-COUntry

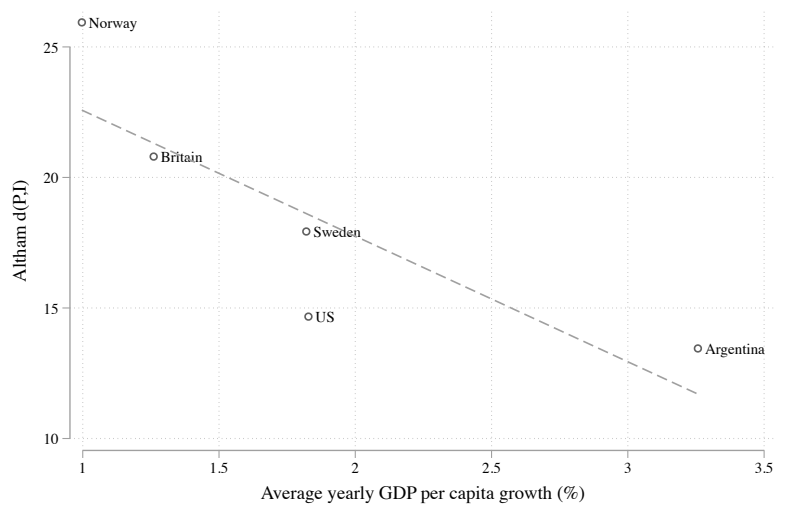

(B) Relative (IM)MOBility: CROSS-COUNTRY

FIGURE 3:

ECONOMIC GROWTH AND MOBILITY ACROSS COUNTRIES AND MUNICIPALITIES

Notes: Panel A displays the cross-country relationship between GDP per capita growth and absolute mobility. Panel B displays the relationship between GDP per capita growth and the Altham $d(\mathbf{P}, \mathbf{I})$ statistic that capture the distance from the case of full mobility where a larger statistic corresponds to less mobility. Average yearly growth rates are measured between the census years used to compute mobility rates based on GDP per capita figures from Bolt et al. (2018).

A related explanation is migration, which may be an important lever to open up avenues for occupational mobility during times of vast disparities in economic and occupational change within

\footnotetext{
${ }^{35}$ It is interesting to note that there is no corresponding relationship between a country's level of economic development and mobility (see Appendix Figure D.9) suggesting that it is the pace of change that matters. For this exercise, we draw GDP data from Bolt et al. (2018) and calculate growth rates as the average yearly increase in GDP per capita between census years used to measure mobility rates.
} 
countries (Long \& Ferrie, 2013a; Tan, 2020; Ward, 2020b; Connor \& Storper, 2020). Previous research indicates that internal migration was quick to respond to the opportunities that opened with industrialization and economic growth. Ericsson \& Molinder (2020) argue that geographical mobility is a key factor in explaining why Swedish real wages grew so fast in the second half of the nineteenth century, while Enflo et al. (2014) show that internal migration was very responsive to wage differentials and shifted supply away from low wage regions, acting as a catalyst for wage growth (see also Collin et al., 2019; Prado et al., 2021). Similarly, Söderberg (1985) compares the stability of the regional population distribution in Sweden, France, Britain, and Prussia in the late nineteenth century and finds most change in the Swedish case. ${ }^{36}$

In line with previous research, migration rates in our linked sample are high: between 1880 and $1910,25 \%$ of sons moved between counties and more than half (59\%) moved between parishes. It is challenging to compare these numbers directly with other countries in our data due to differences in the size of geographical units. ${ }^{37}$ One comparable metric is rural-to-urban migration between Sweden and Norway which used a similar method to designate urban areas in the census. ${ }^{38}$ This comparison is particularly relevant as it corresponds to the type of internal migration which is most strongly associated with intergenerational mobility (Ward, 2021). In Appendix Figure D.10 we plot the share of men observed in the Swedish (1910) and Norwegian (1900) censuses and born in a rural area, that currently reside in an urban area, by age group. In Sweden, about $25 \%$ in ages 20 to 34 had moved to an urban area, while the corresponding number for Norway was below $20 \%$. This pattern remains for older ages as well, suggesting that rural-to-urban migration was a more salient phenomenon in Sweden than in Norway during the period for which we estimate mobility. ${ }^{39}$

Similar motives drove the more than 30 million emigrants who left Europe in search for opportunity in the New World during the Age of Mass Migration. As argued above, Swedish emigrants were likely more mobile than stayers (see also Abramitzky et al., 2012). Thus, emigration might have influenced mobility rates by decreasing the stock of high-mobility individuals in the Old World and increasing it in the New World. However, four facts suggest that emigration has a limited power in explaining country-level differences in mobility. First, we found little evidence that

\footnotetext{
${ }^{36}$ Söderberg (1985) also examines determinants of internal migration, finding that it was most responsive to differences in wages and urbanization rates in Sweden. In Enflo \& Rosés (2015), the responsiveness of internal migration is one of the factors that explain the fast rate of regional GDP convergence over the period 1880-1910, in turn resulting in the lowest dispersion of all countries with comparable data.

${ }^{37}$ Long \& Ferrie (2013a) show that $64 \%$ of sons were observed in different US counties in 1850 and 1880 , while $27 \%$ of sons in Britain changed counties between 1851 and 1881 . However, the size of the average American or British county is not comparable to a Swedish county, but instead falls somewhere between that of a Swedish county and parish.

${ }^{38}$ The designation of towns followed an administrative procedure where a municipality had to receive a town charter in order to be counted as an urban area in the census (Berger \& Enflo, 2017; Ljungberg \& Schön, 2013).

${ }^{39}$ In addition, notwithstanding comparability issues, the numbers for Victorian Britain produced by Long (2005) suggests that rural-to-urban migration rates where lower there while they were greater in the United States (Ward, 2021), lining up with the difference in intergenerational mobility between the two countries.
} 
accounting for emigration affected aggregate mobility in Sweden. Second, while immigrants in the US were indeed more mobile than natives (Abramitzky et al., 2021), intergenerational mobility in the New World was high even among the native born (Pérez, 2019). Third, general equilibrium effects of emigration would partly have offset any selection effect, by decreasing competition for social advancement in sending countries and increasing it in the destination. Fourth, emigration does not explain differences among European countries: both Norway and Sweden were major sending countries, yet had very different levels of mobility.

A third potential factor is education. The provision of human capital is often seen as intertwined with mobility prospects, particularly for those at the bottom of the social ladder. Theory suggests that mobility should be higher where progressivity of public investments in human capital is high and the returns to skills are low (Becker \& Tomes, 1986; Solon, 2004). Both mechanisms may be relevant in the Swedish case. First, Sandberg (1979) argues that Sweden was Europe's "impoverished sophisticate" with the lowest rate of illiteracy in Europe trailing only the US- the world leader in educating its population (Lindert, 2004). Second, earnings differentials between skilled and unskilled Swedish workers were small already in the late-19th century (Ericsson \& Molinder, 2020). Both explanations are seemingly consistent with Sweden's overall high mobility and particularly the low levels of persistence attributable to unskilled groups (see Appendix Figure D.5). Yet, the low levels of literacy and schooling in Argentina (the most mobile country in the sample) and the early commitment to education in Norway (the least mobile country) makes this explanation less compelling. Additionally, it remains disputed whether educational expansions lead to increased or decreased intergenerational transmission (Parman, 2011; Long, 2013; Nybom \& Stuhler, 2014).

Fertility is another potential factor behind mobility differences. The period we study coincides with the onset of a sustained fertility decline, which started among elite groups (Dribe et al., 2014). The shift from child "quantity" to "quality" would have enabled (elite) parents to increase investments per child, and amplified already existing advantages thereby reducing mobility. However, fertility declined broadly at the same time in Britain, Norway, and Sweden (Galor, 2012). Attributing the sharp variation in mobility to class- or country-level fertility differences within Europe is therefore implausible, not least given the differences in persistence among the white-collar elite (see Appendix Figure D.5).

Although it is challenging to discriminate between these (non-mutually exclusive) explanations, the historical evidence discussed in this section highlights two mechanisms-economic development and geographic dynamism — as potentially central to understanding the comparatively high levels of Swedish mobility and the mobility gradient across countries. In the next section, we leverage the substantial variation in mobility within Sweden to examine whether these explanations can also account for observed regional mobility disparities. 


\subsection{Mobility Patterns within Sweden}

\subsubsection{Mobility Differences Across Municipalities}

We first characterize regional differences in mobility across the 282 Swedish municipalities. $\mathrm{Mu}-$ nicipalities are aggregates of parishes, the smallest administrative unit, and arguably capture local labor markets. To estimate local mobility rates, we assign all sons in our linked dataset to the municipality where their household resided when they were aged 16 or below (i.e., in the 1880 census) irrespective of where they reside as adults. ${ }^{40}$ In the median municipality we observe 659 linked sons from our baseline sample, which allows us to estimate both absolute and relative mobility for each individual municipality. ${ }^{41}$

Figure 4A maps the significant variation in absolute intergenerational mobility within Sweden where lighter shades denote a higher level of mobility. Areas in central Sweden close to the capital Stockholm, as well as municipalities in the west and south close to the large cities of Gothenburg and Malmö all show high rates of absolute mobility. To put the magnitudes of these mobility differences in international perspective, Figure 5A plots the distribution of absolute intergenerational mobility by municipality, as well as the aggregate absolute mobility rates in Argentina, Britain, Norway, and the United States. Absolute mobility varies from below $45 \%$ in the bottom decile of Swedish municipalities - higher or on par with levels observed in Britain, Norway, and the United States-to above $62 \%$ in the top decile, a higher level than observed in any of the countries in our sample.

We find similar variation across municipalities in terms of relative mobility. Figure 4B displays the distribution of the Altham $d(\mathbf{P}, \mathbf{I})$ statistic across municipalities. Since larger values of the Altham statistic corresponds to a lower level of relative mobility, darker shades here correspond to a higher level of relative mobility. As shown in Figure 4, municipalities with a higher level of absolute mobility also tend to exhibit higher levels of relative mobility. ${ }^{42}$ Figure $5 \mathrm{~B}$ shows the distribution of Altham $d(\mathbf{P}, \mathbf{I})$ statistics across Swedish municipalites and the estimated national $d(\mathbf{P}, \mathbf{I})$ statistics for Argentina, Britain, Norway, and the United States. Again, the most mobile Swedish municipalities exhibit higher relative mobility rates than those observed in the United States and Argentina, while the least mobile regions exhibit similarly low mobility rates as Britain and Norway. In other words, the variation in absolute and relative mobility within Sweden spans

\footnotetext{
${ }^{40} \mathrm{We}$ present additional results where we assign sons to their municipality of residence in adulthood below, which incorporate sorting across locations into mobility estimates.

${ }^{41}$ In 61 municipalities we end up with at least one empty cell in the $4 \times 4$ mobility table. Since the calculation of the Altham statistic requires that all cells are non-zero, we follow the convention in the mobility literature and add 0.5 to the case count in these empty cells. To ensure that this does not affect our results, we compare both approaches in the 221 municipalities where there are no empty cells, and the correlation of estimates is $r=0.98$.

${ }^{42}$ The cross-municipality correlation between absolute mobility and relative (im)mobility as captured by the Altham $d(\mathbf{P}, \mathbf{I})$ statistic is -0.37 (see Appendix Figure D.11).
} 


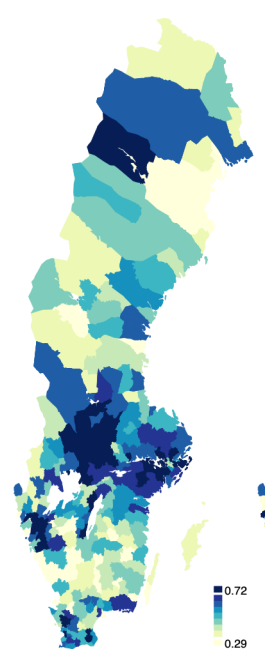

(A) Absolute MOBILITY

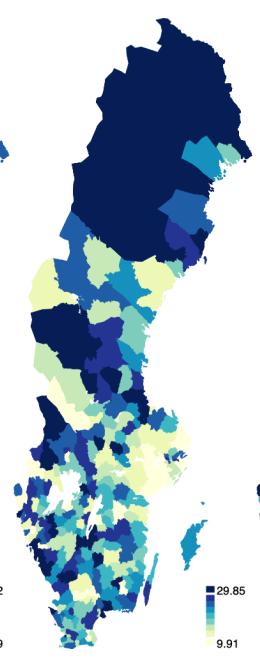

(B) RELATIVE (IM)MOBILITY

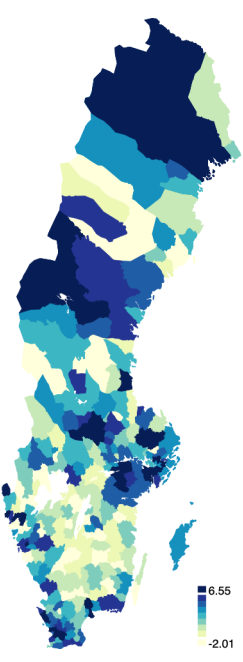

(C) INCOME GROWTH

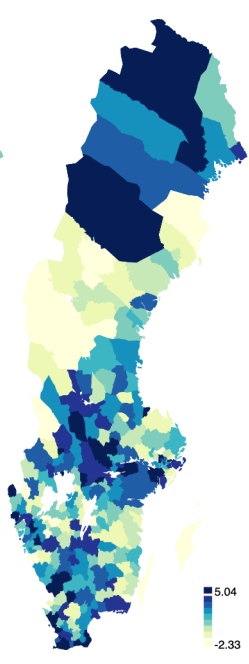

(D) INdustri- (E) Migration ALIZATION

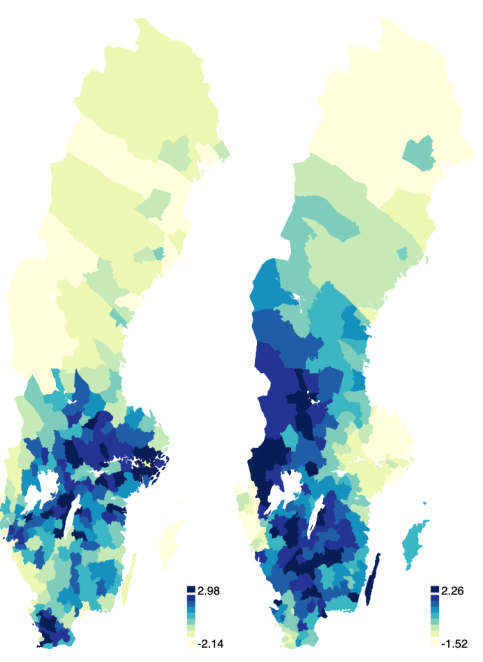

(F)

\section{FIGURE 4: GEOGRAPHY OF OPPORTUNITY AND CORRELATES OF INTERGENERATIONAL MOBILITY}

Notes: Maps display the spatial distribution of mobility and other characteristics across 282 municipalities. A: absolute mobility (the share of sons that transition into a different occupation than their father). B: Altham $d(\mathbf{P}, \mathbf{I})$ statistics that capture the distance from the case of full mobility where a larger statistic corresponds to less mobility. C: ln average changes in incomes between 1880 and 1910. D: changes in the share employed in manufacturing between 1880 and 1910. E: the share of sons that migrate out of each municipality between 1880 and 1910. F: the share of sons in each municipality that emigrated between 1880 and 1910. In C-F the variables are standardized to have a mean 0 and a standard deviation (SD) of 1 . Each variable is divided into 9 equal-sized bins where darker blue shades correspond to higher values. 


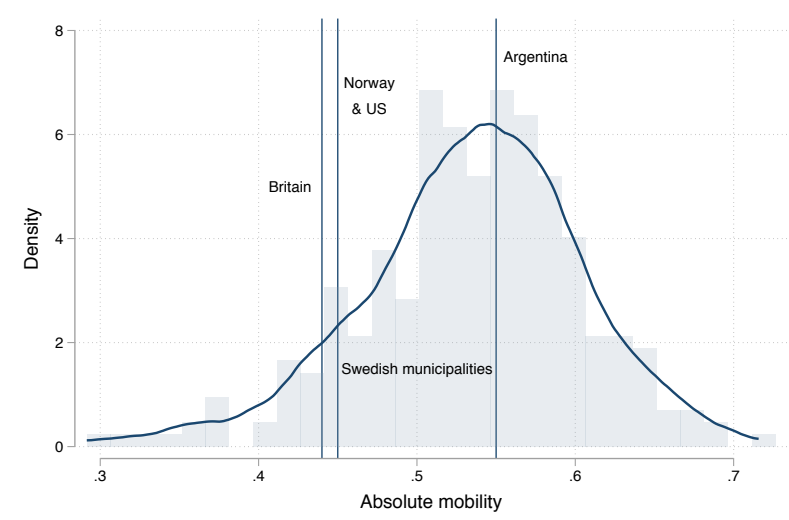

(A) Absolute mobility

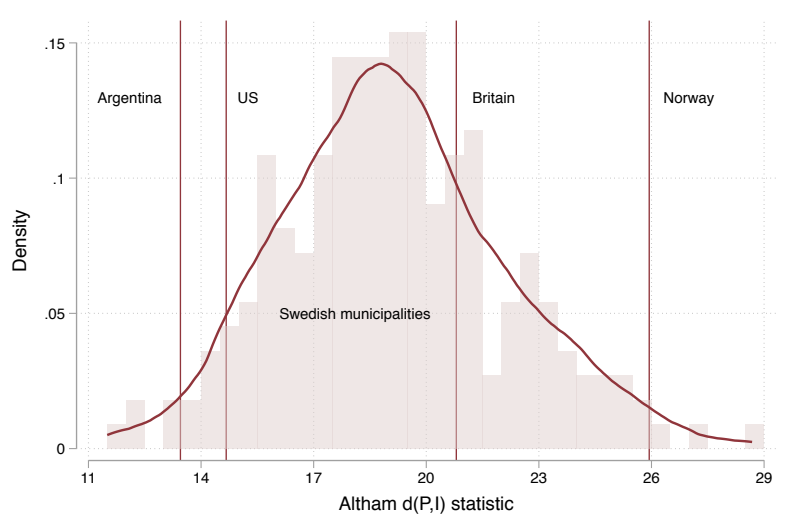

(B) RELATIVE (IM)MOBILITY

FIGURE 5:

GEOGRAPHIC DIFFERENCES IN ABSOLUTE AND RELATIVE (IM)MOBILITY

Notes: Panel A displays a kernel density distribution of absolute mobility rates across Swedish municipalities, while panel B presents a similar density plot of municipality-level Altham $d(\mathbf{P}, \mathbf{I})$ statistics. Also shown as vertical lines in both panels are the country-level absolute mobility rates and Altham statistics $d(\mathbf{P}, \mathbf{I})$ from Figure 1.

the difference in mobility between the most (Argentina) and least (Norway) mobile countries in our sample.

\subsubsection{Correlates of Mobility Across Municipalities}

We next examine the correlates of the mobility differences across Swedish municipalities. Although local determinants of mobility may differ from those that determine mobility at the national level, a local analysis is still likely to be informative about underlying drivers. To this end, we estimate a series of OLS regressions:

$$
y_{m}=\alpha+\sigma C_{m}+\mathbf{X}_{m} \boldsymbol{\beta}+\epsilon_{m}
$$

where $y_{m}$ is the absolute or relative mobility in municipality $m$, and $C_{m}$ corresponds to municipalitylevel proxies for the four explanations discussed above: growth and industrialization, fertility, human capital, and migration. Throughout the analysis, we control for a vector of municipality-level characteristics $\mathbf{X}_{m}$ measured in 1880: $\log$ population size, shares of the four occupational groups, and the share living in urban areas.

We use several proxies for growth and industrialization. First, we calculate changes in population and the share of the population that resides in urban areas from the 1880 and 1910 census. Second, we calculate the average income in each municipality in 1880 and changes between 1880- 


\begin{tabular}{|c|c|c|c|c|c|c|c|c|c|c|}
\hline \multirow{2}{*}{$\begin{array}{l}\text { Dependent variable: } \\
\text { Children allocated to municip. in: }\end{array}$} & \multicolumn{5}{|c|}{ Absolute mobility } & \multicolumn{5}{|c|}{ Altham $d(\mathbf{P}, \mathbf{I})$} \\
\hline & $\begin{array}{c}1880 \\
(1)\end{array}$ & $\begin{array}{c}1880 \\
(2)\end{array}$ & $\begin{array}{c}1880 \\
(3)\end{array}$ & $\begin{array}{c}1880 \\
(4)\end{array}$ & $\begin{array}{c}1910 \\
(5)\end{array}$ & $\begin{array}{c}1880 \\
(6)\end{array}$ & $\begin{array}{c}1880 \\
(7)\end{array}$ & $\begin{array}{c}1880 \\
(8)\end{array}$ & $\begin{array}{c}1880 \\
(9)\end{array}$ & $\begin{array}{c}1910 \\
(10)\end{array}$ \\
\hline \multirow[t]{2}{*}{$\Delta \ln$ Population, $1880-1910$} & 0.001 & & & 0.008 & $0.038^{* * *}$ & 0.143 & & & -0.509 & $-1.064^{*}$ \\
\hline & $(0.009)$ & & & $(0.008)$ & $(0.009)$ & $(0.419)$ & & & $(0.596)$ & $(0.541)$ \\
\hline \multirow[t]{2}{*}{$\Delta$ Urban share, $1880-1910$} & $0.004^{*}$ & & & -0.001 & -0.000 & -0.349 & & & -0.121 & -0.009 \\
\hline & $(0.002)$ & & & $(0.001)$ & $(0.002)$ & $(0.236)$ & & & $(0.226)$ & $(0.138)$ \\
\hline \multirow[t]{2}{*}{ ln Average income, 1880} & & -0.000 & & -0.001 & -0.000 & & 0.258 & & 0.232 & 0.304 \\
\hline & & $(0.009)$ & & $(0.005)$ & $(0.005)$ & & $(0.321)$ & & $(0.229)$ & $(0.264)$ \\
\hline \multirow[t]{2}{*}{$\Delta \ln$ Average income, $1880-1910$} & & $0.019^{*}$ & & 0.001 & 0.005 & & -0.480 & & -0.181 & 0.460 \\
\hline & & $(0.010)$ & & $(0.008)$ & $(0.008)$ & & $(0.423)$ & & $(0.436)$ & $(0.353)$ \\
\hline \multirow[t]{2}{*}{ Industrialization, 1880} & & & 0.002 & $0.032^{* * *}$ & $0.034^{* * *}$ & & & $1.415^{* *}$ & 0.471 & 0.784 \\
\hline & & & $(0.008)$ & $(0.007)$ & $(0.008)$ & & & $(0.533)$ & $(0.483)$ & $(0.493)$ \\
\hline \multirow[t]{2}{*}{$\Delta$ Industrialization, $1880-1910$} & & & $0.024^{* * *}$ & $0.029^{* * *}$ & $0.040^{* * *}$ & & & 0.219 & 0.252 & 0.174 \\
\hline & & & $(0.007)$ & $(0.005)$ & $(0.006)$ & & & $(0.287)$ & $(0.262)$ & $(0.266)$ \\
\hline \multirow[t]{2}{*}{ Child/woman ratio, 1880} & & & & -0.007 & $-0.013^{* *}$ & & & & 0.249 & 0.318 \\
\hline & & & & $(0.004)$ & $(0.005)$ & & & & $(0.349)$ & $(0.270)$ \\
\hline \multirow[t]{2}{*}{ Teachers/children, 1880} & & & & -0.002 & 0.003 & & & & 0.429 & 0.230 \\
\hline & & & & $(0.005)$ & $(0.005)$ & & & & $(0.281)$ & $(0.262)$ \\
\hline \multirow[t]{2}{*}{ Migrant share, $1880-1910$} & & & & $0.055^{* * *}$ & $0.026^{* * *}$ & & & & $-1.655^{* * *}$ & $-0.923^{* *}$ \\
\hline & & & & $(0.005)$ & $(0.007)$ & & & & $(0.469)$ & $(0.389)$ \\
\hline \multirow[t]{2}{*}{ Emigrant share, 1880-1910 } & & & & $-0.010^{* *}$ & 0.005 & & & & $0.646^{* *}$ & -0.247 \\
\hline & & & & $(0.005)$ & $(0.006)$ & & & & $(0.271)$ & $(0.291)$ \\
\hline Municipality controls & Yes & Yes & Yes & Yes & Yes & Yes & Yes & Yes & Yes & Yes \\
\hline Observations & 282 & 282 & 282 & 282 & 282 & 282 & 282 & 282 & 282 & 282 \\
\hline R-squared & 0.15 & 0.17 & 0.25 & 0.53 & 0.70 & 0.09 & 0.08 & 0.13 & 0.24 & 0.27 \\
\hline Mean dep. var. & 0.53 & 0.53 & 0.53 & 0.53 & 0.52 & 19.00 & 19.00 & 19.00 & 19.00 & 18.63 \\
\hline
\end{tabular}

TAble 2: Absolute And Relative (Im)Mobility aCross Municipalities, 1880-1910

Notes: Municipality-level OLS regressions. When estimating absolute and relative mobility rates, we allocate sons to the municipality where they resided in childhood (i.e., in 1880) except in columns 5 and 10 where children are allocated to their municipality of residence in adulthood (i.e., in 1910). All right-hand-side variables are standardized to have mean 0 and and a SD of 1 . Municipality controls include the $\ln$ of population, occupational shares (whitecollar, farmers, skilled/semi-skilled, and unskilled), and the share living in urban areas, all measured in 1880. Robust standard errors clustered at the county level are given in parentheses. ${ }^{* * *} p<0.01,{ }^{* *} p<0.05,{ }^{*} p<0.1$.

1910 among all adult employed men. ${ }^{43}$ Third, we create similar measures of industrialization based on the share of adult males employed in manufacturing from the 1880 and 1910 population census. To measure local differences in fertility and the provision of (primary) schooling, we rely on the 1880 census to calculate the average number of children per woman (aged 20-45), and the ratio of the number of school teachers and the number of school-age children in each municipality. Rates of internal migration and emigration between 1880-1910 are based on our linked sample of sons.

Table 2 reports OLS estimates of equation (1). ${ }^{44}$ To facilitate interpretation, we standardize

\footnotetext{
${ }^{43}$ We base our income measures on data from individual-level tax registers for 1900 collected by Bengtsson et al. (2021). As described in Berger et al. (2021), we use these data to create occupational income scores corresponding the median income for each individual in the 1880 and 1910 census based on 1-digit HISCO codes and county of residence.

${ }^{44}$ We display binned scatterplots of absolute and relative mobility and each of the main covariates respectively in
} 
all independent variables to have a mean 0 and a standard deviation (SD) of 1 . Throughout, all regressions are weighted by the municipality populations in 1880 and standard errors are clustered at the county level to allow for spatial correlation across municipalities.

We first consider the role of local growth and industrialization in accounting for local mobility patterns. Columns 1 and 6 in Table 2 show that changes in population and urbanization are at best weakly correlated with absolute and relative mobility across municipalities. Similarly, the link between income growth and absolute and relative mobility is weak (columns 2 and 7). In contrast, column 3 documents an association between industrialization (i.e., changes in the share employed in manufacturing) and absolute mobility, though not with relative mobility (column 8). ${ }^{45}$ However, the association is relatively small in magnitude: a 1 SD increase in industrialization is associated with a 2.4 percentage point increase in absolute mobility. Similarly, fertility differences or the local provision of human capital are not correlated with either absolute or relative mobility (columns 4 and 9). While these proxies may not fully capture the many ways that fertility and human capital could shape mobility patterns, the lack of a clear link is consistent with the ambiguous pattern across countries.

A potential explanation for the relatively weak link between local economic development and mobility patterns is that we allocate sons to their municipality of residence in childhood (i.e., 1880). Thus, we are effectively asking whether sons that grew up in more rapidly expanding areas experienced higher mobility rates, irrespective of whether they remain in that location as adults as in work that emphasizes the role of childhood environments in shaping mobility outcomes (Chetty et al., 2014). However, recent evidence suggests that childhood environments may have been less relevant a century ago, while the local labour market one resides in mattered more (Tan, 2020). Indeed, Table 2, column 5, shows stronger associations between absolute mobility and growth in population and the share employed in manufacturing when instead allocating sons to their municipality of residence as adults in $1910 .{ }^{46}$ These estimates suggest a relatively larger role of local labour markets, which in turn hints that migration may have been an important lever to take advantage of opportunities in other parts of the country.

Migration flows are indeed highly correlated with both absolute and relative mobility levels across municipalities. Table 2 shows that the fraction who migrates out of a municipality is robustly

Appendix Figure D.12 and D.13. Maps depicting the spatial variation is provided in Appendix Figure D.14.

${ }^{45}$ As discussed above, there exists no unambiguous ranking of occupational groups. However, if one is willing to assume that sons to unskilled workers experience "upward" mobility by transitioning out of their fathers' occupational group, one can consider differences in upward mobility across municipalities. In Appendix Table E.13, we report such estimates where the outcome is the share of son to unskilled fathers that transition into a different occupation in adulthood. Upward mobility rates are higher in industrial areas characterized by more rapid industrialization and migration, consistent with the correlations using absolute mobility as the outcome.

${ }^{46}$ Appendix Figure D. 15 contrasts the variation in absolute and relative mobility across municipalities when allocating sons to their municipality of residence in childhood and adulthood respectively. 


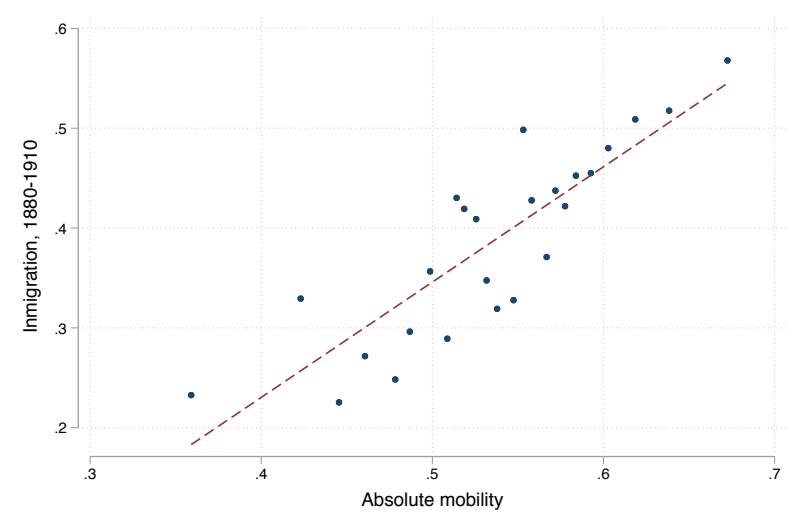

(A) Absolute mobility in DEStination

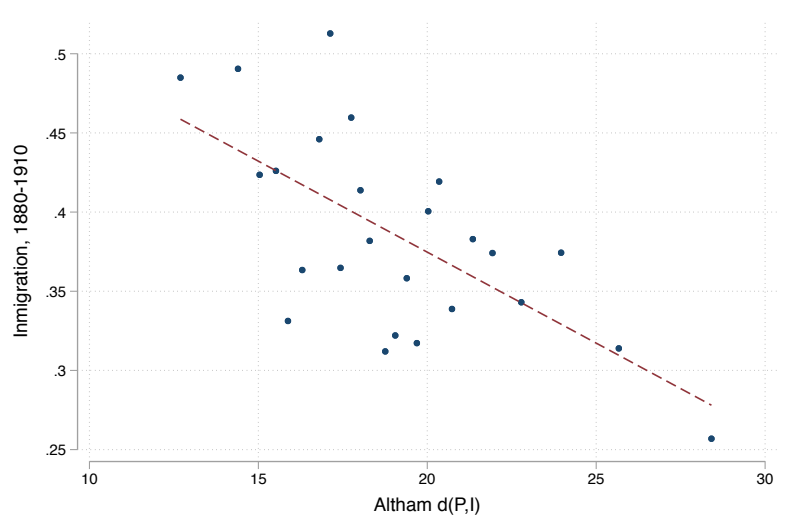

(B) RELATIVE (IM)MOBILITY IN DESTINATION

FIGURE 6:

MigRANTS MOVED TO MORE MOBILE PLACES

Notes: These figures display the share of inmigrants to a municipality between 1880-1910 and the level of absolute and relative mobility. We define inmigration as the share of sons in a municipality in 1910 that did not reside in that municipality in childhood. When estimating mobility rates, we allocate children to their municipality of residence in childhood (i.e., in 1880). To construct each figure, we group all municipalities into 25 equal-sized bins based on their level of absolute or relative mobility where dots denote the mean migrant inflow in each bin. Also shown is a best-fit line estimated from the underlying (ungrouped) data.

associated with both absolute and relative mobility (columns 4 and 8). ${ }^{47}$ Moreover, the association between internal migration and absolute mobility is relatively large: a 1 SD increase in the share of the population that migrates predicts a 5.5 percentage point increase in absolute mobility, or a 1.7 point decline in the Altham $d(\mathbf{P}, \mathbf{I})$ statistic; both corresponding to about one tenth of the sample mean. In contrast to internal migration, higher emigration rates are associated with lower levels of absolute mobility and higher levels of intergenerational persistence (columns 4 and 8), which suggests that emigrants mainly left stagnating places.

\subsection{Migration, Growth, and Occupational Mobility}

Internal migration flows could have enhanced mobility prospects if migrants "moved to opportunity", in the sense that they left less more mobile places for those that provided more opportunities. In Figure 6, we show that the inflow of migrants was indeed much higher in areas characterized by higher levels of absolute and relative mobility. ${ }^{48}$ A similar pattern emerges when one instead con-

\footnotetext{
${ }^{47}$ One concern is that this association is mechanically driven by the fact that we estimate both migration and mobility rates based on the same (linked) sample. Yet we find similar correlations when we instead focus on migrant stocks calculated as the fraction of the local population in a municipality (in either 1880 or 1910) that was born in another municipality (see Appendix Table E.14).

${ }^{48}$ Note that the absolute and relative mobility levels of a municipality are here defined based on mobility outcomes for children residing in that municipality in 1880, while the share of inmigrants is calculated as the share of sons that
} 
siders the rate of income growth or industrialization in migrants' destinations (Appendix Figure D.16), which underscores that migrants sought out more dynamic locations. Yet, while migration flows were directed at more mobile and rapidly developing areas, it is an open question whether migrants also experienced higher rates of occupational mobility.

To bolster the evidence of a link between migration and occupational mobility, we leverage our linked father-son data. We estimate OLS regressions of the following form:

$$
y_{i}=\alpha+\delta M_{i}+\mathbf{X}_{i} \boldsymbol{\beta}+\gamma_{h}+\epsilon_{i}
$$

where $y$ is an indicator taking the value 1 if an individual $i$ experienced absolute mobility (i.e., is observed in a different occupation than his father). $M$ is an indicator capturing whether an individual is observed in a different municipality in adulthood (in 1910) compared to their municipality of residence in childhood (in 1880). In the baseline regressions, we control for a set of household characteristics $(\mathrm{X})$ : the age of fathers and sons, the fathers occupation in 1880, and a set of 1880 county fixed effects. Estimates of $\delta$, however, may partly be driven by selection into migration of more (or less) mobile individuals. To address selection issues, we add a set of household fixed effects $\left(\gamma_{h}\right)$ and identify the returns to migration by comparing migrant-brothers to those that stayed behind. By comparing (non-)migrant brothers, we effectively eliminate all selection due to factors that vary across households, only leaving the potential that migrants may have been selected within households.

Table 3 documents a strong positive link between geographic and occupational mobility. Column 1 shows that individuals that moved between municipalities between 1880-1910 were 17 percentage points more likely to transition into a different occupation than their father. In column 2 , we restrict the identifying variation to within-household comparisons of the 118,000 sons where we observe at least two brothers. Migrant brothers were 15 percentage points more likely to change occupation compared to their brother(s) that stayed behind. Migration was thus an important avenue for occupational mobility, though we cannot completely rule out that sons that move were inherently more mobile than those who stayed behind. ${ }^{49}$

The association between migration and mobility may however conceal variation across occupational groups and migration from different origins. Table 3, columns 3-6 reports estimates by father's occupations. The positive association between migration and absolute mobility is mainly driven by sons to farmers and unskilled workers, while migrant sons to white-collar and skilled/semi-skilled fathers were less likely to transition into a different occupation.

had moved to a particular municipality in 1910. The mobility outcomes of inmigrants does therefore not mechanically raise mobility rates in the destination municipality.

${ }^{49}$ Appendix Table E. 15 shows that results are similar if instead focusing on brothers that move across larger (counties) or smaller (parishes) geographical units. 


\begin{tabular}{|c|c|c|c|c|c|c|c|c|c|c|}
\hline \multirow[t]{3}{*}{ Dependent variable: } & \multicolumn{10}{|c|}{ Absolute mobility $(=1)$} \\
\hline & \multirow[b]{2}{*}{ (1) } & \multirow[b]{2}{*}{ (2) } & \multicolumn{4}{|c|}{ By father's occupational group } & \multicolumn{2}{|c|}{ By origin } & \multicolumn{2}{|c|}{ By mobility in origin } \\
\hline & & & $\begin{array}{l}\text { White-collar } \\
\text { (3) }\end{array}$ & $\begin{array}{l}\text { Farmer } \\
\text { (4) }\end{array}$ & $\begin{array}{l}\text { Skilled } \\
\text { (5) }\end{array}$ & $\begin{array}{l}\text { Unskilled } \\
\text { (6) }\end{array}$ & $\begin{array}{l}\text { Rural (R) } \\
\text { (7) }\end{array}$ & $\begin{array}{c}\text { Urban }(\mathrm{U}) \\
(8)\end{array}$ & $\begin{array}{l}\text { High } \\
(9)\end{array}$ & $\begin{array}{l}\text { Low } \\
(10)\end{array}$ \\
\hline Migrant (=1) & $\begin{array}{c}0.169^{* * *} \\
(0.002)\end{array}$ & $\begin{array}{c}0.150^{* * *} \\
(0.006)\end{array}$ & $\begin{array}{c}-0.068^{* * *} \\
(0.019)\end{array}$ & $\begin{array}{c}0.295^{* * *} \\
(0.008)\end{array}$ & $\begin{array}{c}-0.034^{* *} \\
(0.014)\end{array}$ & $\begin{array}{c}0.073^{* * *} \\
(0.012)\end{array}$ & & & $\begin{array}{c}0.128^{* * *} \\
(0.008)\end{array}$ & $\begin{array}{c}0.175^{* * *} \\
(0.009)\end{array}$ \\
\hline R-to-R migrant (=1) & & & & & & & $\begin{array}{c}0.140^{* * *} \\
(0.007)\end{array}$ & & & \\
\hline R-to-U migrant $(=1)$ & & & & & & & $\begin{array}{c}0.218^{* * *} \\
(0.009)\end{array}$ & & & \\
\hline U-to-U migrant $(=1)$ & & & & & & & & $\begin{array}{c}0.021 \\
(0.021)\end{array}$ & & \\
\hline U-to-R migrant $(=1)$ & & & & & & & & $\begin{array}{l}0.040^{*} \\
(0.021)\end{array}$ & & \\
\hline Son's age & Yes & Yes & Yes & Yes & Yes & Yes & Yes & Yes & Yes & Yes \\
\hline Father's age & Yes & No & No & No & No & No & No & No & No & No \\
\hline Father's 1880 occ. & Yes & No & No & No & No & No & No & No & No & No \\
\hline 1880 county FE & Yes & No & No & No & No & No & No & No & No & No \\
\hline Household FE & No & Yes & Yes & Yes & Yes & Yes & Yes & Yes & Yes & Yes \\
\hline Observations & 240941 & 118019 & 9864 & 57917 & 21649 & 28589 & 106563 & 11456 & 60034 & 57985 \\
\hline R-squared & 0.05 & 0.60 & 0.67 & 0.63 & 0.56 & 0.56 & 0.60 & 0.63 & 0.59 & 0.61 \\
\hline Mean dep. var. & 0.535 & 0.542 & 0.426 & 0.557 & 0.457 & 0.616 & 0.549 & 0.481 & 0.584 & 0.499 \\
\hline
\end{tabular}

TABLE 3: GEOGRAPHIC AND OCCUPATIONAL MOBILITY, 1880-1910: INDIVIDUAL-LEVEL ESTIMATES

Notes: Individual-level OLS regressions. Migrant is an indicator taking the value 1 if an individual is observed in a different municipality in 1910 compared to 1880. The other migration indicators take the value 1 if an individual moved between municipalities from, for example, a rural to (non-)urban municipality. Sample restricted to households with at least two (linked) sons in columns $2-10$. Robust standard errors clustered at the 1880 household level are given in parentheses. ${ }^{* * *} p<0.01,{ }^{* *} p<0.05,{ }^{*} p<0.1$.

Migrants were more likely to improve on their brothers' mobility outcomes when leaving rural places, or those characterized by lower rates of growth and mobility. Table 3, columns 7 and 8 show that there is at best a weak link between migration among sons born in urban areas and mobility, while there is a large and positive association among those born in rural areas, particularly among those moving from the countryside to a city. In the final two columns of Table 3, we differentiate between migrant brothers moving from less and more mobile places. Migrants that moved away from from less mobile origins were 18 percentage points more likely to transition into a different occupation than that held by their father, compared to 13 percentage points among those migrating from high-mobility areas. ${ }^{50}$ Notably, a similar pattern is evident when comparing the association between mobility and migration in municipalities experiencing faster and slower growth in terms of population, income, or employment in manufacturing (Appendix Table E.16).

In sum, the high mobility rates that we observe in Sweden are more pronounced in areas undergoing rapid economic development. But the link from growth to mobility seems to be mediated

\footnotetext{
${ }^{50}$ Here we split the sample based on whether the absolute mobility level in a municipality falls below or above that observed in the median municipality. Also note that the level of absolute mobility is lower in less mobile municipalities, which means that estimated differences in absolute mobility among migrants is even more pronounced relative to the level of mobility observed in these origins.
} 
through migration. In response to uneven patterns of growth and industrialization, migrants flowed from less to more dynamic places. Migration was an important lever to achieve mobility, particularly for children to farmers and unskilled workers that moved away from less dynamic rural regions to the city. While the factors that shape local differences in mobility may differ from those that determine national mobility patterns, the fact that these geographic differences are broadly consistent with cross-country patterns described above offers suggestive evidence of the historical drivers underlying intergenerational mobility variation.

\section{Conclusions}

A widely held belief, going back to contemporary observers such as Tocqueville and Marx, is that the 19th-century United States enjoyed exceptionally high rates of social mobility. Recent advances in data and methods have allowed testing this conjecture with samples from the US, Britain, Argentina, and Norway (Long \& Ferrie, 2013a; Modalsli, 2017; Pérez, 2019). This research appears to confirm that the New and Old World had distinctively different mobility regimes. At the same time, both Britain and Norway are peculiar cases, one the world's earliest industralizer and the other an agrarian economy well into the 20th century.

In this paper we have provided the first historically representative estimates of intergenerational occupational mobility for one of Europe's most rapidly growing economies: Sweden. Using a dataset containing more than 200,000 father-son pairs we have studied the mobility of sons born in the late-19th century who reached adulthood in the early 20th century. In contrast to its European neighbours, we find that both absolute and relative mobility was high in Sweden at this time. In other words, Sweden had high levels of social mobility already before the outbreak of World War I, and several decades prior to the emergence of the modern welfare state.

One implication of these findings is that the factors that explain mobility today are likely to differ from those that did so historically. Indeed, the presence of significant mobility differences in a period characterized by limited cross-country variation in economic equality and redistribution suggests that the link between inequality and intergenerational mobility observed across countries today materialized more recently (Corak, 2013). In particular, the fact that historical levels of mobility in Sweden were so different from those observed in late-20th century Norway-another paradigmatic Scandinavian welfare state_-suggests that forces beyond income equality or generous welfare-state provisions are important in explaining variation in mobility.

What are the historical determinants of intergenerational mobility? We provide evidence of two factors that can explain cross-country differences: Sweden's high levels of mobility are arguably attributable to its exceptionally rapid economic growth and high rates of geographic mobility around the turn of the 20 th century. At the time, Sweden was among the most rapidly growing economies 
in Western Europe with rates of internal migration on par with those observed in the Americas. We corroborate this observation by showing that the same factors that can account for cross-country variation also appear important in explaining the considerable differences in mobility that existed within historical Sweden.

Our reading of this evidence suggests that there was nothing "exceptional" about American mobility in the 19th century: its generally higher mobility rates arguably reflected prevailing economic conditions at the time, rather than deep-seated cultural differences as has been assumed by contemporary and later observers. Other countries are likely to have experienced an increased rate of occupational mobility when regional disparities narrowed, industrialization took off, and the population became more geographically mobile. In fact, we know that this is something that did happen in Norway albeit several decades later (Modalsli, 2017).

These findings raise doubts about a common interpretation of historical mobility differences as a source of different welfare state arrangements today (Piketty, 1995; Long \& Ferrie, 2013a). According to this interpretation, one reason that the US ended up with a more restrictive welfare state is that to the people who designed it, the US was correctly seen as a land of opportunity. Steinbeck (2002, p. 27) is known to have quipped that the US socialist movement's failure was that "we didn't have any self-admitted proletarians ... [e]veryone was a temporarily embarrassed capitalist." The fact that Sweden, despite its high initial levels of mobility, eventually saw the rise of a strong welfare state should lead to skepticism about this hypothesis.

It is important to stress that we study differences in occupational mobility, which may take on a different interpretation with time. While we find that mobility in Sweden around 1900 was higher than that later in the century, it is unclear how much of this mobility actually enhanced welfare for those who experienced it. Changes in occupational structure between 1900 and 1970 make it difficult to make such a comparison. Indeed, we find that the structure of mobility in Sweden in 1900 is closer to that in the US at the same time than it is to mobility in modern-day Sweden. An important avenue for future research should therefore be to complement this work with data on the income or relative rank of occupations, extending present-day estimates of rank mobility back into historical time. 


\section{References}

Abramitzky, R., Boustan, L., Jácome, E., \& Pérez, S. (2021). Intergenerational mobility of immigrants in the united states over two centuries. American Economic Review, 111(2), 580-608.

Abramitzky, R., Boustan, L. P., \& Eriksson, K. (2012). Europe's tired, poor, huddled masses: Selfselection and economic outcomes in the age of mass migration. American Economic Review, 102(5), 1832-56.

Abramitzky, R., Boustan, L. P., Eriksson, K., Feigenbaum, J. J., \& Pérez, S. (2019). Automated linking of historical data. NBER Working Paper No. 25825.

Alesina, A., Hohmann, S., Michalopoulos, S., \& Papaioannou, E. (2019). Intergenerational mobility in Africa. NBER Working Paper No. 25534.

Altham, P. M. (1970). The measurement of association of rows and columns for an $\mathrm{r} \times \mathrm{s}$ contingency table. Journal of the Royal Statistical Society: Series B (Methodological), 32(1), 63-73.

Altham, P. M. \& Ferrie, J. P. (2007). Comparing contingency tables tools for analyzing data from two groups cross-classified by two characteristics. Historical Methods, 40(1), 3-16.

Asher, S., Novosad, P., \& Rafkin, C. (2020). Intergenerational mobility in India: New methods and estimates across time, space, and communities. Mimeo.

Bäcklund, D. (1988). I industrisamhällets utkant: småbrukets omvandling i Lappmarken 18701970. $\mathrm{PhD}$ thesis, Umeå universitet.

Bailey, M., Cole, C., Henderson, M., \& Massey, C. (2017). How well do automated linking methods perform?: Lessons from US historical data. NBER Working Paper No. 24019.

Becker, G. S. \& Tomes, N. (1986). Human capital and the rise and fall of families. Journal of Labor Economics, 4(3, Part 2), S1-S39.

Bengtsson, E., Molinder, J., \& Prado, S. (2021). The Swedish transition to equality: income inequality with new micro data, 1870-1970. Machine-readable data file, Lund University.

Berger, T. \& Enflo, K. (2017). Locomotives of local growth: The short-and long-term impact of railroads in Sweden. Journal of Urban Economics, 98, 124-138.

Berger, T. \& Engzell, P. (2019). American geography of opportunity reveals european origins. Proceedings of the National Academy of Sciences, 116(13), 6045-6050. 
Berger, T., Engzell, P., Eriksson, B., \& Molinder, J. (2021). Income scores for Swedish census data. Mimeo.

Bielby, W. T., Hauser, R. M., \& Featherman, D. L. (1977). Response errors of nonblack males in models of the stratification process. Journal of the American Statistical Association, 72(360a), $723-735$.

Björklund, A. \& Jäntti, M. (2000). Intergenerational mobility of socio-economic status in comparative perspective. Nordic Journal of Political Economy, 26, 3-32.

Björklund, A. \& Jäntti, M. (2009). Intergenerational income mobility and the role of family background. Oxford Handbook of Economic Inequality, 491, 521.

Blanden, J. (2013). Cross-country rankings in intergenerational mobility: A comparison of approaches from economics and sociology. Journal of Economic Surveys, 27(1), 38-73.

Bolt, J., Inklaar, R., de Jong, H., \& Van Zanden, J. L. (2018). Rebasing 'Maddison’: new income comparisons and the shape of long-run economic development. GGDC Research Memorandum 174.

Bouchet-Valat, M. (2019). General marginal-free association indices for contingency tables: From the Altham index to the intrinsic association coefficient. Sociological Methods \& Research, 0049124119852389.

Breen, R. \& Jonsson, J. O. (1997). How reliable are studies of social mobility: an investigation into the consequences of errors in measuring social class. Research in Social Stratification and Mobility, 15, 91-114.

Breen, R. \& Jonsson, J. O. (2005). Inequality of opportunity in comparative perspective: Recent research on educational attainment and social mobility. Annual Review of Sociology, 31, 223243.

Breen, R. \& Jonsson, J. O. (2007). Explaining change in social fluidity: Educational equalization and educational expansion in twentieth-century Sweden. American Journal of Sociology, 112(6), $1775-1810$.

Breen, R. \& Jonsson, J. O. (2020). Sweden, the middle way?: Trends and patterns in social mobility and educational inequality. In R. Breen \& W. Müller (Eds.), Education and Intergenerational Social Mobility in Europe and the United States. Stanford University Press. 
Chetty, R., Hendren, N., Kline, P., \& Saez, E. (2014). Where is the land of opportunity?: The geography of intergenerational mobility in the United States. Quarterly Journal of Economics, 129(4), 1553-1623.

Chetty, R., Hendren, N., Kline, P., Saez, E., \& Turner, N. (2014). Is the United States still a land of opportunity? recent trends in intergenerational mobility. American Economic Review, 104(5), 141-47.

Clark, G. (2015). The son also rises: Surnames and the history of social mobility. Princeton University Press.

Collin, K., Lundh, C., \& Prado, S. (2019). Exploring regional wage dispersion in swedish manufacturing, 1860-2009. Scandinavian Economic History Review, 67(3), 249-268.

Connor, D. S. \& Storper, M. (2020). The changing geography of social mobility in the united states. Proceedings of the National Academy of Sciences, 117(48), 30309-30317.

Corak, M. (2013). Income inequality, equality of opportunity, and intergenerational mobility. Journal of Economic Perspectives, 27(3), 79-102.

Deming, W. E. \& Stephan, F. F. (1940). On a least squares adjustment of a sampled frequency table when the expected marginal totals are known. Annals of Mathematical Statistics, 11(4), $427-444$.

Dribe, M., Eriksson, B., \& Scalone, F. (2019). Migration, marriage and social mobility: Women in Sweden 1880-1900. Explorations in Economic History, 71, 93-111.

Dribe, M., Helgertz, J., \& Van de Putte, B. (2015). Did social mobility increase during the industrialization process?: A micro-level study of a transforming community in southern Sweden 1828-1968. Research in Social Stratification and Mobility, 41, 25-39.

Dribe, M., Oris, M., \& Pozzi, L. (2014). Socioeconomic status and fertility before, during, and after the demographic transition: An introduction. Demographic Research, 31, 161-182.

Enflo, K., Lundh, C., \& Prado, S. (2014). The role of migration in regional wage convergence: Evidence from Sweden 1860-1940. Explorations in Economic History, 52, 93-110.

Enflo, K. \& Rosés, J. R. (2015). Coping with regional inequality in Sweden: Structural change, migrations, and policy, 1860-2000. Economic History Review, 68(1), 191-217. 
Ericsson, J. \& Molinder, J. (Forthcoming, 2020). Economic growth and the development of real wages: Swedish construction workers' wages in comparative perspective, 1831-1900. Journal of Economic History.

Erikson, R. \& Goldthorpe, J. H. (1992). The constant flux: A study of class mobility in industrial societies. Oxford University Press.

Federation of Swedish Genealogical Societies (2018). Swedish Death Index 7.

Feigenbaum, J. J. (2016). Automated census record linking: A machine learning approach. Manuscript.

Feigenbaum, J. J. (2018). Multiple measures of historical intergenerational mobility: Iowa 1915 to 1940. Economic Journal, 128(612), F446-F481.

Ferrie, J. (1996). A new sample of males linked from the public use microdata sample of the 1850 US federal census of population to the 1860 US federal census manuscript schedules. Historical Methods, 29(4), 141-156.

Galor, O. (2012). The demographic transition: Causes and consequences. Cliometrica, 6(1), 1-28.

Goodman, L. A. (1996). A single general method for the analysis of cross-classified data: Reconciliation and synthesis of some methods of Pearson, Yule, and Fisher, and also some methods of correspondence analysis and association analysis. Journal of the American Statistical Association, 91(433), 408-428.

Güell, M., Pellizzari, M., Pica, G., \& Rodríguez Mora, J. V. (2018). Correlating social mobility and economic outcomes. Economic Journal, 128(612), F353-F403.

IPUMS (2019). Integrated public use microdata series, international: Version 7.2; Minnesota Population Center. https://doi.org/10.18128/D020.V7.2.

Jonsson, J. O. \& Mills, C. (1993). Social mobility in the 1970s and 1980s: A study of men and women in england and Sweden. European Sociological Review, 9(3), 229-248.

Lindahl, M., Palme, M., Massih, S. S., \& Sjögren, A. (2015). Long-term intergenerational persistence of human capital: An empirical analysis of four generations. Journal of Human Resources, $50(1), 1-33$.

Lindert, P. H. (2004). Growing public: Volume 1, the story: Social spending and economic growth since the eighteenth century, volume 1. Cambridge University Press. 
Lipset, S. M. \& Bendix, R. (1959). Social mobility in industrial society. University of California Press.

Ljungberg, J. \& Schön, L. (2013). Domestic markets and international integration: paths to industrialisation in the nordic countries. Scandinavian Economic History Review, 61(2), 101-121.

Long, J. (2005). Rural-urban migration and socioeconomic mobility in victorian britain. The Journal of Economic History, 65(1), 1-35.

Long, J. (2013). The surprising social mobility of Victorian Britain. European Review of Economic History, 17(1), 1-23.

Long, J. \& Ferrie, J. (2007). The path to convergence: Intergenerational occupational mobility in Britain and the US in three eras. Economic Journal, 117(519), C61-C71.

Long, J. \& Ferrie, J. (2013a). Intergenerational occupational mobility in Great Britain and the United States since 1850. American Economic Review, 103(4), 1109-37.

Long, J. \& Ferrie, J. (2013b). Intergenerational occupational mobility in Great Britain and the United States since 1850: Reply. American Economic Review, 103(5), 2041-49.

Maas, I. \& Van Leeuwen, M. H. (2002). Industrialization and intergenerational mobility in Sweden. Acta Sociologica, 45(3), 179-194.

Marx, K. (1852). The Eighteenth Brumaire of Louis Bonaparte.

Modalsli, J. (2017). Intergenerational mobility in Norway, 1865-2011. Scandinavian Journal of Economics, 119(1), 34-71.

Myrdal, J. \& Morell, M. (2011). The agrarian history of Sweden: 4000 BC to AD 2000. Nordic Academic Press.

Nybom, M. \& Stuhler, J. (2014). Interpreting trends in intergenerational mobility. Swedish Institute for Social Research (SOFI) Working Paper 3/2014.

Olivetti, C. \& Paserman, M. D. (2015). In the name of the son (and the daughter): Intergenerational mobility in the United States, 1850-1940. American Economic Review, 105(8), 2695-2724.

Parman, J. (2011). American mobility and the expansion of public education. Journal of Economic History, 71(1), 105-132.

Pérez, S. (2019). Intergenerational occupational mobility across three continents. The Journal of Economic History, 79(2), 383-416. 
Piketty, T. (1995). Social mobility and redistributive politics. Quarterly Journal of Economics, $110(3), 551-584$.

Piketty, T. (2014). Capital in the 21st Century. Harvard University Press.

Prado, S., Lundh, C., Collin, K., \& Enflo, K. (2021). Labour and the 'law of one price': regional wage convergence of farm workers in sweden, 1757-1980. Scandinavian Economic History Review, 69(1), 41-62.

Roine, J. \& Waldenström, D. (2008). The evolution of top incomes in an egalitarian society: Sweden, 1903-2004. Journal of Public Economics, 92(1-2), 366-387.

Sandberg, L. G. (1979). The case of the impoverished sophisticate: Human capital and Swedish economic growth before World War I. Journal of Economic History, 39(1), 225-241.

Söderberg, J. (1985). Regional economic disparity and dynamics, 1840-1914: a comparison between france, great britain, prussia and sweden. Journal of European Economic History, 14(2), 273.

Solon, G. (2004). A model of intergenerational mobility variation over time and place. Generational income mobility in North America and Europe, 2, 38-47.

Solon, G. (2018). What do we know so far about multigenerational mobility? Economic Journal, $128(612), \mathrm{F} 340-\mathrm{F} 352$.

Song, X., Massey, C. G., Rolf, K. A., Ferrie, J. P., Rothbaum, J. L., \& Xie, Y. (2019). Long-term decline in intergenerational mobility in the United States since the 1850s. Proceedings of the National Academy of Sciences.

Steinbeck, J. (2002). Of Men and Their Making: The Selected Non-fiction of John Steinbeck. Allen Lane.

Swedish Emigrant Institute and Federation of Swedish Genealogical Societies (2005). EMIBAS.

Swedish National Archives (2014). National sample of the 1880 census of Sweden, version 2.0; Swedish National Archives, Umeå University, and Minnesota Population Center. Minneapolis: Minnesota Population Center [distributor].

Swedish National Archives (2016). National sample of the 1910 census of Sweden, version 1.0; Swedish National Archives and Minnesota Population Center. Minneapolis: Minnesota Population Center [distributor]. 
Tan, H. R. (2020). A different land of opportunity: The geography of intergenerational mobility in the early 20th-century US. Mimeo.

Tocqueville, A. d. (1835). Democracy in America.

Torche, F. \& Corvalan, A. (2018). Estimating intergenerational mobility with grouped data: A critique of clark's the son also rises. Sociological Methods \& Research, 47(4), 787-811.

Van Leeuwen, M. H. \& Maas, I. (2011). HISCLASS: A historical international social class scheme. Leuven: Leuven University Press.

Van Leeuwen, M. H., Maas, I., \& Miles, A. (2002). HISCO: Historical international standard classification of occupations. Leuven Univ Pr.

Vogel, J., Andersson, L.-G., Davidsson, U., \& Häll, L. (1988). Inequality in Sweden: Trends and current situation. Stockholm: Statistics Sweden.

Ward, Z. (2020a). Intergenerational mobility in American history: Accounting for race and measurement error. Mimeo.

Ward, Z. (2020b). Internal migration, education, and intergenerational mobility: Evidence from american history. Journal of Human Resources, 0619-10265R2.

Ward, Z. (2021). Internal migration, education, and intergenerational mobility: Evidence from american history. Journal of Human Resources.

Winkler, W. E. (1990). String comparator metrics and enhanced decision rules in the Fellegi-Sunter model of record linkage. Proceedings of the Section on Survey Research Methods, 354-359.

Xie, Y. (1992). The log-multiplicative layer effect model for comparing mobility tables. American Sociological Review, 380-395.

Xie, Y. \& Killewald, A. (2013). Intergenerational occupational mobility in Great Britain and the United States since 1850: Comment. American Economic Review, 103(5), 2003-20.

Young, A. (2013). Inequality, the urban-rural gap, and migration. Quarterly Journal of Economics, 128(4), 1727-1785.

Zhou, X. (2015). Shrinkage estimation of log-odds ratios for comparing mobility tables. Sociological Methodology, 45(1), 320-356. 
Appendix for: Social Mobility in Sweden Before the Welfare State 


\section{A Linking Procedure}

In this section, we provide a more detailed description of the procedure used to link individuals between the 1880 and 1910 censuses. In the 1880 census, we observe children residing in their childhood households. We identify their fathers (occupation) through co-residence in the same household and/or relationship pointers in cases where a child's father resides in a different household. The 1880 census sample is restricted to male children aged 16 or below, which results in a baseline sample of 849,996 boys. We then want to link these individuals forward to the 1910 census where we can observe their occupational attainment when they are in their 30s and 40s.

To link individuals from the 1880 to the 1910 census, we first designate a set of index variables that have to match exactly for two records to be considered potential matches: sex, birth year and parish of birth. ${ }^{51}$ We find a potential match with identical sex, birth year, and parish of birth in the 1910 census for 848,949 individuals out of the 849,996 boys in our baseline sample from the 1880 census.

The next, and most critical, step in the linking process involves separating true links from false among all these potential matches. To identify which of these potential matches is the same individual, we rely on first and last names as recorded in the censuses. However, names are in some cases recorded with a certain degree of imprecision in the digitized censuses, due to transcription errors or differences in spelling. We thus need to allow for the fact that the name of the same individual may not be identical in the 1880 and 1910 census. To reduce the influence of minor differences in spelling or transcription errors, we first standardize names by removing nobility prefixes, patronymic suffixes and all non-alphabetic characters. To allow for the fact that even standardized names may differ between censuses for the same individual, we then use the JaroWinkler (JW) algorithm (Winkler, 1990) to estimate the similarity of first and last names recorded for potential matches. The JW algorithm assigns a similarity score between 0 (no similarity) and 1 (identical) by comparing characters and transpositions in text strings. ${ }^{52}$

When choosing a threshold for the JW similarity score there exists a tradeoff between the resulting sample size and the quality of matches. By prioritizing a high number of matches by lowering the required similarity between names, the risk of introducing false positives increase. This, in turn, might create a false impression of high social mobility (Bailey et al., 2017). A low match rate due to a overly restrictive similarity threshold, on the other hand, reduces the number of false positives but results in a smaller sample that might be an unrepresentative subset of the full

\footnotetext{
${ }^{51}$ In appendix Table E.7 we summarize the characteristics and variables used for linking in comparable samples. Although the precision by which variables are recorded differ, the basic approach is similar across the samples in terms of indexation and comparisons of names.

${ }^{52}$ The JW algorithm adjusts for when strings have the same initial characters and accounts for the fact that irregularities are more common in longer strings than in shorter.
} 


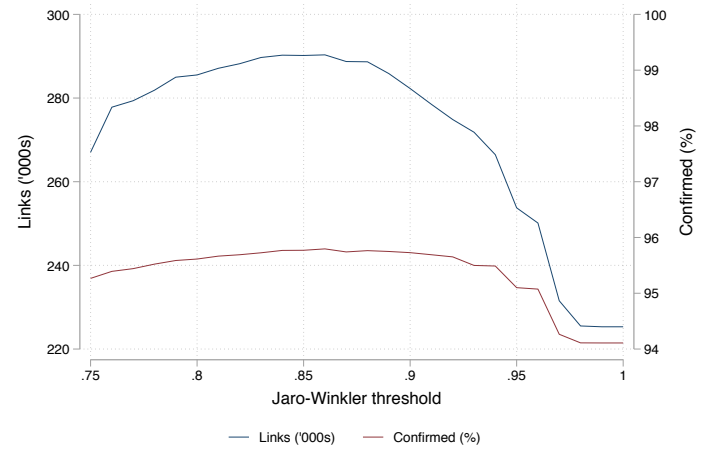

(A) LINKS BASED ON ONE FIRST NAME

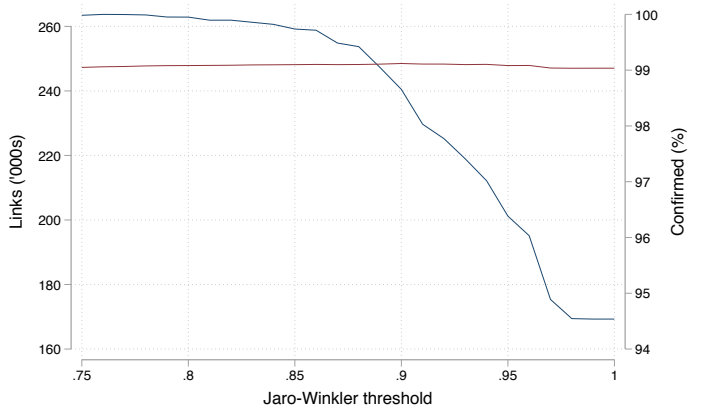

— Links ('000s) — Confirmed (\%)

(B) LINKS BASED ON TWO FIRST NAMES

FIGURE A.1:

EVALUATION OF JARO-WINKLER TRESHOLDS

Notes: These figures display the number of links and the share of links that are confirmed for different Jaro-Winkler thresholds using one and two first names respectively.

population. ${ }^{53}$ We thus need to find an optimal threshold for the JW similarity score that maximises the number of linked individuals, while maintaining a low rate of false positives.

To identify an optimal JW threshold, we use secondary characteristics not used for the original match to evaluate the quality of links at different threshold levels for the JW similarity score. Here a link is classified as "true" if there is a unique candidate in the 1910 census whose similarity score exceeds the chosen JW threshold for both the first and last name. If there is no such candidate, or more than one, no link is made. To assess the quality of the links, we evaluate the share of matches that we can confirm using information on additional first ("middle") names that are not used to generate the original link. We consider a link as confirmed if middle name initials match.

Figure A.1 displays the number of resulting links and the share of confirmed links at different JW thresholds. For links made using one first name, the share confirmed as true based on the second first name initials (95.8\%), as well as the number of resulting links, is maximized at a JW score of 0.85 (Figure A.1A). For individuals that can be linked on the basis of two first names, the share of confirmed links based on third first name initials is consistently higher across all JW thresholds and relatively stable around 99\% (Figure A.1B). The number of links, however, start to decrease substantially beyond a JW threshold of 0.85 . Thus, in order to maximize the number of links that can be confirmed as true, while minimizing the number of false positives, we set the JW threshold to 0.85 .

Using this threshold for the JW similarity score, we identify unique links for 310,183 out of

\footnotetext{
${ }^{53}$ Recently developed tools to address this challenge include machine learning techniques based on manually linked training data (Bailey et al., 2017; Feigenbaum, 2016) and fully automated processes which seeks to identify optimal thresholds that separate true links from false (Ferrie, 1996; Abramitzky et al., 2019; Dribe et al., 2019).
} 
the 848,949 sons observed in the 1880 census with at least one potential match (with identical sex, birth year, and place of birth) in the 1910 census. In order to get to our analytical sample we only include sons whose father's age was between 30-60 in 1880 (272,153). Because of sons or fathers with missing or indistinct occupational titles which cannot be assigned into one of the four occupational groups, a further 31,212 observations are excluded. This leaves us with a sample of 240,941 father-son pairs that constitutes the baseline sample used in the main analysis. 


\section{B Alternative Measures of Association}

In robustness tests in the main text, we apply several adjustments to the Altham $d(\mathbf{P}, \mathbf{I})$ statistic that account for potential drawbacks of the original method. The first issue is variability due to small cell counts. The standard approach using the Altham statistic assigns equal importance to each odds-ratio contrast, making it sensitive to sparsely populated cells where sampling variability could be significant. Based on a Bayesian framework, Zhou (2015) presents a shrinkage estimator that we apply to the Altham $d(\mathbf{P}, \mathbf{I})$ statistic presented in Figure B.1C. An alternative solution to the problem of unequal cell sizes is to weight each odds-ratio contrast by the table's marginal proportions (Bouchet-Valat, 2019), and we present results using this approach in Figure B.1E.

Another shortcoming of the Altham statistic is that it lacks an upper bound, and that it increases (weakly) with the number of dimensions in a table. Drawing on a framework first developed by Goodman (1996), a transformation has been proposed by Bouchet-Valat (2019) which is bounded in the $[0,1]$ range and that behaves similarly to a correlation. If we let $\sum \log \theta_{i j, i^{\prime} j^{\prime}}$ denote the log-odds ratios from the full set of pairwise comparisons:

$$
\sum \log \theta_{i j, i^{\prime} j^{\prime}}=\sum_{i=1}^{r} \sum_{j=1}^{s} \sum_{i^{\prime}=1}^{r} \sum_{j^{\prime}=1}^{s}\left[\log \left(\frac{p_{i j} p_{i^{\prime} j^{\prime}}}{p_{i j^{\prime}} p_{i^{\prime} j}}\right)\right]
$$

then the Bouchet-Valat statistic ${ }^{54}$ is defined as:

$$
B V=\sqrt{1+1 /\left(\frac{1}{(r s)^{2}} \sum \log \theta_{i j, i^{\prime} j^{\prime}}\right)^{2}}-1 /\left(\frac{1}{(r s)^{2}} \sum \log \theta_{i j, i^{\prime} j^{\prime}}\right) .
$$

As the notation suggest, the Bouchet-Valat statistic is closely related to the Altham $d(\mathbf{P}, \mathbf{I})$ statistic. Specifically, the two are related through the equation $d(\mathbf{P}, \mathbf{I})=2 r s \frac{B V}{1-B V^{2}}$. In Figure B.1B we present results using the Bouchet-Valat statistic with uniform weights, in Figure B.1D the Bouchet-Valat statistic with Bayesian shrinkage for small cells, and in Figure B.1F the BouchetValat statistic with cell contributions weighted by the table margins. Across all these measures of association, our main result remains robust. The main difference from our baseline results is that Britain appear less mobile once odds ratios are weighted by margin sizes. This is mainly a result of the disproportionately high mobility out of farming, which is smaller in Britain than any of the other countries.

\footnotetext{
${ }^{54}$ These estimations were carried out using the logmult package for the $\mathrm{R}$ statistical computing environment. Bouchet-Valat (2019) refers to $B V$ as $\tau^{\dagger}$ or the normalized intrinsic association coefficient with uniform weighting. We use the author's name in analogy with the Altham statistic.
} 


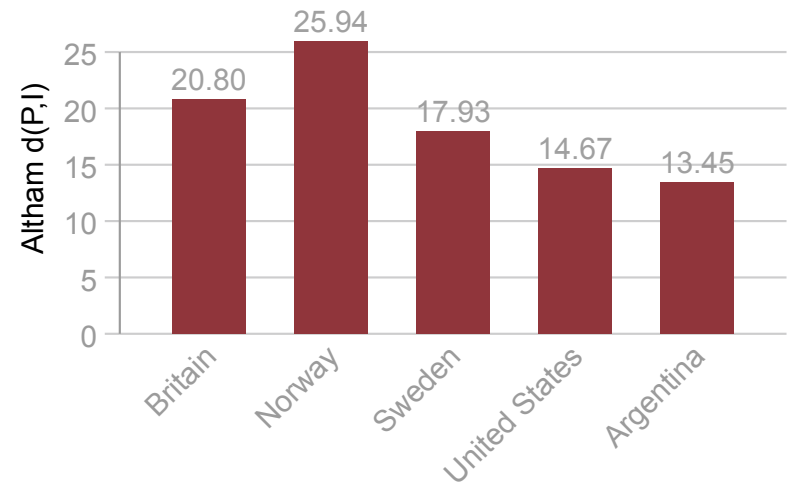

(A) Altham D(P,I)

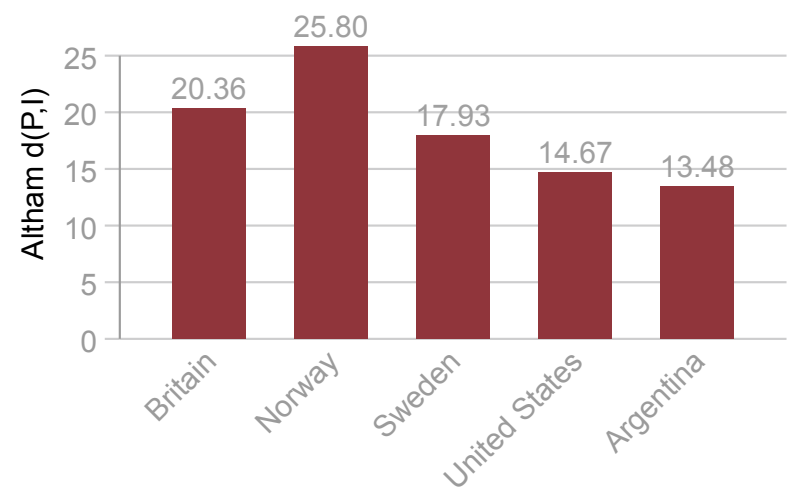

(C) Altham D(P,I), With Shrinkage

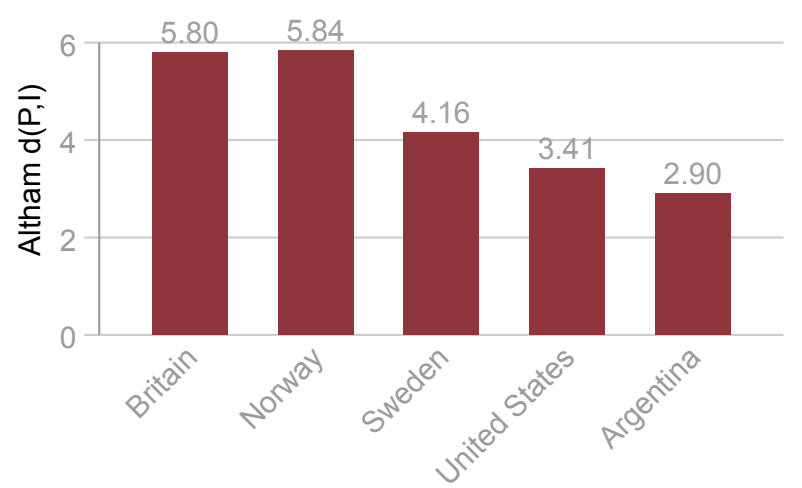

(E) Altham D(P,I), MARgin-Weighted

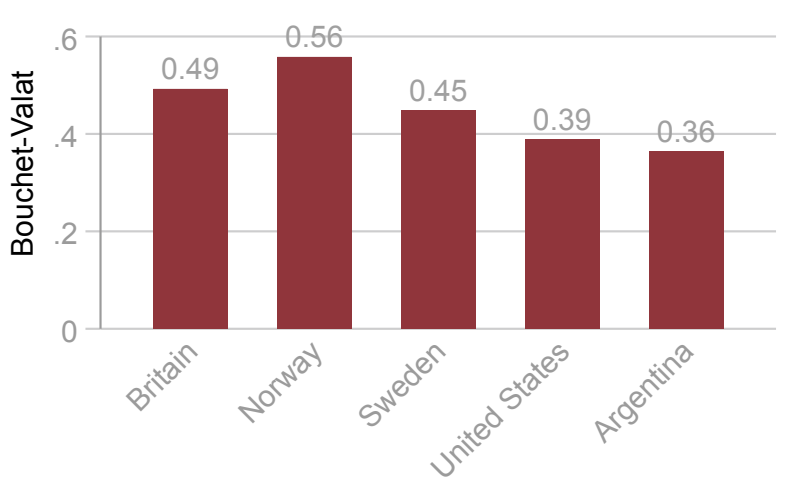

(B) Bouchet-Valat Statistic

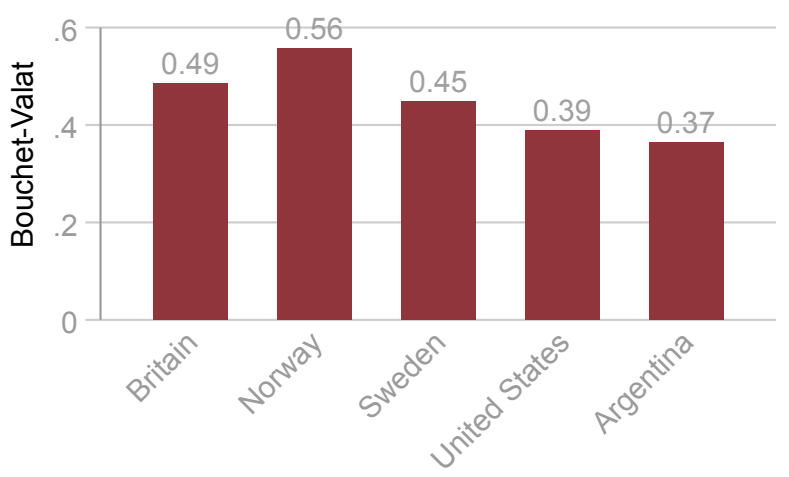

(D) BOUCHET-VALAT, WITH SHRINKAGE

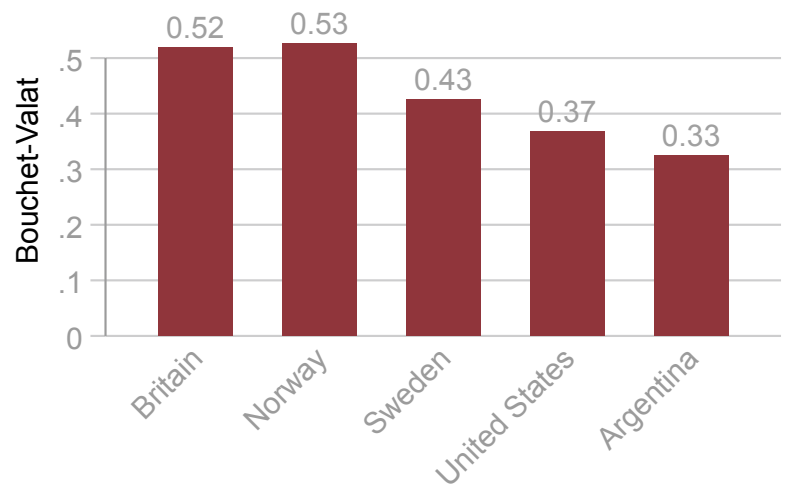

(F) BOUCHET-VALAT, MARGIN-WEIGHTED

\section{Figure B.1: Alternative MEASURES OF RELATIVE MOBILITy}

Notes: The left column (panels A, C, and E) displays Altham $d(\mathbf{P}, \mathbf{I})$ statistics. The right column (panels B, D, and F) present Bouchet-Valat statistics. In panels A and B we make no adjustment for cell sizes; panels C and D are estimated with Bayesian shrinkage for small cells; panels $\mathrm{E}$ and $\mathrm{F}$ are estimated with weights proportional to table margins. 


\section{Counterfactual Mobility Estimates Including Emigrants}

Swedish emigration to the New World peaked in the 1880s and 1890s, which are the cohorts whose social mobility we are interested in. Self-selection into emigration means that emigrants likely differ from stayers both with regard to their social background and occupational attainment in adulthood. Moreover, the fact that almost a quarter of Swedish population emigrated in itself makes overseas migration a potential source of bias: it would lead us to overestimate mobility if emigrants were less mobile, or underestimate mobility if emigrants were more mobile.

To examine the extent to which emigration may bias our estimates of Swedish mobility, we construct a counterfactual mobility table which includes sons that emigrated between 1880-1910. For this we need to know: (1) the number of emigrants in the relevant cohorts; and (2) what their occupational attainment would have been had they stayed behind in Sweden.

First we calculate the number of emigrants in our studied cohorts by subtracting all decedents between 1881 and 1910 and those enumerated in Sweden in 1910 from the initial number enumerated in $1880 .{ }^{55}$ In order to identify sons lost to emigration in our cohorts, we link the 1880 census records to EMIBAS (Swedish Emigrant Institute and Federation of Swedish Genealogical Societies, 2005), an emigrant register containing the majority of all Swedish emigrants between 1880-1910, allowing us to identify sons that are "missing" in 1910 due to emigration. ${ }^{56}$

Because the occupations of sons that emigrated are not observed, we need to construct a proxy for their occupational attainment had they stayed in Sweden. We leverage the fact that in many cases emigrants had brothers who stayed behind, which can be used as a proxy for the occupations that emigrants would have attained. ${ }^{57}$ Under the assumption that inherently more mobile brothers were more prone to emigrate, the occupational attainment of their stayer brothers is likely a conservative estimate of emigrants' attainment had they stayed in Sweden. In that case, our counterfactual estimate would underestimate the level of mobility.

Using information on the number of emigrants and our proxy for their occupational attainment, we proceed to construct the counterfactual mobility table that includes emigrants. To do this, we add the predicted occupational transitions for emigrants to the baseline mobility table, which

\footnotetext{
${ }^{55}$ Of the 849,996 sons observed in $1880,543,155$ were enumerated again in 1910 . The loss of 128,750 sons is attributable to mortality between the two censuses, leaving 178,091 sons whose loss we can attribute to emigration, meaning that 21 per cent of all sons observed in 1880 emigrated during the following 30 years. We collect information about the number of decedents from the Swedish Death Index (Federation of Swedish Genealogical Societies, 2018).

${ }^{56}$ Since emigration registers contain the same identifying information as the censuses, we apply the same linking method as for the main sample, described in Appendix A. We are able to locate a large number of emigrants by linking individuals in the 1880 census to emigrant lists. In total we identify 101,508 emigrants who meet the same linking restrictions that we imposed on our main analytical sample. The social background of these emigrants confirm the notion that emigration was more common among sons with lower skilled and unskilled fathers.

${ }^{57}$ Of the identified emigrants, 20,381 are observed with at least one brother in 1880 who in turn is linked to 1910 with their own occupational title. When multiple brothers are identified, we favor the brother closest in age.
} 
Brother's occupation

Father's occupation White-collar Farmer Skilled/semi-skilled Unskilled Total

\begin{tabular}{lccccc} 
& $\%$ & $\%$ & $\%$ & $\%$ & $\%$ \\
\hline White-collar & 48 & 12 & 26 & 13 & 100 \\
Farmer & 9 & 48 & 23 & 20 & 100 \\
Skilled/semi-skilled & 15 & 11 & 55 & 19 & 100 \\
Unskilled & 11 & 16 & 40 & 33 & 100 \\
Total & 13 & 32 & 33 & 22 & 100 \\
\hline $\mathrm{N}$ & 2,687 & 6,588 & 6,663 & 4,443 & 20,381
\end{tabular}

TABLE C.1: OCCUPATIONAL TRANSITIONS FOR FATHERS AND EMIGRANT’S BROTHERS, 1880-1910

Notes: This table displays occupational transitions for emigrants' brothers relative to their fathers. Each column corresponds to the occupational group of brothers observed in the 1910 census. Each row corresponds to the occupation of fathers observed in the 1880 census.

includes sons that resided in Sweden in 1910. We impute occupational transitions for emigrants using the attainment of non-emigrant brothers, which we scale to the actual number of emigrants between 1880-1910 to also include emigrants without brothers enumerated in the 1910 census.

We then use this counterfactual mobility table to estimate the Altham $d(\mathbf{P}, \mathbf{I})$ statistic separately for stayers (i.e., our baseline estimate), emigrants (E), and stayers and emigrants combined (S): ${ }^{58}$

$$
d(\mathbf{P}, \mathbf{I})=17.9 \quad d(\mathbf{E}, \mathbf{I})=15.7 \quad d(\mathbf{S}, \mathbf{I})=17.6
$$

The counterfactual mobility of emigrants $d(\mathbf{E}, \mathbf{I})$ indicate that they were more mobile than stayers. Yet, when accounting for emigration in $d(\mathbf{S}, \mathbf{I})$, estimated social mobility increases only slightly, despite the large number of emigrants. Thus, compositional effects due to emigration is unlikely to be an important explanation for the high social mobility in Sweden at the time.

\footnotetext{
${ }^{58}$ We present the full occupational transition matrix for emigrants' brothers in Appendix Table C.1.
} 


\section{Additional Figures}

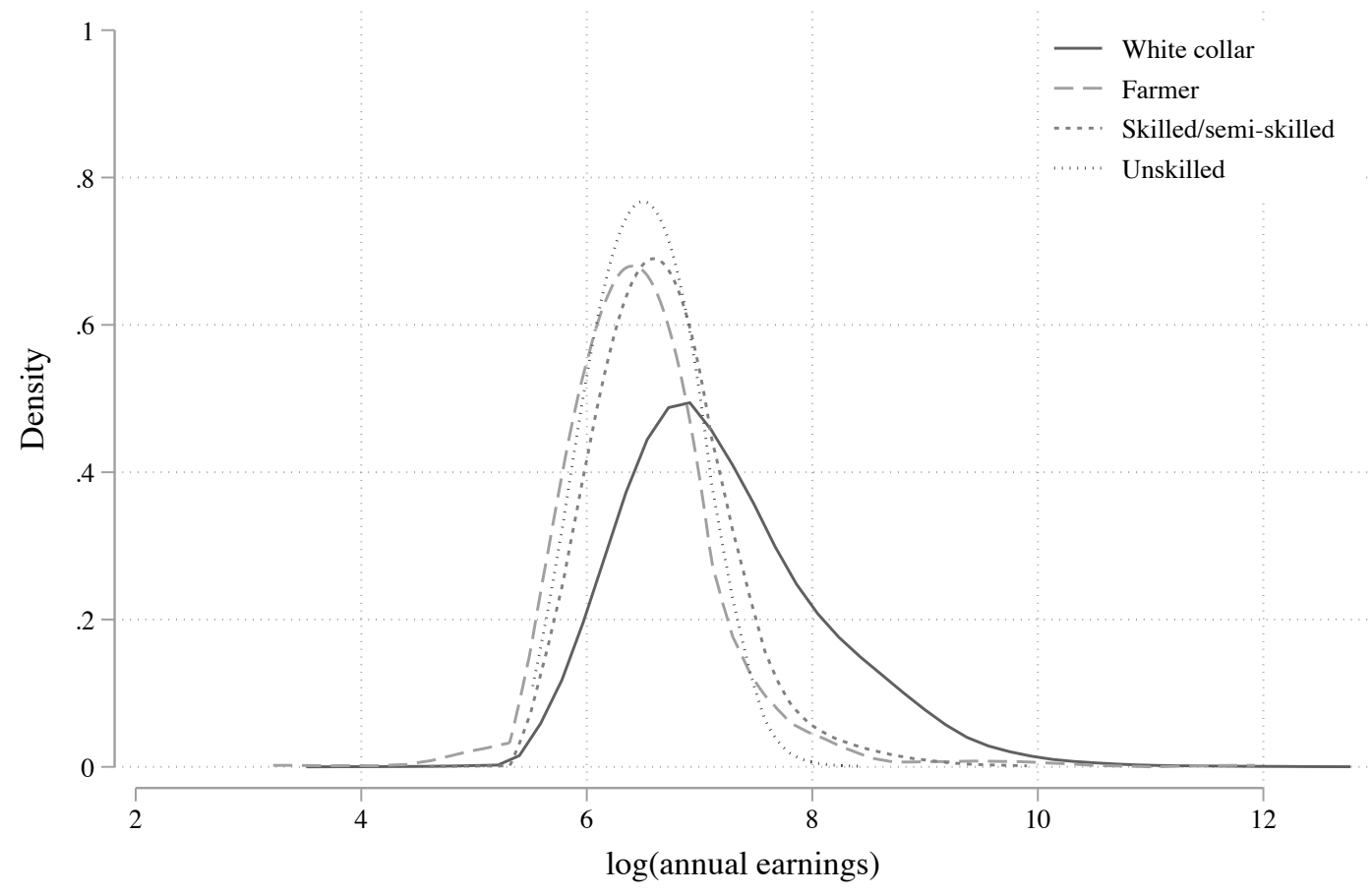

FIGURE D.1:

Distribution of Log(ANNUAL EARNings) IN SWEDEN, 1900

Notes: This figure shows the distribution of male $\log$ (annual earnings) in Sweden in 1900 among the stratified sample of approximately 15000 taxpayers collected by Bengtsson et al. (2021). 


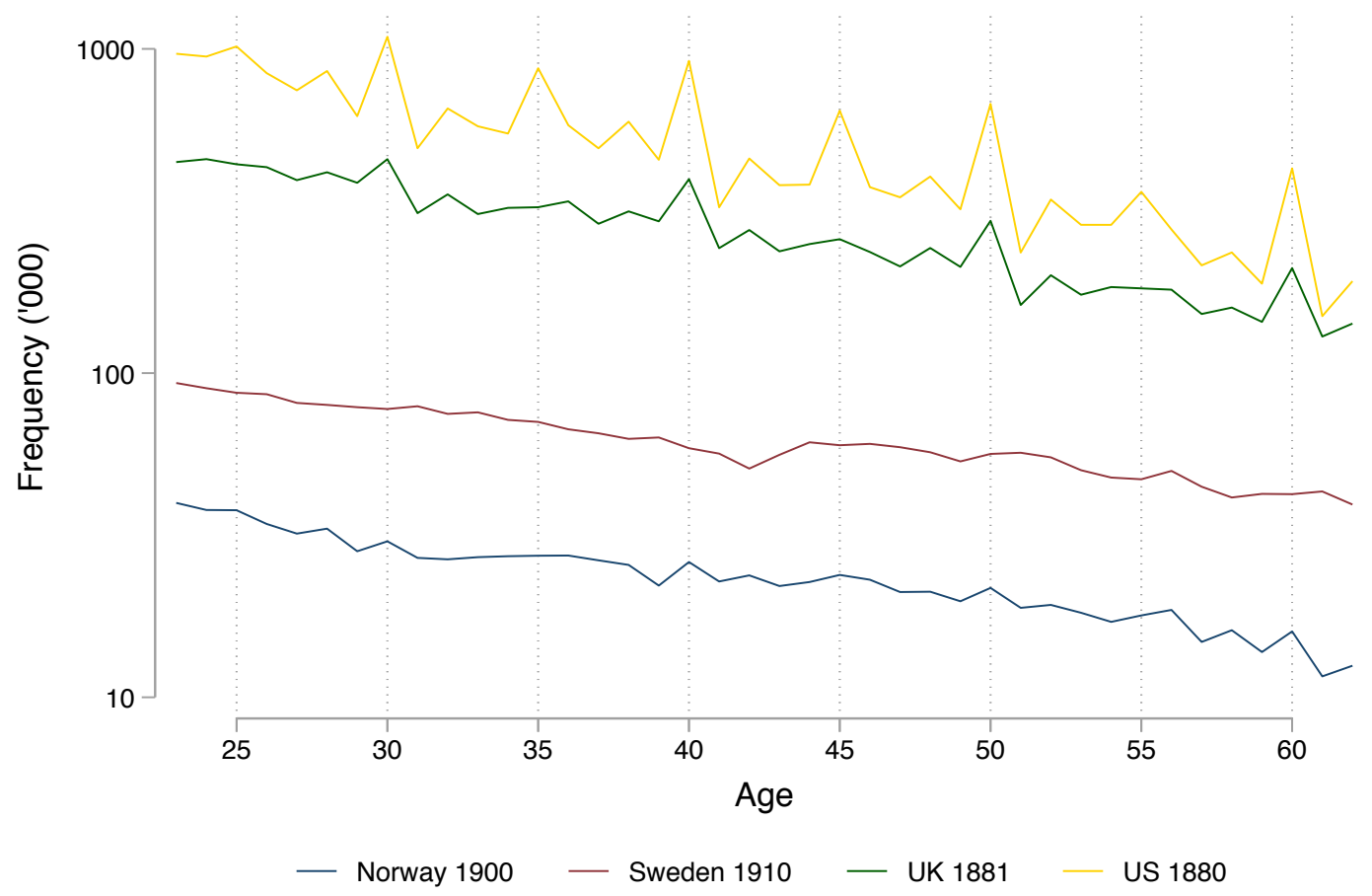

Figure D.2: Distributions of REPORTEd ages in the SWEDish, Norwegian, UK AND US CENSUSES

Notes: The figure shows the distribution of ages in the Swedish 1910, Norwegian 1900, UK 1881 and US 1880 censuses. The distributions and the corresponding Whipple's indices (Sweden 1910, 100.2; Norway 1900, 105.4; UK 1881, 114.8; US 1881, 144.5) suggests that reported ages are significantly more accurate in the Swedish census. 


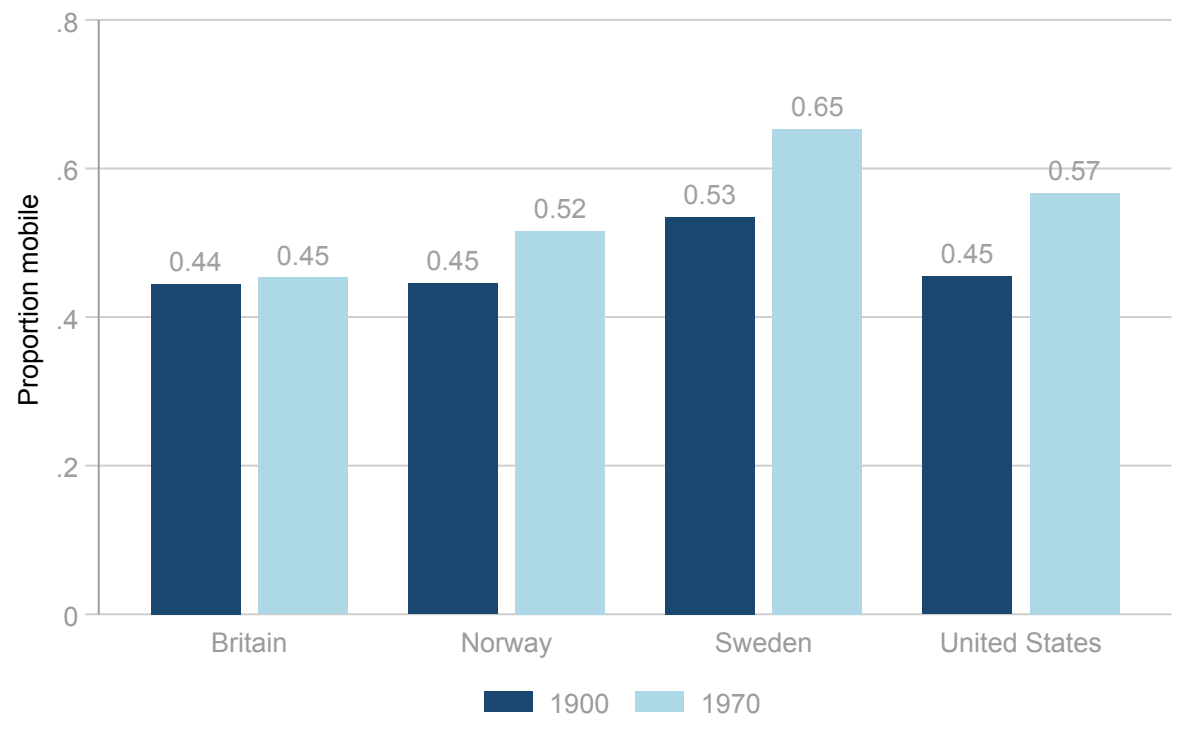

(A) Absolute mobility

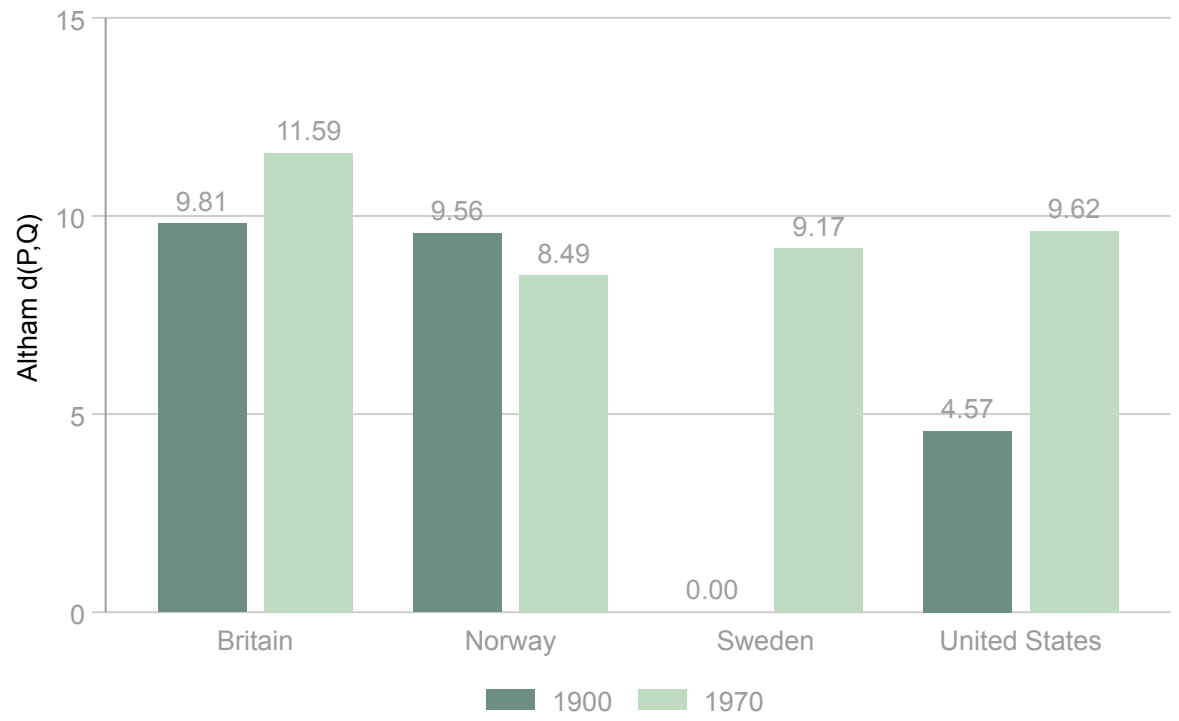

(B) Relative Mobility (VS Historical SWEDEN)

FigURE D.3: MOBILITY IN HISTORICAL AND MODERN SAMPLES

Notes: Panel A displays estimates of absolute mobility, or the share of sons that are observed in a different occupational group than their father. Panel B displays Altham $d(\mathbf{P}, \mathbf{Q})$ statistics that measure the distance between each countryperiod mobility table and the historical Swedish mobility table. 


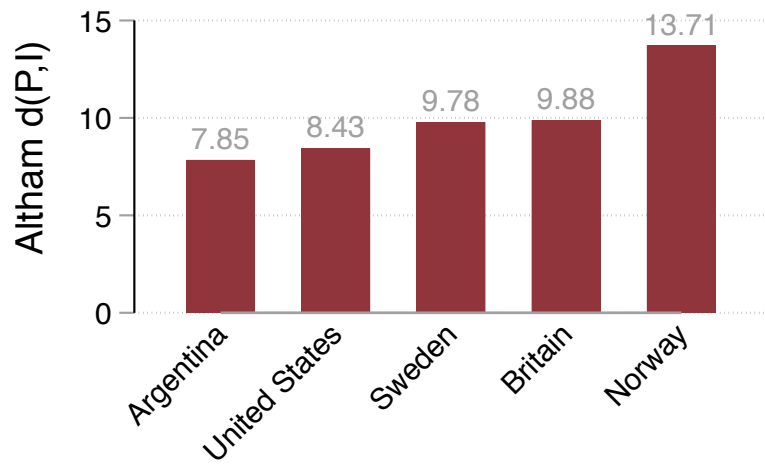

(A) Relative Mobility (VS INDEPENDENCE)

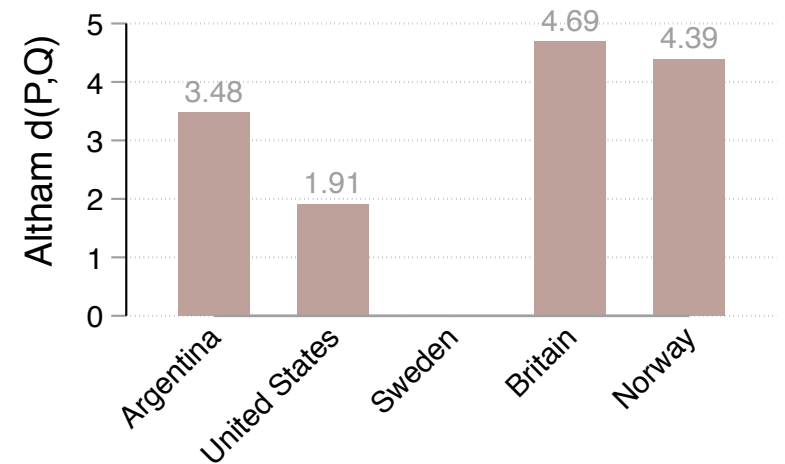

(B) Relative mobility (Vs SWEDEN)

Figure D.4: Mobility IN THE Old AND New World: EXCluding FARMERS

Notes: Panels A and B display Altham $d(\mathbf{P}, \mathbf{I})$ and $d(\mathbf{P}, \mathbf{Q})$ statistics respectively when excluding farmers from the underlying samples. 


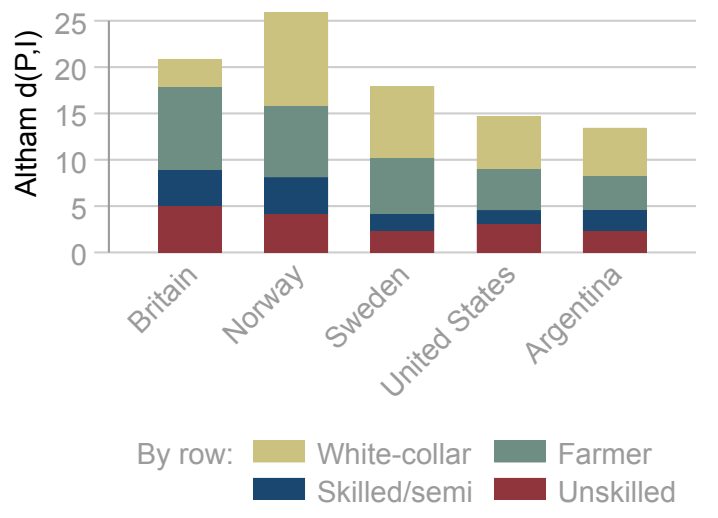

(A) CONTRIBUTION BY ROW (FATHER)

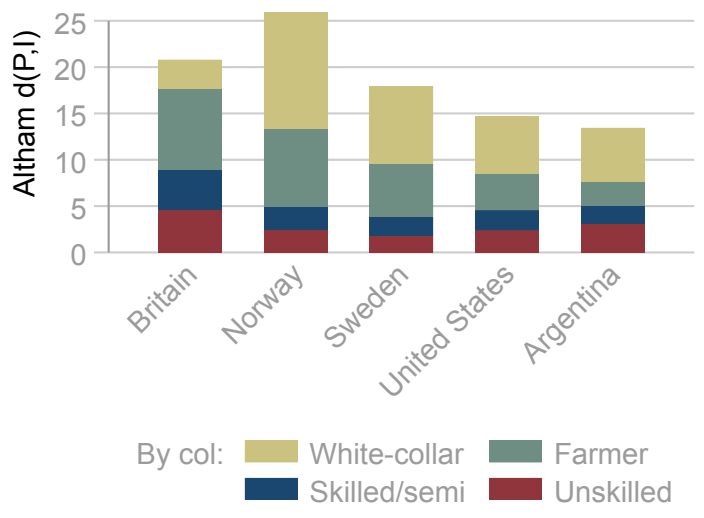

(B) CONTRIBUtion By COLUMN (SON)

FIGURE D.5:

DECOMPOSING MOBILITY RATES ACROSS COUNTRIES

Notes: Panel A displays the contribution of each occupational group by row to the Altham $d(\mathbf{P}, \mathbf{I})$. Panel B presents the contribution of each occupational group by column to the estimated $d(\mathbf{P}, \mathbf{I})$ statistic. 


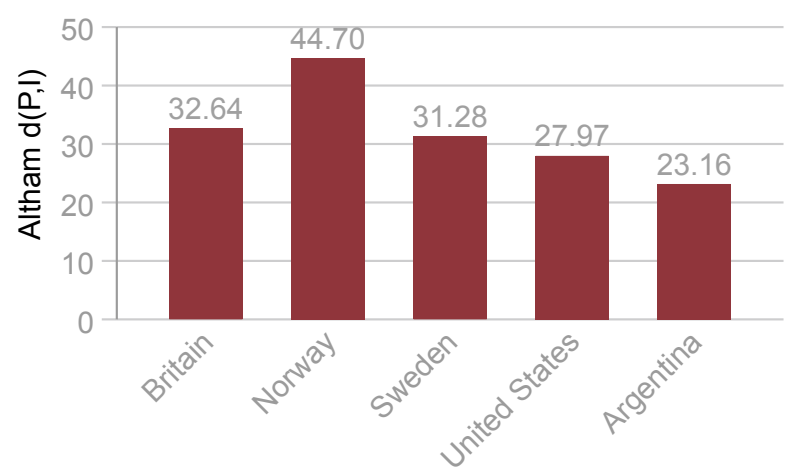

(A) LOW VS HIGH WHITE-COLLAR

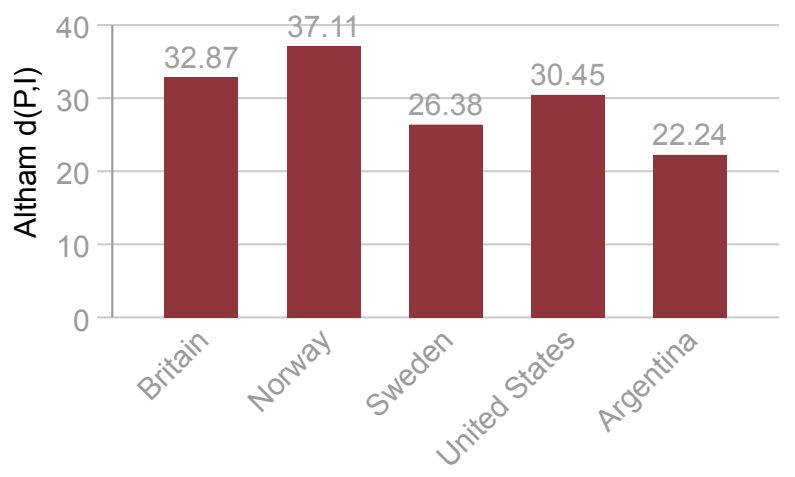

(B) FARM LABOR VS OTHER UNSKILLED

FiguRE D.6: RELATIVE MOBILITY WITH FIVE OCCUPATIONAL CATEGORIES

Notes: Panel A displays Altham $d(\mathbf{P}, \mathbf{I})$ statistics when separating "low" and "high" white-collar occupations. Panel B reports Altham $d(\mathbf{P}, \mathbf{I})$ statistics when distinguishing "farm laborers" and other unskilled occupations. 


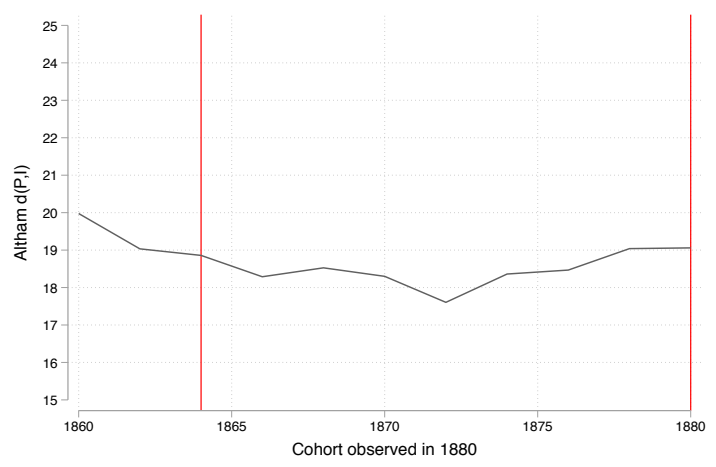

(A) SONS COHORT

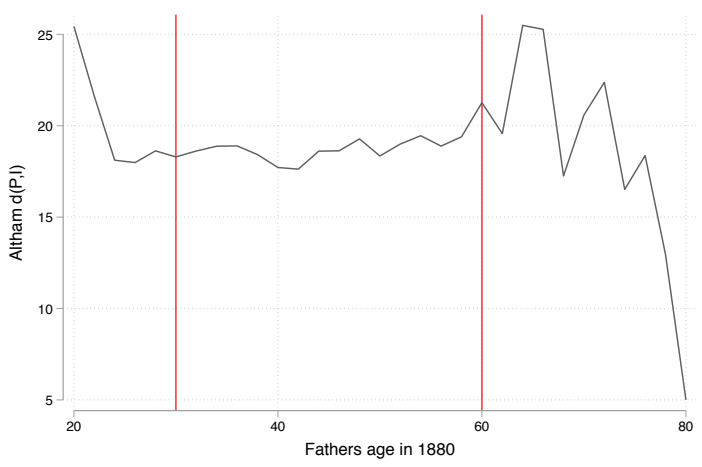

(B) FATHERS AGE IN 1880

FIGURE D.7:

Altham $d(\mathbf{P}, \mathbf{I})$ STATISTICS WITH DIFFERENT AGE SPANS FOR SONS AND FATHERS

Notes: Panel A displays Altham $d(\mathbf{P}, \mathbf{I})$ statistics estimated for each cohort of sons in our main sample. Panel B displays Altham $d(\mathbf{P}, \mathbf{I})$ statistics when restricting the sample by fathers' age in 1880 in 5-year bins. Two vertical red lines denote the age restrictions we impose in our baseline sample in both panels. 


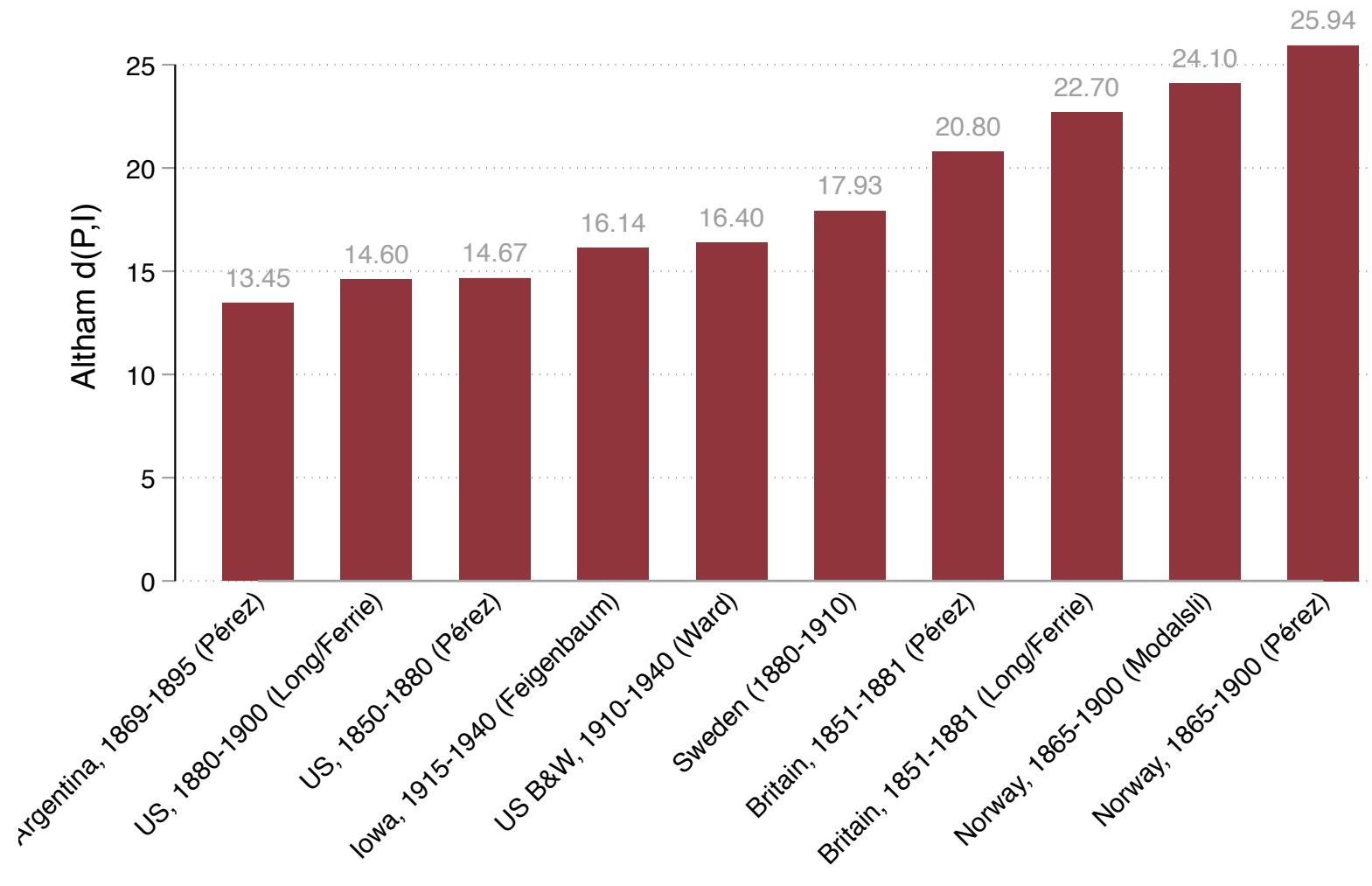

FIGURE D.8:

Mobility IN THE Old AND NeW World: AdDitional SAMPles

Notes: This figure displays Altham $d(\mathbf{P}, \mathbf{I})$ statistics that capture the distance from the case of full mobility where a larger statistic corresponds to less mobility. Data are drawn from Long \& Ferrie (2013a), Pérez (2019), Ward (2020a), Feigenbaum (2018), and Modalsli (2017). 


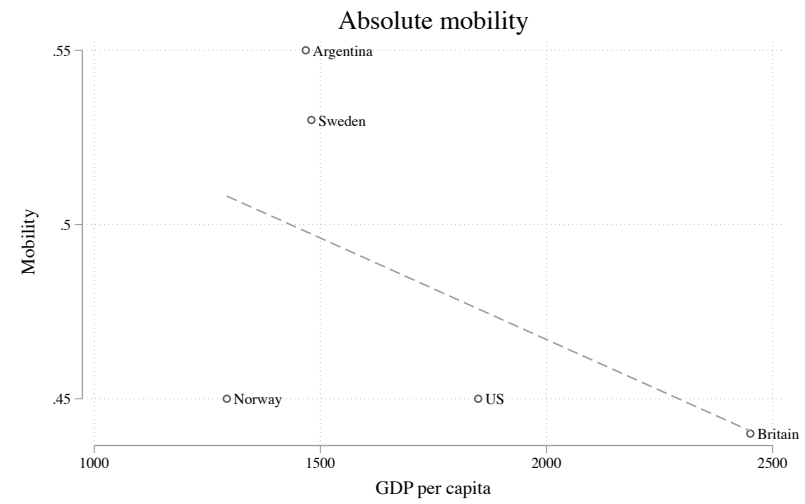

(A) Absolute mobility - Cross-Country

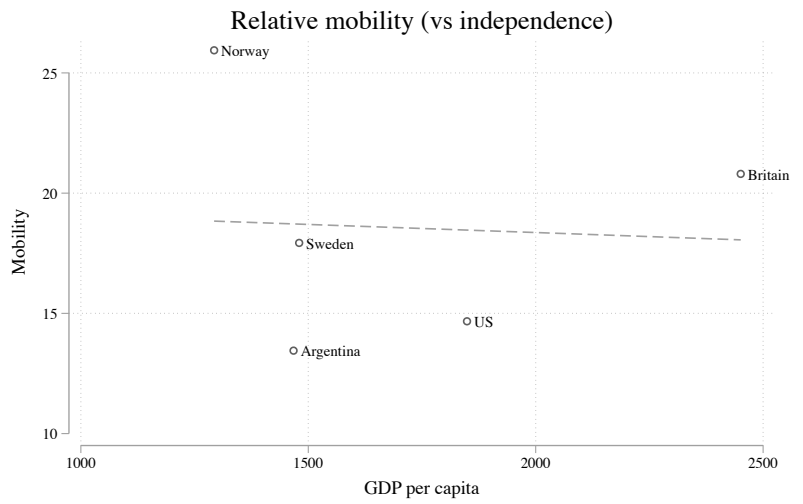

(B) Absolute mobility - Municipalities

FIGURE D.9:

CROSS-COUNTRY CORRELATION BETWEEN GDP PER CAPITA LEVELS AND MOBILITY

Notes: This figure shows the cross-country correlation between absolute and relative mobility and GDP per capita levels. GDP per capita levels are measured in the first census year used to compute mobility rates. GDP per capita figures from Bolt et al. (2018). 


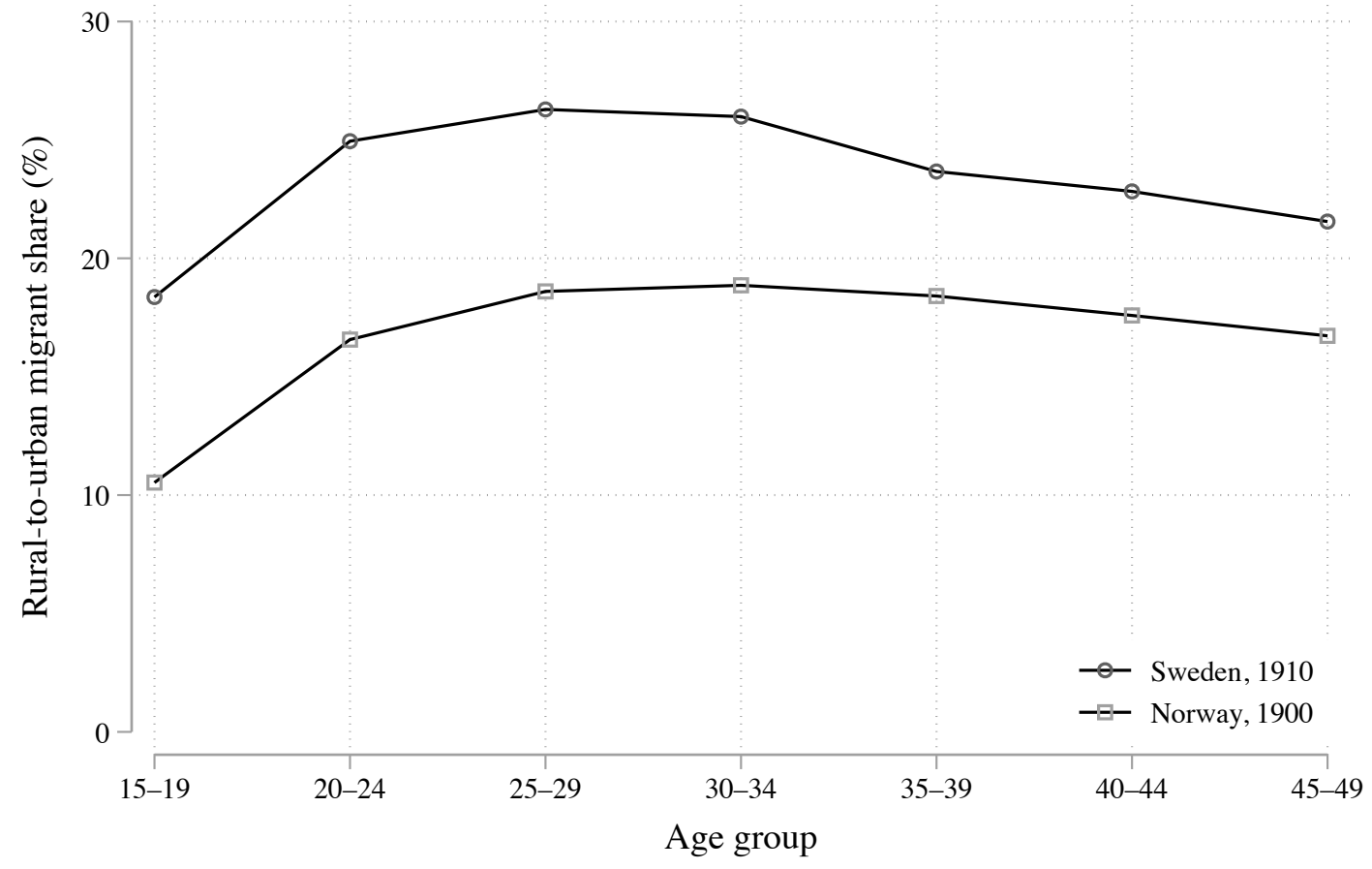

Figure D.10: RATES OF RURAL-TO-URbAN MigRATION, SWEDEN AND NORWAY.

Notes: This figure displays the share of men born in rural areas living in an urban area when observed in the census by age group. For Sweden, the data is from the 1910 census and for Norway the 1900 census. 


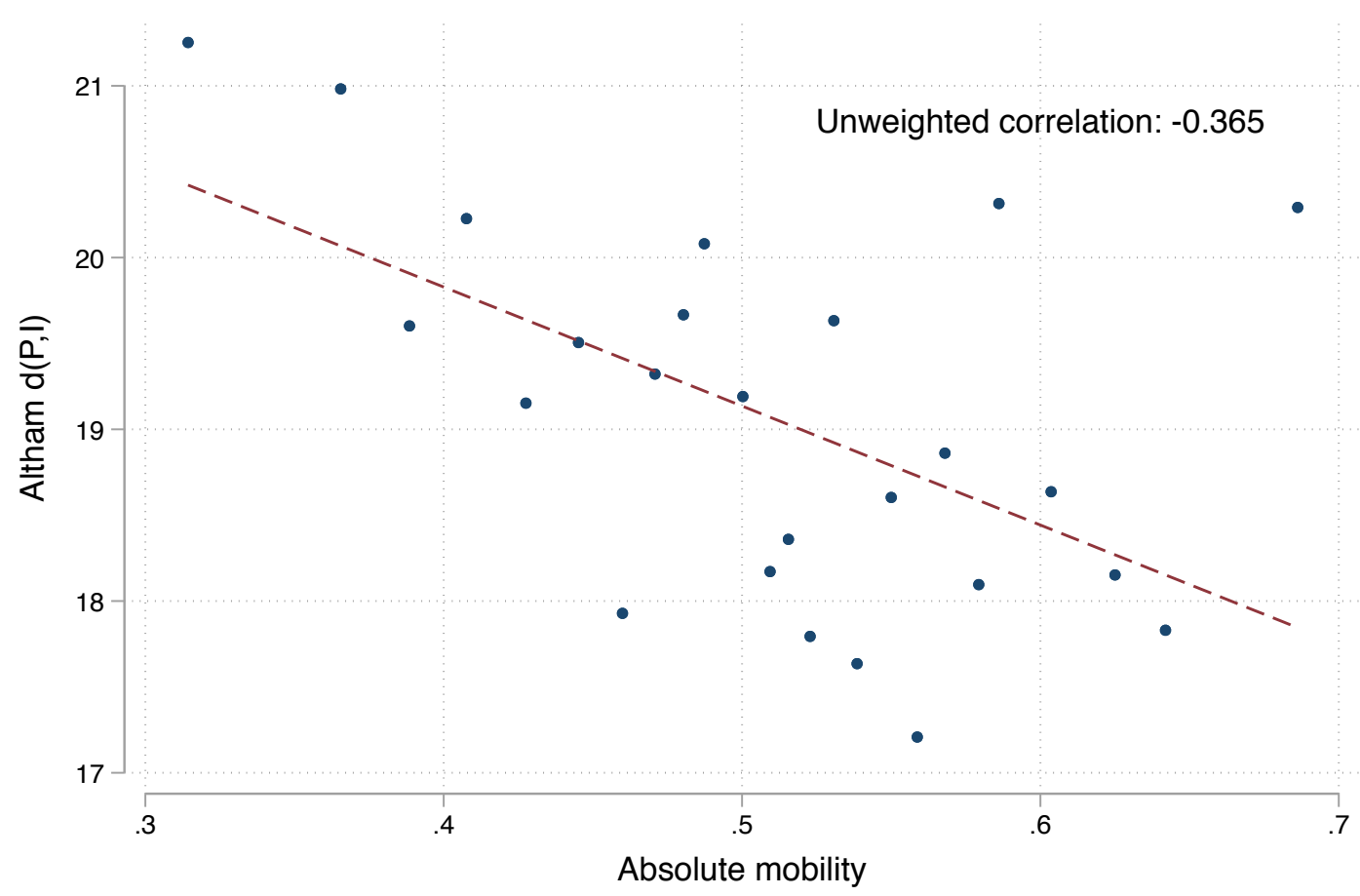

FiguRE D.11: ABSOLUTE AND RELATIVE MOBILITy ACROSS MUNICIPALITIES, 1880-1910.

Notes: This figure displays the non-parametric relationship between relative mobility measured by the Altham $d(\mathbf{P}, \mathbf{I})$ statistic and absolute mobility (the share of sons transitioning into another occupation than that held by their father) across 282 municipalities. Sons are allocated to the municipality where they resided in childhood (i.e., in 1880). We group all municipalities into 25 equal-sized bins based on municipalities' absolute mobility rate where dots denote the mean level of relative mobility in each bin. Also shown is a best-fit line estimated from the underlying (ungrouped) data. 

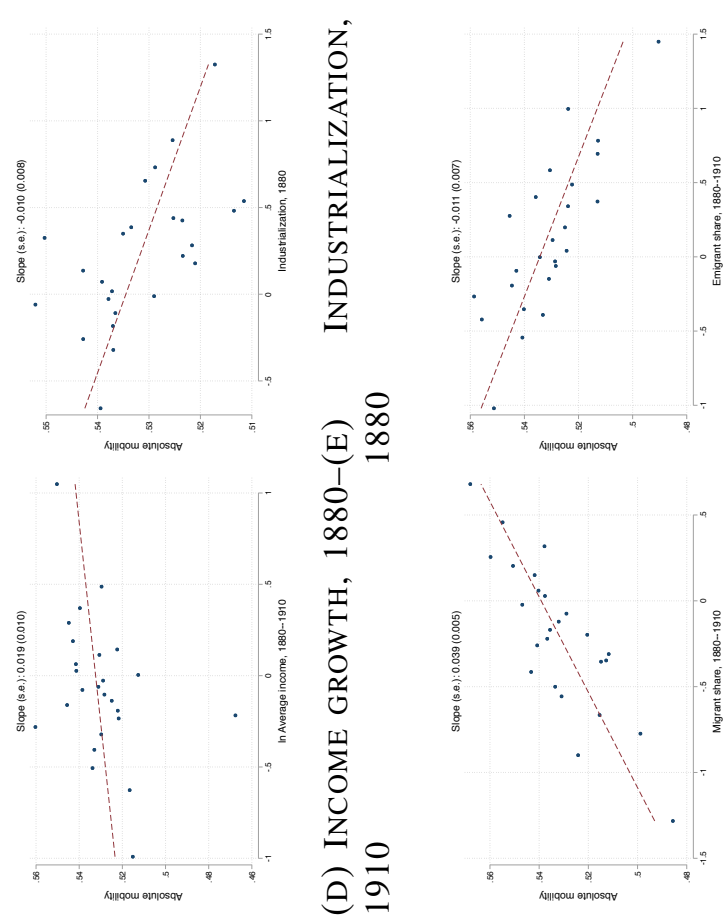

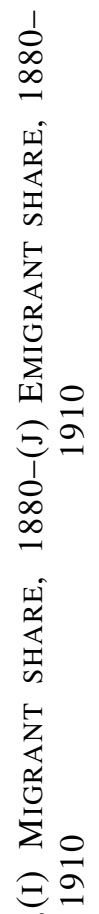
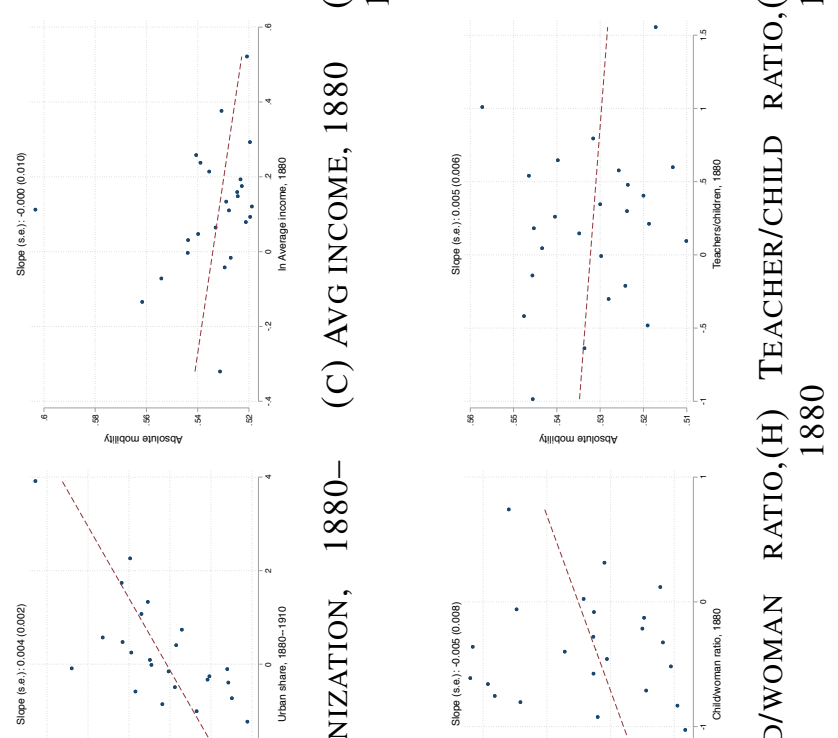

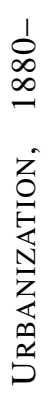
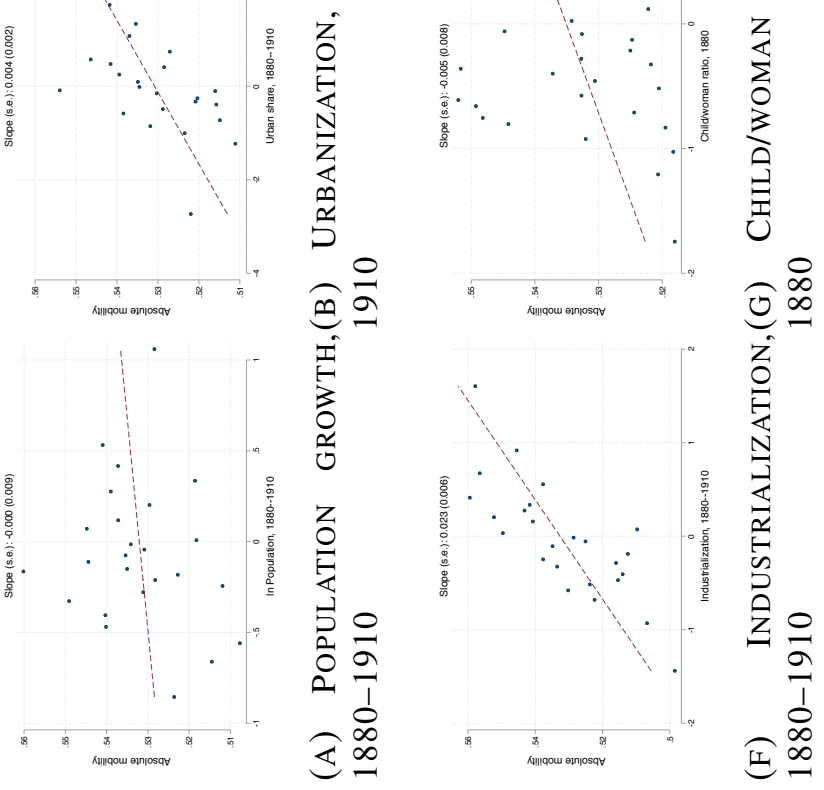

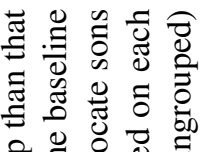

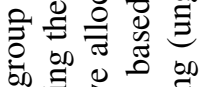

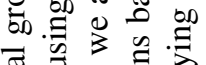

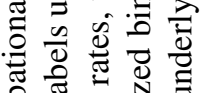

莄

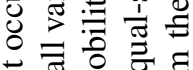

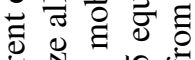

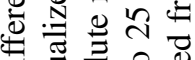

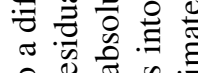

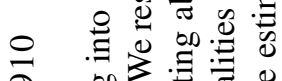

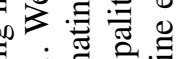

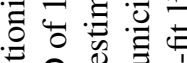

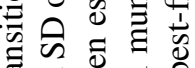

ॠ

䒕. 은

定 $0 \begin{gathered}0 \\ 0\end{gathered}$

¿

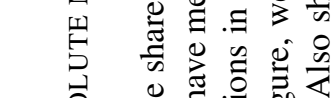

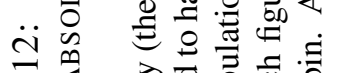

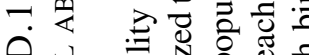

뇟 돈

츨 웜

占

흥

웡

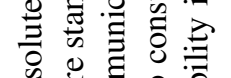

范

च

ष्ञ

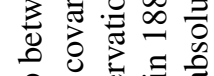

鲟牙

पै

.월 元

.

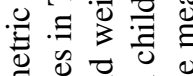

兽志.

큰

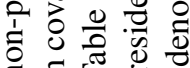

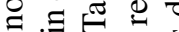

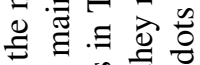

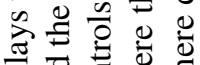

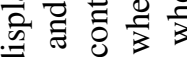

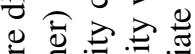

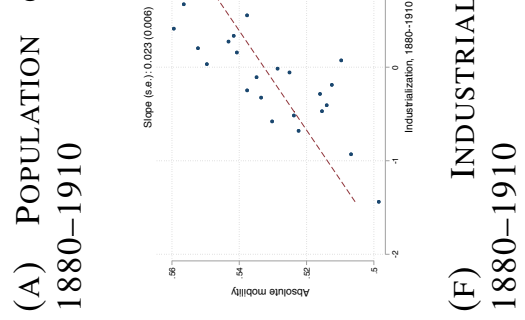

施 䓌

$\therefore \cdot \frac{0}{0} \cdot \overline{0}$

氖导声怘

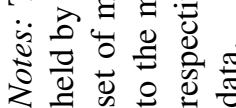




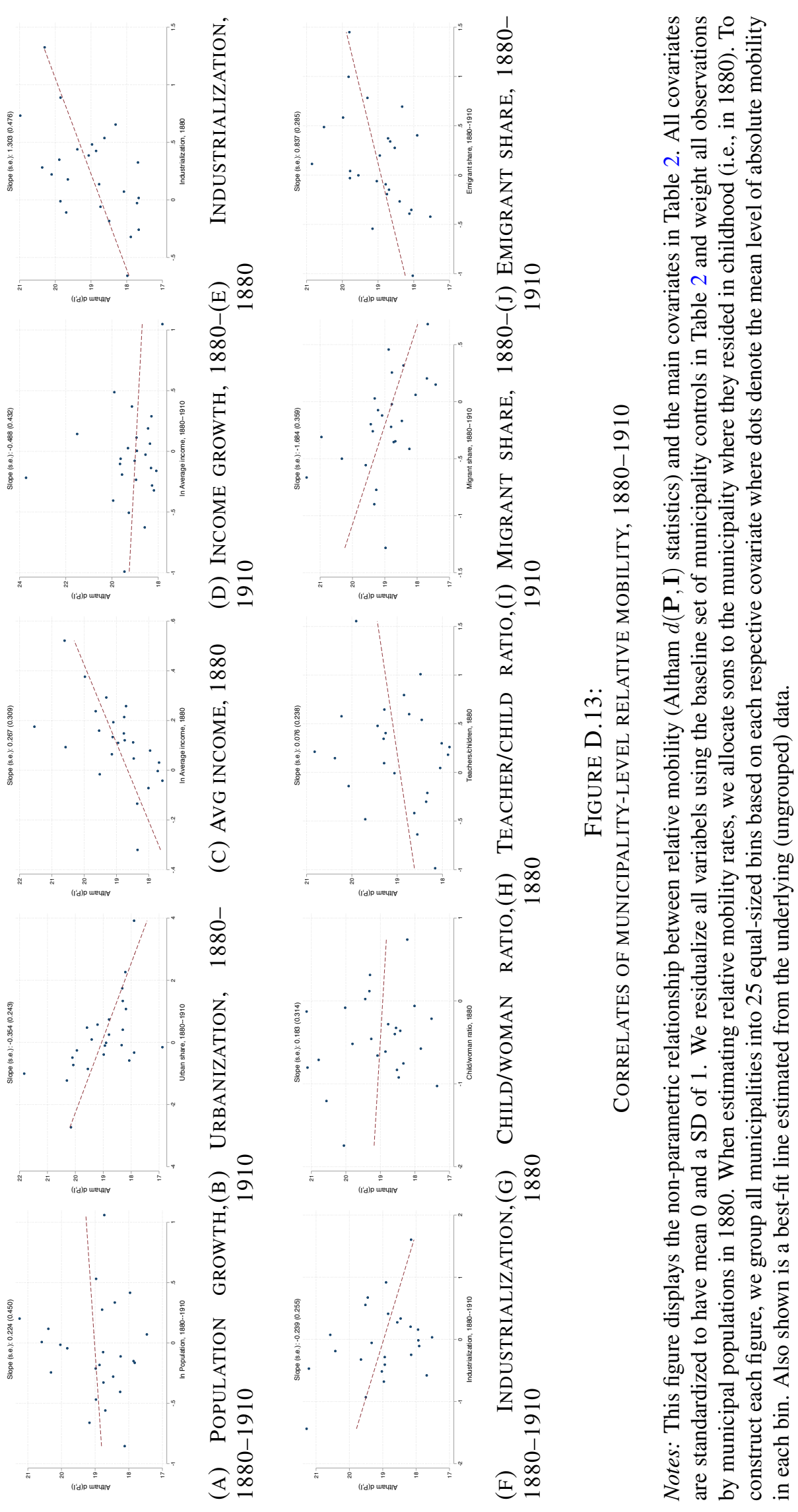




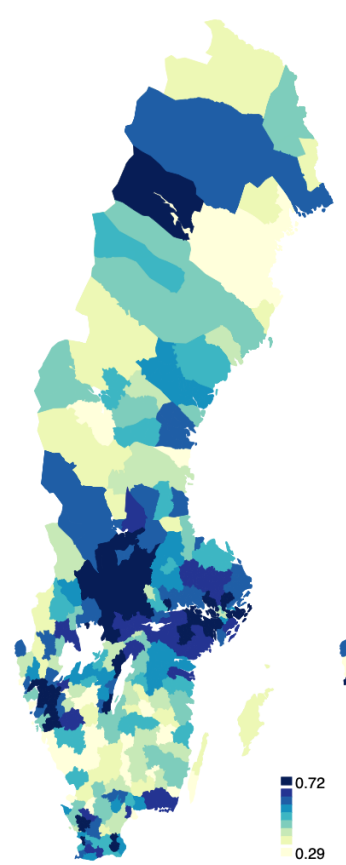

(A)

ABSOLUTE MOBILITY

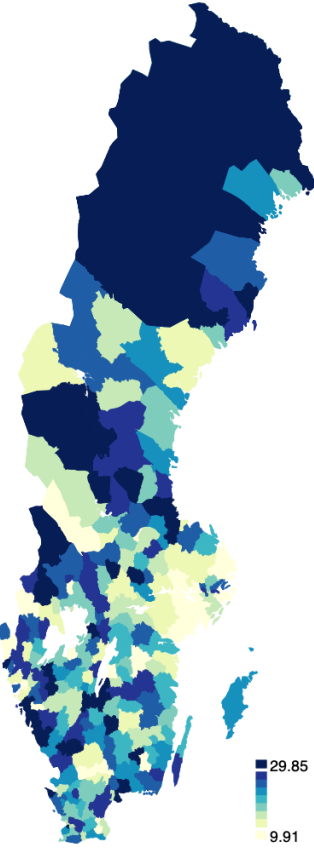

(B)

Altham $d(\mathbf{P}, \mathbf{I})$

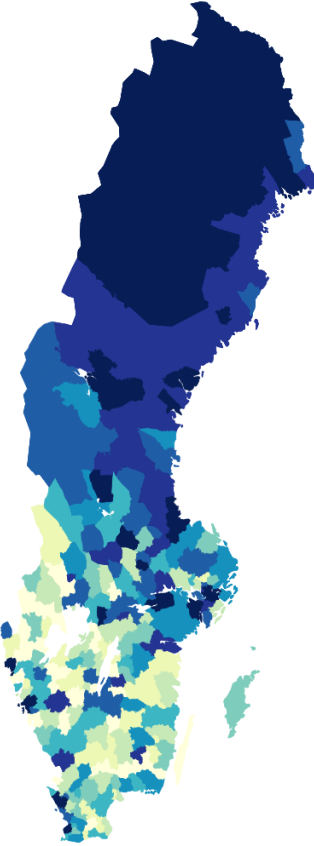

(C)

POPULATION

GROWTH

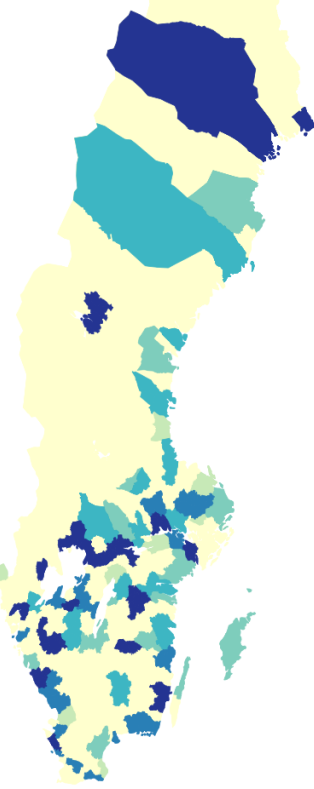

(D)

URBANIZATION

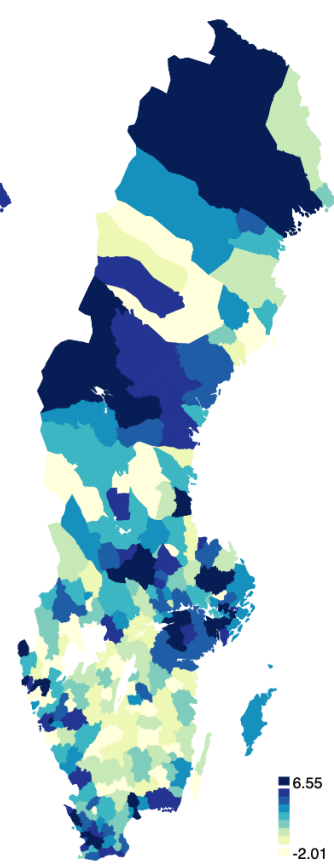

(E)

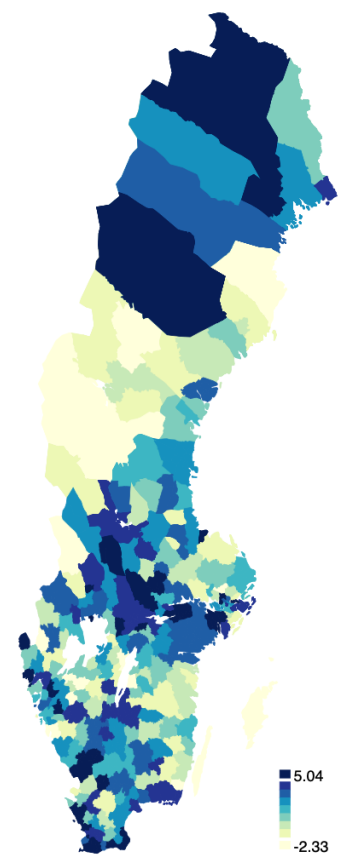

(F)

INDUSTRIALIZATION

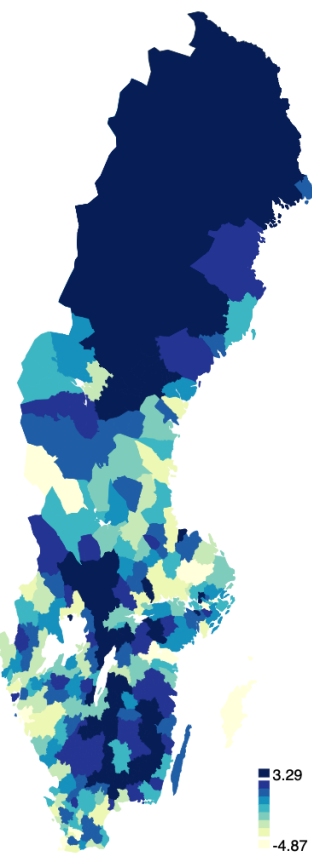

(G)

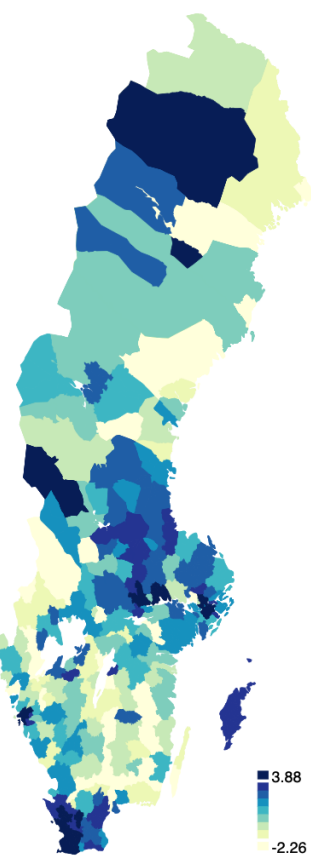

(H)

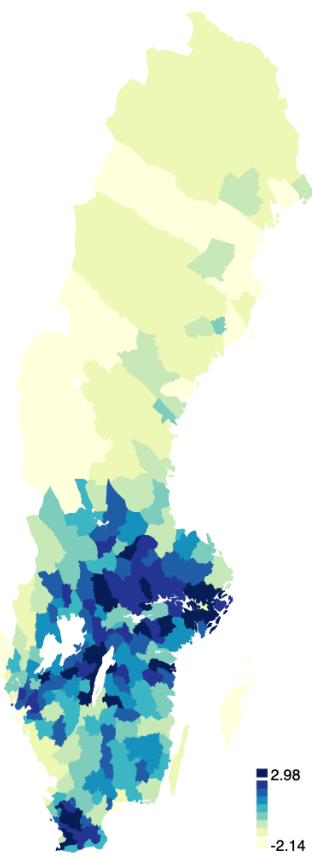

(I)

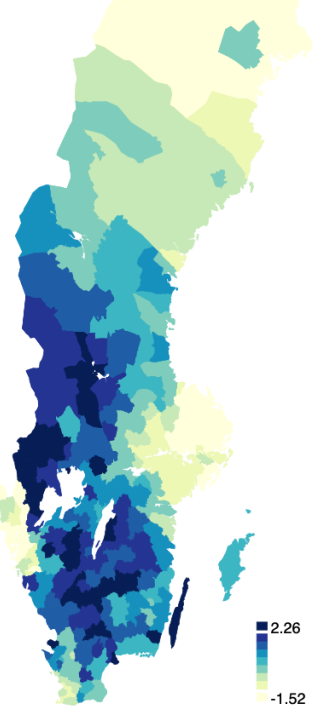

(J)

TEACHERS

EMIGRATION

FIGURE D.14: GEOGRAPHY OF OPPORTUNITY AND CORRELATES OF INTERGENERATIONAL MOBILITY

Notes: Maps display the distribution of absolute and relative mobility and other characterstics across 282 municipalities. Each variable is divided into 9 equal-sized bins where darker blue shades correspond to higher values. 
Mobility by municipality of residence in childhood (1880)

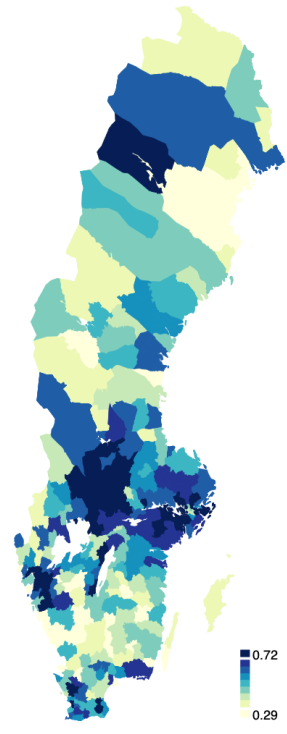

(A)

ABSOLUTE MOBILITY

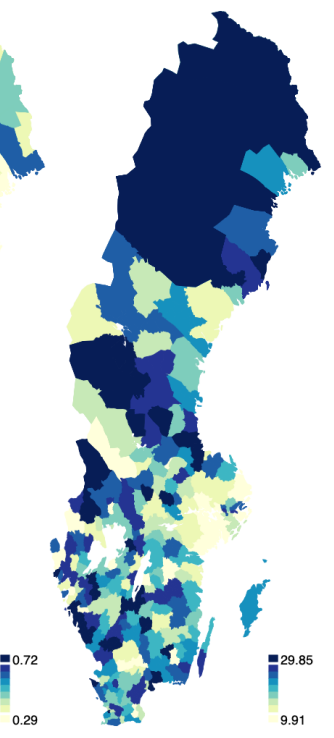

(B)

Mobility by Municipality of Residence in Adulthood (1910)

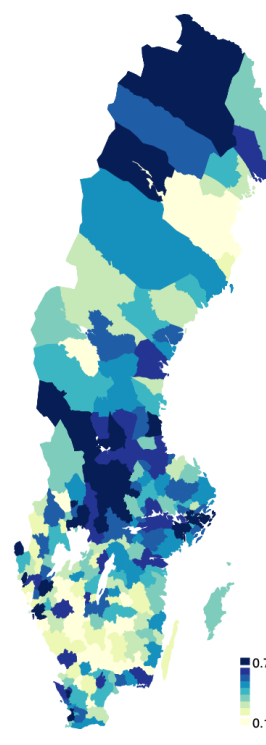

(C)

ABSOLUTE MOBILITY

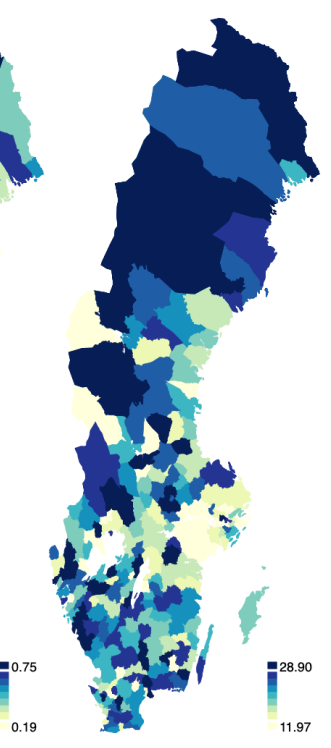

(D)

Altham $d(\mathbf{P}, \mathbf{I})$

FIGURE D.15:

Mobility by Municipality of RESIDENCE IN CHILDHOOd AND Adulthood

Notes: Panels A and C displays municipality-level measures of absolute mobility, or the fraction of sons that are observed in a different occupational group than their father. Panels B and D displays municipality-level Altham $d(\mathbf{P}, \mathbf{I})$ statistics that capture the distance from the case of full mobility where a larger statistic corresponds to less mobility. Son's geographical location is defined based on their municipality of residence in childhood/adulthood in the 1880/1910 census respectively in the upper and lower panel. 


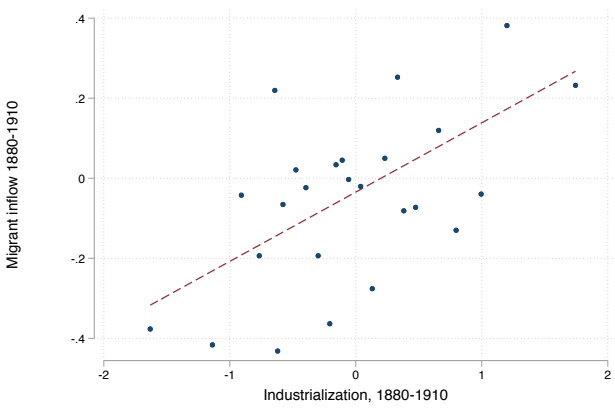

(A) Migrant INFLOW

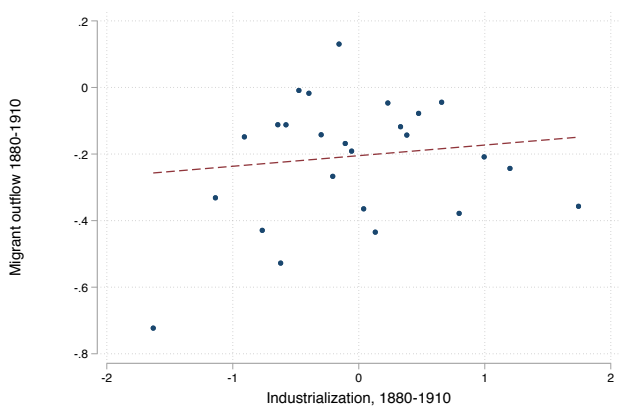

(C) Migrant outflow

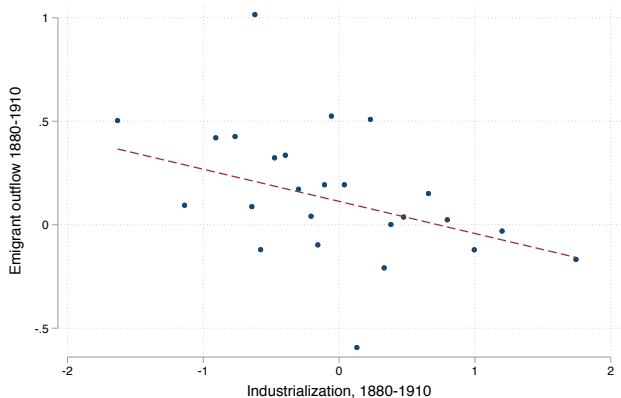

(E) EMIGRANT OUTFLOW

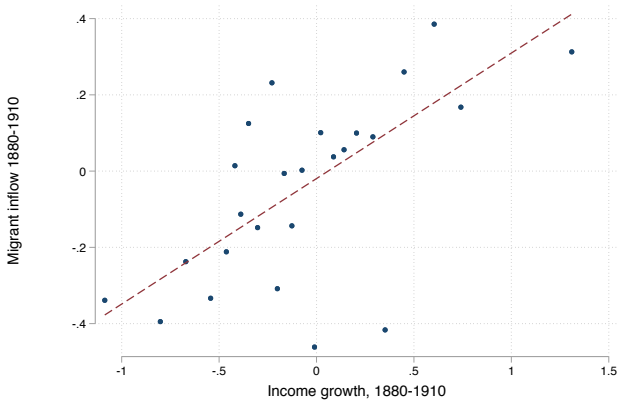

(B) MigRant InFLOW

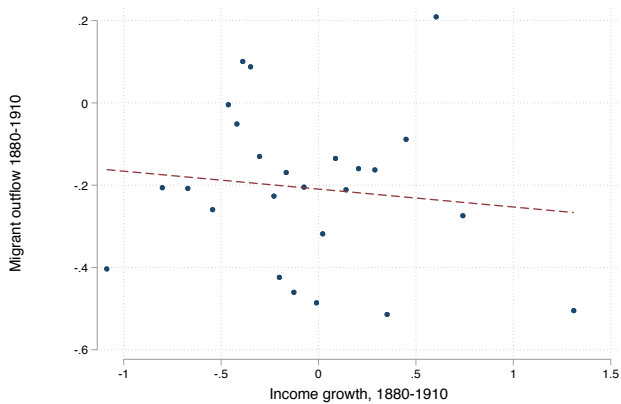

(D) Migrant OutFlow

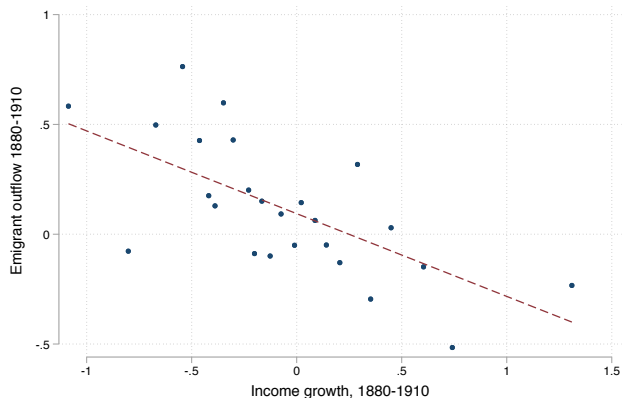

(F) EMIGRANT OUTFLOW

FIGURE D.16:

MIGRANT FLOWS AND LOCAL GROWTH ACROSS MUNICIPALITIES

Notes: This figure displays the non-parametric relationship between migration flows and industrialization or changes in average incomes between 1880-1910 respectively. In panels A and B we calculate migrant inflows by assigning sons in our linked sample to their municipality of residence in 1910 and calculate the share that did not reside in that municipality in 1880 . In panels $\mathrm{C}$ and $\mathrm{D}$ we calculate migrant outflows by assigning sons in our linked sample to their municipality of residence in 1880 and calculate the share of sons that left that municipality by 1910. In panels E and $\mathrm{F}$ we define emigrant outflows by assigning sons in our linked sample to their municipality of residence in 1880 and calculate the share of sons that emigrate between 1880-1910. Both proxies for industrialization and growth are standardized to have mean 0 and and a SD of 1 . We residualize all variabels using the baseline set of municipality controls in Table 2 and weight all observations by municipal populations in 1880. To construct each figure, we then group all municipalities into 25 equal-sized bins based on either the rate of industrialization or income growth where dots denote the mean migrant flow in each bin. Also shown is a best-fit line estimated from the underlying (ungrouped) data. 


\section{E Additional Tables}

TABle E.1: SAmple Characteristics

\begin{tabular}{|c|c|c|c|c|c|c|}
\hline & \multicolumn{3}{|c|}{1880} & \multicolumn{3}{|c|}{1910} \\
\hline & $\begin{array}{l}\text { All } \\
(1)\end{array}$ & $\begin{array}{l}\text { Linked } \\
\text { (2) }\end{array}$ & $\begin{array}{c}\operatorname{Diff}(2)-(1) \\
(3)\end{array}$ & $\begin{array}{l}\text { All } \\
(4)\end{array}$ & $\begin{array}{l}\text { Linked } \\
(5)\end{array}$ & $\begin{array}{c}\operatorname{Diff}(5)-(4) \\
(6)\end{array}$ \\
\hline Age & 8 & 7.9 & -0.099 & 37.4 & 37.4 & 0.000 \\
\hline Father's age & 43.3 & 43.4 & 0.100 & . & . & \\
\hline Urban & 0.12 & 0.11 & -0.010 & 0.26 & 0.24 & -0.020 \\
\hline County migrant & 0.06 & 0.04 & -0.020 & 0.28 & 0.27 & -0.009 \\
\hline Parish migrant & 0.21 & 0.17 & -0.039 & 0.64 & 0.63 & -0.009 \\
\hline \multicolumn{7}{|l|}{ Father's occ } \\
\hline White collar & 0.08 & 0.08 & 0.000 & . & . & . \\
\hline Farmer & 0.50 & 0.50 & 0.000 & . & . & . \\
\hline Skilled/semi-skilled & 0.18 & 0.18 & 0.000 & . & . & . \\
\hline Unskilled & 0.24 & 0.24 & 0.000 & . & . & . \\
\hline \multicolumn{7}{|l|}{ Son's occ } \\
\hline White collar & . & . & . & 0.15 & 0.14 & -0.010 \\
\hline Farmer & . & . & . & 0.25 & 0.28 & 0.030 \\
\hline Skilled/semi-skilled & . & . & . & 0.34 & 0.33 & -0.009 \\
\hline Unskilled & - & . & . & 0.26 & 0.26 & 0.000 \\
\hline Observations & 575,831 & 235,008 & & 498,500 & 293,264 & \\
\hline
\end{tabular}

Notes: This table reports descriptives for linked sons compared to the full population after applying the sample restrictions set out in the main text. Columns (1) and (2) reports descriptives for individuals in the 1880 census. Columns (4) and (5) similarly compares linked individuals when they are observed as adults in the 1910 census, after applying the same sample restrictions to the underlying census data. 
Table E.2: Probability of Matching a Record from the 1880 Census to the 1910 Census, Probit Model, Marginal efFects, Sons ObServed in 1880

\begin{tabular}{|c|c|c|c|c|}
\hline & (1) & (2) & (3) & (4) \\
\hline \multicolumn{5}{|l|}{ Father's occupation: } \\
\hline White collar & $\begin{array}{c}0.045^{* * *} \\
(0.004)\end{array}$ & $\begin{array}{c}0.044 * * * \\
(0.004)\end{array}$ & $\begin{array}{c}0.023 * * * \\
(0.004)\end{array}$ & $\begin{array}{c}0.019 * * * \\
(0.004)\end{array}$ \\
\hline Farmer & $\begin{array}{c}0.019 * * * \\
(0.003)\end{array}$ & $\begin{array}{c}0.019 * * * \\
(0.003)\end{array}$ & $\begin{array}{c}0.031 * * * \\
(0.003)\end{array}$ & $\begin{array}{c}0.027 * * * \\
(0.003)\end{array}$ \\
\hline Skilled/semi-skilled & $\begin{array}{c}0.011 * * * \\
(0.003)\end{array}$ & $\begin{array}{c}0.012 * * * \\
(0.003)\end{array}$ & $\begin{array}{l}-0.003 \\
(0.003)\end{array}$ & $\begin{array}{c}-0.007 * * \\
(0.003)\end{array}$ \\
\hline Unskilled & $\begin{array}{c}0.023 * * * \\
(0.003)\end{array}$ & $\begin{array}{c}0.024 * * * \\
(0.003)\end{array}$ & $\begin{array}{c}0.026 * * * \\
(0.003)\end{array}$ & $\begin{array}{c}0.016^{* * * *} \\
(0.003)\end{array}$ \\
\hline \multicolumn{5}{|l|}{ Ages: } \\
\hline Age & & $\begin{array}{c}-0.003 * * * \\
(0.000)\end{array}$ & $\begin{array}{c}-0.002 * * * \\
(0.000)\end{array}$ & $\begin{array}{c}-0.002 * * * \\
(0.000)\end{array}$ \\
\hline Father's age & & $\begin{array}{c}0.001 * * * \\
(0.000)\end{array}$ & $\begin{array}{c}0.002 * * * \\
(0.000)\end{array}$ & $\begin{array}{c}-0.002 * * * \\
(0.000)\end{array}$ \\
\hline \multicolumn{5}{|l|}{ Name characteristics: } \\
\hline First name length & & & $\begin{array}{c}0.002 * * * \\
(0.000)\end{array}$ & $\begin{array}{c}0.004 * * * \\
(0.000)\end{array}$ \\
\hline Last name length & & & $\begin{array}{c}0.001 * * * \\
(0.000)\end{array}$ & $\begin{array}{c}0.002 * * * \\
(0.000)\end{array}$ \\
\hline First name commonness & & & $\begin{array}{c}-0.074 * * \\
(0.000)\end{array}$ & $\begin{array}{c}-0.083 * * * \\
(0.002)\end{array}$ \\
\hline Last name commonness & & & $\begin{array}{c}-0.009 * * * \\
(0.000)\end{array}$ & $\begin{array}{c}-0.008 * * * \\
(0.000)\end{array}$ \\
\hline County of birth FE & No & No & No & Yes \\
\hline Observations & 613,137 & 613,137 & 613,137 & 613,137 \\
\hline McFadden's R2: & 0.000 & 0.001 & 0.007 & 0.024 \\
\hline
\end{tabular}

Notes: This table displays marginal effects from probit models with a indicator variable for a successful match as the outcome. Name commonness is measured as the percentage of individuals holding the same name in the 1880 census. Marginal effects calculated holding all other variables at the mean of the sample. Standard errors clustered at the household level are given in parentheses. ${ }^{* * *} p<0.01,{ }^{* *} p<0.05,{ }^{*} p<0.1$. 
Table E.3: Occupational Classification Schemes

Panel A. HISCLASS and the Abbreviated Class Scheme

\begin{tabular}{lll}
\hline \multicolumn{2}{l}{ HISCLASS } & Abbreviated \\
\cline { 2 - 2 } Number & Title & Title \\
\hline 1 & Higher managers & White-collar \\
2 & Higher professionals & \\
3 & Lower managers & \\
4 & Lower professionals, clerical and sales personnel & \\
5 & Lower clerical and sales personnel & Skilled/semi-skilled \\
\hline 6 & Foremen & \\
7 & Medium-skilled workers & Farmers \\
\hline 8 & Farmers and fishermen & Unskilled \\
\hline 9 & Low-skilled workers & \\
10 & Low-skilled farm workers & \\
11 & Unskilled workers & \\
12 & Unskilled farm workers &
\end{tabular}

Panel B. Erikson-Goldthorpe and the Abbreviated Class Scheme

\begin{tabular}{lll}
\hline \multicolumn{2}{l}{ Erikson-Goldthorpe } & Abbreviated \\
\cline { 2 - 3 } Number & Title & Title \\
\hline I & Large proprietors, higher professionals, and managers & White-collar \\
II & Lower professionals and managers & \\
IIIa & Routine nonmanual workers, higher grade & \\
IIIb & Routine nonmanual workers, lower grade & \\
\hline IVa & Small proprietors, with employees & Skilled/semi-skilled \\
IVb & Small proprietors, without employees & \\
V & Lower grade technicians and manual supervisors & \\
VI & Skilled manual workers & Farmers \\
IVc & Self-employed farmers, with employees & \\
IVd & Self-employed farmers, without employees & Unskilled \\
\hline VIIa & Unskilled manual workers & \\
VIIb & Agricultural laborers & \\
\hline
\end{tabular}


TABLE E.4: OCCUPATIONAL TRANSITION MATRIX: FREQUENCIES

Son's occupation

Father's occupation White-collar Farmer Skilled/semi-skilled Unskilled Total

\begin{tabular}{lccccc} 
& No. & No. & No. & No. & No. \\
\hline White-collar & 10,896 & 1,738 & 4,129 & 2,442 & 19,205 \\
Farmer & 11,080 & 55,090 & 26,429 & 25,185 & 117,784 \\
Skilled/semi-skilled & 6,927 & 4,172 & 23,256 & 9,408 & 43,763 \\
Unskilled & 5,889 & 8,209 & 23,285 & 22,806 & 60,189 \\
Total & 34,792 & 69,209 & 77,099 & 59,841 & 240,941
\end{tabular}

Notes: This table displays frequencies of occupational transitions for father-son pairs across the four HISCLASS groups used in the main analysis. Each column corresponds to the occupational group of sons observed in the 1910 census. Each row corresponds to the occupation of fathers observed in the 1880 census. 
TABle E.5: Occupational transition Matrix: MOdern SWEden

Panel A. Frequencies

\begin{tabular}{lccccc} 
& \multicolumn{5}{c}{ Son's occupation } \\
Father's occupation & 1 & 2 & 3 & 4 & Total \\
& No. & No. & No. & No. & No. \\
\hline 1 & 974 & 6 & 243 & 119 & 1342 \\
2 & 574 & 227 & 520 & 429 & 1750 \\
3 & 1112 & 16 & 904 & 428 & 2460 \\
4 & 918 & 17 & 823 & 655 & 2413 \\
Total & 3578 & 266 & 2490 & 1631 & 7965 \\
\hline N & 3,578 & 266 & 2,490 & 1,631 & 7,965
\end{tabular}

\section{Panel B. Row percentages}

\begin{tabular}{lccccc} 
& \multicolumn{5}{c}{ Son's occupation } \\
Father's occupation & 1 & 2 & 3 & 4 & Total \\
& $\%$ & $\%$ & $\%$ & $\%$ & $\%$ \\
\hline 1 & 73 & 0 & 18 & 9 & 100 \\
2 & 33 & 13 & 30 & 25 & 100 \\
3 & 45 & 1 & 37 & 17 & 100 \\
4 & 38 & 1 & 34 & 27 & 100 \\
Total & 45 & 3 & 31 & 20 & 100 \\
\hline N & 3,578 & 266 & 2,490 & 1,631 & 7,965
\end{tabular}

Notes: This table displays occupational transitions for father-son pairs in the modern Swedish sample. Each row corresponds to the occupational group of sons born 1915-1930 and interviewed in the 1976-1990 Swedish Study of Living Conditions (ULF), carried out annually by Statistics Sweden (Vogel et al., 1988). Each row corresponds to the occupation that the respondent reports as their father's main occupation when they grew up (until age 16). See Table E. 3 for a description of the modern EGP schema and the coding of the four groups. 
TABLE E.6: ABSOLUTE MOBILITY, STANDARD ERRORS

\begin{tabular}{lcc}
\hline & (1) Absolute Mobility & (2) Margin-adjusted \\
\hline Sweden & $($ ref. $)$ & $($ ref. $)$ \\
& & \\
Britain & $-0.090^{* * *}$ & $-0.076^{* * *}$ \\
& $(0.010)$ & $(0.010)$ \\
Norway & $-0.090^{* * *}$ & $-0.049^{* * *}$ \\
& $(0.004)$ & $(0.004)$ \\
United States & $-0.080^{* * *}$ & $0.031^{* * *}$ \\
& $(0.002)$ & $(0.002)$ \\
Argentina & $0.012^{* *}$ & $0.054^{* * *}$ \\
& $(0.005)$ & $(0.005)$ \\
Constant & $0.535^{* * *}$ & $0.535^{* * *}$ \\
& $(0.001)$ & $(0.001)$ \\
Observations & 452,489 & 452,425 \\
\hline
\end{tabular}

Notes: This table shows the uncertainty and significance associated with estimates of absolute mobility in other countries relative to Sweden (compare Figure 1A and 1B). Column 1 reports estimates of absolute mobility, or the share of sons that are observed in a different occupational group than their father, with Sweden as the reference group. Column 2 reports similar measures of absolute mobility adjusted to the occupational distribution in Sweden. Linear probability model estimated with OLS, robust standard errors in parentheses. ${ }^{* * *} p<0.01,{ }^{* *} p<0.05,{ }^{*} p<0.1$. 
TABLE E.7: SUMMARY OF LINKED SAMPLES CHARACTERISTICS

\begin{tabular}{|c|c|c|c|c|c|c|c|c|c|c|c|c|c|c|c|}
\hline & \multirow[b]{2}{*}{$\begin{array}{l}\text { Country/region } \\
\text { (1) }\end{array}$} & \multicolumn{4}{|c|}{$\bar{t}$} & \multicolumn{3}{|c|}{$\overline{t+1}$} & \multirow[b]{2}{*}{$\begin{array}{l}\text { Links } \\
\text { (9) }\end{array}$} & \multicolumn{2}{|c|}{ Linkage rate } & \multicolumn{3}{|c|}{ Index variables } & \multirow[b]{2}{*}{$\begin{array}{l}\text { Name comparison algorithm } \\
\text { (15) }\end{array}$} \\
\hline & & $\begin{array}{l}\text { Age restriction } \\
\text { (2) }\end{array}$ & $\begin{array}{l}\text { Year } \\
(3)\end{array}$ & $\begin{array}{l}\text { Sample size } \\
(4)\end{array}$ & $\begin{array}{l}\text { Observations } \\
\quad(5)\end{array}$ & $\begin{array}{l}\text { Year } \\
(6)\end{array}$ & $\begin{array}{c}\text { Sample } \\
\text { (7) }\end{array}$ & $\begin{array}{l}\text { Observations } \\
(8)\end{array}$ & & $\begin{array}{l}\text { Prospective } \\
(10)\end{array}$ & $\begin{array}{l}\text { Retrospective } \\
\text { (11) }\end{array}$ & $\begin{array}{l}\text { Birth place } \\
(12)\end{array}$ & $\begin{array}{l}\text { Birth year } \\
\text { (13) }\end{array}$ & $\begin{array}{c}\text { Initials } \\
(14)\end{array}$ & \\
\hline \multirow{5}{*}{ Perez (2017) } & Sweden & $\leq 16$ & 1880 & $100 \%$ & 849,996 & 1910 & $100 \%$ & 543,155 & 310,183 & $36.5 \%$ & $57.1 \%$ & Parish & Exact & None & Jaro-Winkler \\
\hline & Argentina & $\leq 16$ & 1869 & $95 \%$ & 208,432 & 1895 & $100 \%$ & - & 24,615 & $11.8 \%$ & - & Province & \pm 5 years & First and last name & Jaro-Winkler \\
\hline & United States & $\leq 16$ & 1850 & $100 \%$ & 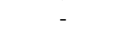 & 1880 & $100 \%$ & - & - & - & - & State & \pm 5 years & First and last name & Jaro-Winkler \\
\hline & Norway & $\leq 16$ & 1865 & $100 \%$ & - & 1900 & $100 \%$ & - & - & - & - & Municipality & \pm 5 years & First and last name & Jaro-Winkler \\
\hline & Britain & $\leq 16$ & 1851 & $2 \%$ & - & 1881 & $100 \%$ & - & - & - & & Parish & \pm 5 years & First and last name & Jaro-Winkler \\
\hline Modalsli (2017) & Norway & & 1865 & $100 \%$ & - & 1900 & $100 \%$ & 160,352 & - & - & $37 \%$ & Municipality & \pm 5 years & None & Levenshtein \\
\hline \multirow{2}{*}{ Ferrie and Long (2013a) } & United States & $\leq 25$ & 1850 & $1 \%$ & 43,438 & 1880 & $100 \%$ & - & 9,497 & $21.9 \%$ & - & State & \pm 3 years & None & SOUNDEX/SPEDSIS \\
\hline & England and Wales & $\leq 25$ & 1851 & $2 \%$ & 69,785 & 1881 & $100 \%$ & - & 14,191 & $20.3 \%$ & - & Parish & \pm 5 years & None & SOUNDEX/SPEDSIS \\
\hline Ward & United States & $\leq 14$ & 1910 & $100 \%$ & 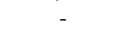 & 1940 & $100 \%$ & - & 394,864 & $4.6 \%$ & - & State & \pm 2 years & First and last name & Jaro-Winkler \\
\hline Feigenbaum (2018) & Iowa & 3-17 & 1915 & $1.8-5.5 \%$ & 7,580 & 1940 & $100 \%$ & - & - & $59 \%$ & - & State & \pm 3 years & None & Jaro-Winkler \\
\hline
\end{tabular}

Notes: This table summarizes variables used for linking across historical census data together with number of observations and linkage rates. 
Son's occupation

Father's occupation White-collar Farmer Skilled/semi-skilled Unskilled Total

\begin{tabular}{lccccc} 
& $\%$ & $\%$ & $\%$ & $\%$ & $\%$ \\
\hline White-collar & 62 & 7 & 20 & 11 & 100 \\
Farmer & 11 & 46 & 22 & 21 & 100 \\
Skilled/semi-skilled & 19 & 8 & 53 & 20 & 100 \\
Unskilled & 11 & 12 & 40 & 37 & 100 \\
Total & 19 & 24 & 33 & 23 & 100 \\
\hline $\mathrm{N}$ & 25,190 & 31,167 & 43,100 & 30,233 & 129,690
\end{tabular}

TABLE E.8: OCCUPATIONAL TRANSITIONS FOR FATHERS AND SONS, 1880-1910 (SUPPLEMENTARY LiNKED SAMPLE 1)

Notes: This table displays occupational transitions for sons relative to their fathers. Each column corresponds to the occupational group of sons observed in the 1910 census. Each row corresponds to the occupation of fathers observed in the 1880 census. The sample was created using our preferred method of linking using county of birth in place of parish of birth.

Son's occupation

Father's occupation White-collar Farmer Skilled/semi-skilled Unskilled Total

\begin{tabular}{lccccc} 
& $\%$ & $\%$ & $\%$ & $\%$ & $\%$ \\
\hline White-collar & 66 & 6 & 19 & 9 & 100 \\
Farmer & 14 & 43 & 22 & 21 & 100 \\
Skilled/semi-skilled & 22 & 7 & 53 & 19 & 100 \\
Unskilled & 13 & 11 & 41 & 36 & 100 \\
Total & 25 & 20 & 34 & 21 & 100 \\
\hline $\mathrm{N}$ & 16,554 & 13,351 & 22,383 & 14,289 & 66,577
\end{tabular}

TABLE E.9: OCCUPATIONAL TRANSITIONS FOR FATHERS AND SONS, 1880-1910 (SUPPLEMENTARY LINKED SAMPLE 2)

Notes: This table displays occupational transitions for sons relative to their fathers. Each column corresponds to the occupational group of sons observed in the 1910 census. Each row corresponds to the occupation of fathers observed in the 1880 census. The sample was created using our preferred method of linking using county of birth in place of parish of birth and allowing for birth years to differ by up to 5 years. 
Son's occupation

Father's occupation White-collar Farmer Skilled/semi-skilled Unskilled Total

\begin{tabular}{lccccc} 
& $\%$ & $\%$ & $\%$ & $\%$ & $\%$ \\
\hline White-collar & 64 & 7 & 19 & 10 & 100 \\
Farmer & 12 & 45 & 22 & 21 & 100 \\
Skilled/semi-skilled & 18 & 8 & 54 & 20 & 100 \\
Unskilled & 10 & 13 & 39 & 38 & 100 \\
Total & 19 & 25 & 32 & 23 & 100 \\
\hline $\mathrm{N}$ & 13,893 & 17,819 & 23,109 & 16,791 & 71,612
\end{tabular}

TABLE E.10: OCCUPATIONAL TRANSITIONS FOR FATHERS AND SONS, 1880-1910 (SUPPLEMENTARY LINKED SAMPLE 3)

Notes: This table displays occupational transitions for sons relative to their fathers. Each column corresponds to the occupational group of sons observed in the 1910 census. Each row corresponds to the occupation of fathers observed in the 1880 census. The sample was created using Pérez (2019) methodology.

Son's occupation

Father's occupation White-collar Farmer Skilled/semi-skilled Unskilled Total

\begin{tabular}{lccccc} 
& $\%$ & $\%$ & $\%$ & $\%$ & $\%$ \\
\hline White-collar & 61 & 8 & 20 & 11 & 100 \\
Farmer & 11 & 45 & 23 & 21 & 100 \\
Skilled/semi-skilled & 17 & 9 & 53 & 20 & 100 \\
Unskilled & 10 & 13 & 38 & 38 & 100 \\
Total & 18 & 26 & 32 & 24 & 100 \\
\hline $\mathrm{N}$ & 19,292 & 28,734 & 35,275 & 26,129 & 109,430
\end{tabular}

TABLE E.11: OCCUPATIONAL TRANSITIONS FOR FATHERS AND SONS, 1880-1910 (SUPPLEMENTARY LINKED SAMPLE 4)

Notes: This table displays occupational transitions for sons relative to their fathers. Each column corresponds to the occupational group of sons observed in the 1910 census. Each row corresponds to the occupation of fathers observed in the 1880 census. The sample was created using Abramitzky et al. (2019) methodology. 
Son's occupation

Father's occupation White-collar Farmer Skilled/semi-skilled Unskilled Total

\begin{tabular}{lccccc} 
& $\%$ & $\%$ & $\%$ & $\%$ & $\%$ \\
\hline White-collar & 64 & 7 & 19 & 10 & 100 \\
Farmer & 12 & 45 & 22 & 21 & 100 \\
Skilled/semi-skilled & 18 & 8 & 54 & 20 & 100 \\
Unskilled & 10 & 13 & 39 & 38 & 100 \\
Total & 19 & 25 & 32 & 23 & 100 \\
\hline $\mathrm{N}$ & 13,798 & 17,699 & 22,959 & 16,671 & 71,127
\end{tabular}

TABLE E.12: OCCUPATIONAL TRANSITIONS FOR FATHERS AND SONS, 1880-1910 (SUPPLEMENTARY LINKED SAMPLE 5)

Notes: This table displays occupational transitions for sons relative to their fathers. Each column corresponds to the occupational group of sons observed in the 1910 census. Each row corresponds to the occupation of fathers observed in the 1880 census. The sample was created by using the intersection of links made using our preferred method and links made using Pérez (2019) and Abramitzky et al. (2019) methodologies. 


\begin{tabular}{|c|c|c|c|c|}
\hline \multirow[t]{2}{*}{ Dependent variable: } & \multicolumn{4}{|c|}{ Upward mobility } \\
\hline & (1) & (2) & (3) & (4) \\
\hline \multirow[t]{2}{*}{$\Delta \ln$ Population, $1880-1910$} & 0.007 & & & 0.012 \\
\hline & $(0.010)$ & & & $(0.015)$ \\
\hline \multirow[t]{2}{*}{$\Delta$ Urban share, $1880-1910$} & 0.004 & & & 0.004 \\
\hline & $(0.003)$ & & & $(0.003)$ \\
\hline \multirow{2}{*}{ In Average income, 1880} & & -0.004 & & -0.003 \\
\hline & & $(0.010)$ & & $(0.010)$ \\
\hline \multirow[t]{2}{*}{$\Delta \ln$ Average income, $1880-1910$} & & 0.002 & & -0.011 \\
\hline & & $(0.009)$ & & $(0.010)$ \\
\hline \multirow[t]{2}{*}{ Industrialization, 1880} & & & $0.038^{* * *}$ & $0.056^{* * *}$ \\
\hline & & & $(0.009)$ & $(0.011)$ \\
\hline \multirow[t]{2}{*}{$\Delta$ Industrialization, $1880-1910$} & & & $0.025^{* * *}$ & $0.028^{* * *}$ \\
\hline & & & $(0.008)$ & $(0.009)$ \\
\hline \multirow[t]{2}{*}{ Child/woman ratio, 1880} & & & & 0.008 \\
\hline & & & & $(0.008)$ \\
\hline \multirow[t]{2}{*}{ Teachers/children, 1880} & & & & -0.005 \\
\hline & & & & $(0.008)$ \\
\hline \multirow[t]{2}{*}{ Migrant share, 1880-1910 } & & & & $0.039^{* *}$ \\
\hline & & & & $(0.016)$ \\
\hline \multirow[t]{2}{*}{ Emigrant share, 1880-1910 } & & & & -0.004 \\
\hline & & & & $(0.008)$ \\
\hline Municipality controls & Yes & Yes & Yes & Yes \\
\hline Observations & 282 & 282 & 282 & 282 \\
\hline R-squared & 0.12 & 0.12 & 0.19 & 0.25 \\
\hline Mean dep. var. & 0.63 & 0.63 & 0.63 & 0.63 \\
\hline
\end{tabular}

TABle E.13: Upward Mobility across Municipalities, 1880-1910

Notes: Municipality-level OLS regressions. When estimating upward mobility rates, we allocate sons to the municipality where they resided in childhood (i.e., in 1880). All right-hand-side variables are standardized to have mean 0 and and a SD of 1 . Municipality controls include $\ln$ population, occupational shares (white-collar, farmers, skilled/semiskilled, and unskilled), and the share living in urban areas, all measured in 1880. Robust standard errors clustered at the county level are given in parentheses. ${ }^{* * *} p<0.01,{ }^{* *} p<0.05,{ }^{*} p<0.1$. 


\begin{tabular}{|c|c|c|c|c|c|c|}
\hline \multirow[t]{2}{*}{ Dependent variable: } & \multicolumn{3}{|c|}{ Absolute mobility } & \multicolumn{3}{|c|}{ Altham $d(\mathbf{P}, \mathbf{I})$} \\
\hline & (1) & $(2)$ & (3) & (4) & (5) & (6) \\
\hline Migrant share, 1880-1910 & $\begin{array}{c}0.039^{* * *} \\
(0.005)\end{array}$ & & & $\begin{array}{c}-1.684^{* * *} \\
(0.359)\end{array}$ & & \\
\hline Share born in diff muni (1880 census) & & $\begin{array}{c}0.014 \\
(0.009)\end{array}$ & & & $\begin{array}{c}-1.500^{* * *} \\
(0.522)\end{array}$ & \\
\hline Share born in diff muni (1910 census) & & & $\begin{array}{c}0.027^{* * *} \\
(0.009)\end{array}$ & & & $\begin{array}{c}-1.985^{* * *} \\
(0.491)\end{array}$ \\
\hline Municipality controls & Yes & Yes & Yes & Yes & Yes & Yes \\
\hline Observations & 282 & 282 & 282 & 282 & 282 & 282 \\
\hline R-squared & 0.33 & 0.15 & 0.19 & 0.17 & 0.11 & 0.15 \\
\hline Mean dep. var. & 0.53 & 0.53 & 0.53 & 19.00 & 19.00 & 19.00 \\
\hline
\end{tabular}

TABle E.14: Absolute And Relative mobility aCross municipalities, 1880-1910: Alternative MEASURES OF LOCAL MIGRATION

Notes: Municipality-level OLS regressions. Alternative measures of local migration are all standardized to a have mean 0 and a standard deviation of 1 . Municipality controls include $\ln$ population, occupational shares (white-collar, farmers, skilled/semi-skilled, and unskilled), and the share living in urban areas, all measured in 1880. Robust standard errors clustered at the county level are given in parentheses. ${ }^{* * *} p<0.01,{ }^{* *} p<0.05,{ }^{*} p<0.1$. 


\begin{tabular}{lccc} 
Dependent variable: & \multicolumn{3}{c}{ Absolute mobility $(=1)$} \\
\cline { 2 - 4 } & $(1)$ & $(2)$ & $(3)$ \\
\hline Municipality migrant (=1) & $0.150^{* * *}$ & & \\
& $(0.006)$ & & \\
County migrant (=1) & \multicolumn{3}{c}{$0.135^{* * *}$} \\
& & $(0.007)$ & \\
Parish migrant (=1) & & & $0.167^{* * *}$ \\
& & & $(0.006)$ \\
Son's age & Yes & Yes & Yes \\
Household FE & Yes & Yes & Yes \\
Observations & 118019 & 118019 & 118019 \\
R-squared & 0.60 & 0.60 & 0.60 \\
Mean dep. var. & 0.542 & 0.542 & 0.542 \\
\hline
\end{tabular}

TABLE E.15: GEOGRAPHIC AND OCCUPATIONAL MOBILITY, 1880-1910: INDIVIDUAL-LEVEL ESTIMATES

Notes: Individual-level OLS regressions. Sample restricted to households with at least two (linked) sons. Robust standard errors clustered at the 1880 household level are given in parentheses. ${ }^{* * *} p<0.01,{ }^{* *} p<0.05,{ }^{*} p<0.1$. 
Dependent variable:

Absolute mobility (=1)

\begin{tabular}{|c|c|c|c|c|c|c|c|c|}
\hline & \multicolumn{2}{|c|}{$\Delta \ln$ Population } & \multicolumn{2}{|c|}{$\Delta$ Urban share } & \multicolumn{2}{|c|}{$\Delta \ln$ Average Income } & \multicolumn{2}{|c|}{$\Delta$ Share in manufacturing } \\
\hline & $\begin{array}{l}\text { High } \\
\text { (1) }\end{array}$ & $\begin{array}{l}\text { Low } \\
\text { (2) }\end{array}$ & $\begin{array}{l}\text { High } \\
\text { (3) }\end{array}$ & $\begin{array}{l}\text { Low } \\
\text { (4) }\end{array}$ & $\begin{array}{l}\text { High } \\
(5)\end{array}$ & $\begin{array}{l}\text { Low } \\
(6)\end{array}$ & $\begin{array}{l}\text { High } \\
\text { (7) }\end{array}$ & $\begin{array}{l}\text { Low } \\
(8)\end{array}$ \\
\hline Migrant (=1) & $\begin{array}{c}0.120^{* * *} \\
(0.008)\end{array}$ & $\begin{array}{c}0.181^{* * *} \\
(0.009)\end{array}$ & $\begin{array}{c}0.126^{* * *} \\
(0.009)\end{array}$ & $\begin{array}{c}0.174^{* * *} \\
(0.009)\end{array}$ & $\begin{array}{c}0.134^{* * *} \\
(0.008)\end{array}$ & $\begin{array}{c}0.168^{* * *} \\
(0.009)\end{array}$ & $\begin{array}{c}0.136^{* * *} \\
(0.008)\end{array}$ & $\begin{array}{c}0.166^{* * *} \\
(0.009)\end{array}$ \\
\hline Son's age & Yes & Yes & Yes & Yes & Yes & Yes & Yes & Yes \\
\hline Household FE & Yes & Yes & Yes & Yes & Yes & Yes & Yes & Yes \\
\hline Observations & 61608 & 56411 & 56126 & 61893 & 61462 & 56557 & 59544 & 58475 \\
\hline R-squared & 0.60 & 0.60 & 0.60 & 0.60 & 0.59 & 0.60 & 0.60 & 0.59 \\
\hline Mean dep. var. & 0.544 & 0.540 & 0.545 & 0.539 & 0.553 & 0.530 & 0.555 & 0.529 \\
\hline
\end{tabular}

TABLE E.16: GEOGRAPHIC AND OCCUPATIONAL MOBILITY, 1880-1910: INDIVIDUAL-LEVEL ESTIMATES BY DIFFERENT MIGRANT ORIGINS

Notes: Individual-level OLS regressions. Sample restricted to households with at least two (linked) sons. Each pair of columns reports estimates separately for individuals residing in municipalities above/below the median municipality in terms of growth in population, urbanization, income, and employment share in manufacturing. Robust standard errors clustered at the 1880 household level are given in parentheses. ${ }^{* * *} p<0.01,{ }^{* *} p<0.05,{ }^{*} p<0.1$. 